NBER WORKING PAPER SERIES

\title{
VALUING PRIVATE EQUITY STRIP BY STRIP
}

\author{
Arpit Gupta \\ Stijn Van Nieuwerburgh \\ Working Paper 26514 \\ http://www.nber.org/papers/w26514
NATIONAL BUREAU OF ECONOMIC RESEARCH
1050 Massachusetts Avenue
Cambridge, MA 02138
November 2019

The authors would like to thank Thomas Gilbert, Arthur Korteweg, Stavros Panageas, Antoinette Schoar, and Morten Sorensen (discussants); as well as Ralph Koijen, Neng Wang, and seminar and conference participants at the the 2018 UNC Real Estate Research Symposium, the 2019 American Finance Association annual meetings, the Southern California Private Equity Conference, NYU Stern, the 2019 NBER Long-Term Asset Management conference, the University of Michigan, SITE 2019: Asset Pricing Theory and Computation, the Western Finance Association, Arizona State University, the MIT Junior Finance Conference, the Advances in Financial Research Conference at the San Francisco Fed, Columbia GSB, and 11th Annual PERC Symposium. We thank Burgiss and the Private Equity Research Consortium for assistance with data. This work is supported by the NYU Stern Infrastructure Initiative. The views expressed herein are those of the authors and do not necessarily reflect the views of the National Bureau of Economic Research.

NBER working papers are circulated for discussion and comment purposes. They have not been peer-reviewed or been subject to the review by the NBER Board of Directors that accompanies official NBER publications.

(C) 2019 by Arpit Gupta and Stijn Van Nieuwerburgh. All rights reserved. Short sections of text, not to exceed two paragraphs, may be quoted without explicit permission provided that full credit, including $(\subset$ notice, is given to the source. 
Valuing Private Equity Strip by Strip

Arpit Gupta and Stijn Van Nieuwerburgh

NBER Working Paper No. 26514

November 2019

JEL No. G00,G11,G12,G23,G32,R30,R51

\begin{abstract}
$\underline{\text { ABSTRACT }}$
We propose a new valuation method for private equity investments. First, we construct a cashflow replicating portfolio for the private investment, applying Machine Learning techniques on cash-flows on various listed equity and fixed income instruments. The second step values the replicating portfolio using a flexible asset pricing model that accurately prices the systematic risk in bonds of different maturities and a broad cross-section of equity factors. The method delivers a measure of the risk-adjusted profit earned on a PE investment and a time series for the expected return on PE fund categories. We apply the method to buyout, venture capital, real estate, and infrastructure funds, among others. Accounting for horizon-dependent risk and exposure to a broad cross-section of equity factors results in negative average risk-adjusted profits. Substantial cross-sectional variation and persistence in performance suggests some funds outperform. We also find declining expected returns on PE funds in the later part of the sample.
\end{abstract}

Arpit Gupta

Stern School of Business

44 West 4th Street

New York, NY 10012

agupta3@stern.nyu.edu

Stijn Van Nieuwerburgh

Columbia University

Graduate school of Business

Uris Hall, office 809

3022 Broadway

New York, NY 10027

and NBER

svnieuwe@gsb.columbia.edu

Dividend Strip data is available at https://github.com/arpitrage/Dividend_Strip 


\section{Introduction}

Private equity investments have risen in importance over the past twenty-five years, relative to public equity. Indeed, the number of publicly listed firms has been falling since 1997, especially among smaller firms. Private equity funds account for $\$ 5.8$ trillion in assets under management, and raised nearly $\$ 800$ billion in new capital in 2018 (Bökberg, Carrellas, Chau, and Duane, 2019). Large institutional investors now allocate substantial fractions of their portfolios to such private investments. For example, the celebrated Yale University endowment has a portfolio weight of over $50 \%$ in alternative investments. Pension funds and sovereign wealth funds have also ramped up their allocations to alternatives. As the fraction of overall wealth that is held in the form of private investment grows, so does the importance of developing appropriate valuation methods. The nontraded nature of these assets and their irregular cash-flows makes this a challenge.

As with any investment, the value of a private equity (PE) investment equals the present discounted value of its cash-flows. The general partner (GP, fund manager) deploys the capital committed by the limited partners (LPs, investors) by investing in a portfolio of risky projects. The risky projects may pay some interim cash-flows that are distributed back to the LPs. The bulk of the cash flows accrue when the GP sells the projects, and distributes the proceeds net of fees (carry, promote) to the LPs. The main challenge in evaluating a PE investment is how to adjust the profits the LP earns for the systematic risk inherent in the distribution cash flows. Industry practice is to report the ratio of distributions to capital contributions (TVPI) and the internal rate of return (IRR). Neither metric takes into account the riskiness of the cash-flows.

We propose a novel, two-step methodology that centers on the nature and the timing of cash-flow risk for PE investments. In a first step, we estimate the exposure of PE funds' cash-flows to the cash-flows of a set of publicly listed securities. The main analysis considers Treasury bonds, the aggregate stock market, a real estate stock index (REIT), an infrastructure stock index, small stocks, value stocks, growth stocks, and natural resource stocks as its set of public market risk factors. The method considers a much richer cross-section of risks than the literature hitherto, and can easily accommodates additional publicly-traded risk factors. Inspired by Lettau and Wachter (2011) and van Binsbergen, Brandt, and Koijen (2012), we "strip" the sequence of PE cash-flows horizon by horizon, and estimate exposures of the PE cash flow strips to public market strips. We use both dividend strips and capital gains strips for each of our equity factors. Our identification assumes that the systematic cash-flow exposures depend on PE category, horizon, and 
the underlying market conditions at the time of fund origination. All PE funds within the same category and vintage have the same exposures to the public market strips. We estimate the exposures using OLS, which necessitates a much smaller cross-section of two factors, as well as using an Elastic Net estimation, which handles the large cross-section using a regularization approach and enforces a positivity constraint so that the replicating portfolio is long-only.

In a second step, we use a rich, no-arbitrage asset pricing model that prices the asset strips. Except for dividend strips on the aggregate stock market for short subsample, strips on REITs, infrastructure, or any other cross-sectional equity factor are unavailable, as are capital gains strips for all assets. We use the asset pricing model to back them out. The model estimates prices of risk by closely matching the history of bond yields of different maturities, as well as prices and expected returns on the seven equity indices (aggregate stock, small stock, value stock, growth stock, REIT, natural resource, and infrastructure markets). It also matches the data on aggregate stock market dividend strips reported in van Binsbergen, Brandt, and Koijen (2012); van Binsbergen, Hueskes, Koijen, and Vrugt (2013); van Binsbergen and Koijen (2017). The asset pricing model deliver a rich time series and cross-section of risk and return. We use the shock price elasticities of Borovička and Hansen (2014) to understand how risk change with horizon in the model.

Combining the cash-flow replicating portfolio of strips obtained from the first step with the prices for these strips from the asset pricing model estimated in the second step, we obtain the fair price for the PE-replicating portfolio in each vintage and category. To estimate the risk-adjusted profit (RAP) of private equity funds, we compare the difference between excess returns delivered by private equity funds against that the replicating portfolio. We subtract from this the relative cost of the replicating portfolio and the PE investment; the latter is normalized to $\$ 1$ of capital committed in the data. Private equity funds deliver the realized cash flow minus this of capital. Under the joint null hypothesis of the correct asset pricing model and the absence of (asset selection or market timing) skill, the RAP is zero. A fund with positive RAP delivers the same systematic risk exposure more cheaply than it can be purchased for in the public bond and equity markets.

The asset pricing model is used also to compute the expected return on a PE investment, which reflects the systematic risk exposure of the PE fund. Our method breaks down the expected return into its various horizon components (strips), and, at each horizon, into its exposures to the various risk factors. Since the expected return on the listed strips varies with the state of the economy, so does the expected return on PE investments. 
Our method can also be used to ask what the expected return is on all outstanding PE investments, by aggregating across current vintages. By providing the expected return on $\mathrm{PE}$, and the covariances of PE funds with traded securities, our approach facilitates portfolio analysis with alternatives for which return time series are unavailable.

We use data from Preqin on all PE funds with non-missing cash-flow information that were started between 1980 and 2017. Cash-flow data until December 2017 are used in the analysis, corresponding to after-fee receipts by investors at the fund level. Our sample includes 4,219 funds in eight investment categories. The largest categories are Buyout, Real Estate, and Venture Capital. The main text reports results for these three categories as well as Infrastructure, and relegates the results for the other four categories (Restructuring, Debt Funds, Fund of Funds, and Natural Resources) to the Appendix. The PE data from Preqin are subject to the usual selection bias concerns, which we address by also examining data from Burgiss. We find similar results on that data set. ${ }^{1}$

A contribution of our work is methodological: we develop a novel approach for assessing the factor exposure for non-listed securities. Though our primary application here is on private equity, a particularly important asset class, our approach can be applied more broadly to consider the risk and expected return of generic streams of cash flows-a topic of increasing importance with the rise of privately listed assets.

We also contribute to the private equity literature specifically. We find strong evidence that private equity funds have exposure to cross-sectional factor exposures that are not typically considered in the literature. The nature of this factor exposure varies in ways related to the nature of the underlying asset the fund invests in. Real estate funds, for instance, take on listed real estate exposure; infrastructure funds have some additional listed infrastructure factor exposure; and Venture Capital (VC) funds have distribution payoffs best proxied by growth gains strips, corresponding to a strategy of selling growth stocks. Buyout funds have a more complicated factor exposure, but include substantial amounts of small, growth, and value exposures for both dividend and capital gains strips. Economically, this accords well with strategies which buy a range of companies, harvest some dividends in early stages, and then sell them of near the end of the life of the fund.

Our finding that private equity funds take on substantial cross-sectional factor exposure beyond the aggregate stock index and bonds has large implications for our assessment of private equity. First, it suggests that LPs in PE vehicles need to carefully assess

\footnotetext{
${ }^{1}$ Preqin data are thought to understate performance. Some high-performing funds that are closed to outside investors to protect from FOIA requests are not in our dataset. Brown, Harris, Jenkinson, Kaplan, and Robinson (2015) reports superior coverage of these funds in Burgiss.
} 
portfolio selection and risk management, given that their PE investments provide exposure to a range of factors which may overlap considerably with other investments in their portfolios. Second, it suggests that we may be arriving at a distorted assessment of factor exposures. We find, for instance, that $\mathrm{VC}$ funds have large exposure to the risk in growth stocks. This exposure may have been attributed to the aggregate stock market in a simpler model of risk and return. Third, and maybe most importantly, we find that accounting for a richer factor exposure leads to large changes in average risk-adjusted profits (RAP). A substantial component of the returns to $\mathrm{PE}$, which previous research has considered to be excess returns, can instead be attributed to missing factor exposure. We estimate negative average RAP of around -18 cents per $\$ 1$ invested in the Buyout category, -11 cents per $\$ 1$ invested in VC, -17 cents in real Estate, and -10 cents in Infrastructure. However, there is substantial cross-sectional variation, with about a quarter of funds delivering in excess of 10 cents of RAP. We also find considerable persistence in our RAP measure, though less than in conventional performance metrics. Fourth. both profits and expected returns have been trending downward, and are especially low in recent periods. The decline in expected returns for PE funds reflects a broad-based decline in expected returns in public markets.

Related Literature This paper contributes to a large empirical literature on performance evaluation in private equity funds, such as Kaplan and Schoar (2005), Cochrane (2005), Korteweg and Sorensen (2017), Harris, Jenkinson, and Kaplan (2014), Phalippou and Gottschalg (2009), Robinson and Sensoy (2011), among many others. Most of this literature focuses on Buyout and Venture Capital funds. Recent work in valuing privately-held real estate assets includes Peng (2016) and Sagi (2017); Ammar and Eling (2015) and Andonov, Kräussl, and Rauh (2018) have studied infrastructure investments. This literature has found mixed results regarding PE fund outperformance and its persistence, depending on the data set and period in question. Our analysis spans the full sample from 1980 until 2017 and all PE investment categories. Our replicating portfolio approach results in a substantially negative estimate of average risk-adjusted profits for PE funds across all categories, albeit with large cross-sectional and time-series variation.

While performance evaluation in private equity is still often expressed as an internal rate of return or a ratio of distributions to capital committed, several important papers have incorporated risk into the analysis. The public market equivalent (PME) approach of Kaplan and Schoar (2005) compares the private equity investment to a public market 
benchmark (the aggregate stock market) with the same magnitude and timing of cashflows. Sorensen and Jagannathan (2015) assess the PME approach from a SDF perspective. The closest antecedent to our paper is Korteweg and Nagel (2016), who propose a generalized PME approach (GPME) that relaxes the assumption that the beta of PE funds to the stock market is one. This is particularly important in their application to VC funds. Like ours, the PME and GPME approaches avoid making strong assumptions on the return-generating process of the PE fund, because they work directly with the cash-flows. Cochrane (2005) and Korteweg and Sorensen (2010) discuss this distinction. In contrast, much of the earlier literature assumes linear beta-pricing relationships, e.g., Ljungqvist and Richardson (2003), Driessen, Lin, and Phalippou (2012).

The literature that estimates beta exposures of PE funds with respect to the stock market has generally estimated stock market exposures of Buyout funds above one and even higher estimates for VC funds (e.g., Gompers and Lerner, 1997; Ewens, Jones, and Rhodes-Kropf, 2013; Peng, 2001; Woodward, 2009; Korteweg and Nagel, 2016). Our work contributes to this literature by allowing not for a flexible estimation of aggregate stock market exposure across horizon and vintage, but also by allowing risk exposure estimates to differ by PE fund category, considering a broader set of PE categories than typically examined, and especially by going beyond the aggregate stock market as the only source of aggregate risk. VC funds are found to load on small stock and growth stock risk. Finally, we connect the systematic risk exposures of funds to a rich asset pricing model, which allows us to estimate risk-adjusted profits and time-varying expected returns.

Like Korteweg and Nagel (2016), we estimate a stochastic discount factor (SDF) from public securities. Our SDF contains additional risk factors and richer price-of-risk dynamics. Those dynamics are important for generating realistic, time-varying risk premia on bond and stock strips, which are the building blocks of our PE valuation method. The SDF model extends earlier work by Lustig, Van Nieuwerburgh, and Verdelhan (2013) who value a claim to aggregate consumption to help guide the construction of consumptionbased asset pricing models. The asset pricing model combines a vector auto-regression model for the state variables as in Campbell $(1991,1993,1996)$ with a no-arbitrage model for the (SDF) as in Duffie and Kan (1996); Dai and Singleton (2000); Ang and Piazzesi (2003). The SDF model needs to encompass the sources of aggregate risk that the investor has access to in public securities markets and that PE funds are exposed to. The question of performance evaluation then becomes whether, at the margin, PE funds add value to a portfolio that already contains these traded assets. 
In complementary work, Ang, Chen, Goetzmann, and Phalippou (2017) filter a time series of realized private equity returns using Bayesian methods. They then decompose that time series into a systematic component, which reflects compensation for factor risk exposure, and an idiosyncratic component (alpha). While our approach does not recover a time series of realized PE returns, it does recover a time series of expected PE returns. At each point in time, the asset pricing model can be used to revalue the replicating portfolio for the PE fund. Since it does not require a difficult Bayesian estimation step, our approach is more flexible in terms of number of factors as well as the factor risk premium dynamics. Other important methodological contributions to the valuation of private equity include Driessen, Lin, and Phalippou (2012), Sorensen, Wang, and Yang (2014), and Metrick and Yasuda (2010).

The rest of the paper is organized as follows. Section 2 describes our methodology. Section 3 sets up and solves the asset pricing model. Section 4 presents the main results on the risk-adjusted profits and expected returns of PE funds. Section 5 concludes. Appendices A provide additional derivations, while Appendix B has additional detail on the VAR estimation. Appendix C provides estimates on shock-exposure elasticities of our estimates. Appendix D includes results on additional fund categories. Appendix E performs a validation exercise on public equities, and Appendix F provides estimates on the Burgiss dataset.

\section{Methodology}

PE investments are finite-horizon strategies, typically around ten years in duration. Upon inception of the fund, the investor (LP) commits capital to the fund manager (GP). The GP deploys that capital at her discretion, but typically within the first 2-4 years. Intermediate cash-flows may accrue from the operations of the assets, for example, net operating income from renting out an office building. Towards the end of the life of the fund (typically in years 5-10), the GP "harvests" the assets and distributes the proceeds to the LPs after subtracting fees (including performance fees called the carry or promote). These distribution cash-flows are risky, and understanding (and pricing) the nature of the risk in these cash-flows is the key question in this paper.

Denote the sequence of net-of-fee cash-flow distributions for fund $i$ by $\left\{X_{t+h}^{i}\right\}_{h=0}^{T}$. Time $t$ is the inception quarter of the fund, the vintage. The horizon $h$ indicates the number of quarters since fund inception. The maximum horizon $H$ is set to 60 quarters to 
allow for "zombie" funds that continue past their projected life span of approximately 10 years. All cash flows observed after quarter 60 are allocated evenly to quarters 6164. We do so to ensure evenly spaced quarterly cash flows, and interpret the last year of cash flows as this terminal cash flow event. Monthly fund cash-flows are aggregated to the quarterly frequency. All PE cash-flows in our data are reported for a $\$ 1$ investor commitment.

Once the capital is committed, the GP has discretion to call that capital. We take the perspective that the risk-adjusted profit (RAP) measure should credit the GP for the skillful timing of capital calls. Correspondingly, we assume that the replicating portfolio is fully invested at time $t$. If strategic delay in capital deployment results in better investment performance, the RAP will reflect this. In sum, we purposely do not use the data on capital calls, only the distribution cash flow data. ${ }^{2}$ In Appendix E, we benchmark against a standard factor-correction as in Fama and French (1992).

\subsection{Two-Step Approach}

In a first step, we use our asset pricing model, spelled out in the next section, to price the time series and cross-section of zero coupon bond and equity strips. Let the $H K \times 1$ vector $\boldsymbol{F}_{t, t+h}$ be the vector of cash flows on the securities in the replicating portfolio. The first $\mathrm{H}$ elements of $\boldsymbol{F}_{t, t+h}$ are constant equal to 1 . They are the cash-flows on nominal zerocoupon U.S. Treasury bonds that pay $\$ 1$ at time $t+h$. The other $H(K-1)$ elements of $\boldsymbol{F}_{t, t+h}$ denote risky cash-flow realizations at time $t+h$. They are the payoffs on "dividend strips" (Lettau and Wachter, 2011; van Binsbergen, Brandt, and Koijen, 2012) and "capital gain strips." Dividend strips pay one risky stock dividend at time $t+h$ and nothing at any other date. We scale the risky dividend at $t+h$ by the cash flow at fund inception time $t$. For example, a risky cash-flow of $F_{t, t+h}(k)=\frac{D_{t+h}(k)}{D_{t}(k)}=1.05$ implies that there was a $5 \%$ realized cash-flow growth rate between periods $t$ and $t+h$ on the $k^{t h}$ asset in the replicating portfolio. This scaling makes the payoffs on dividend strips comparable in magnitude to that of zero coupon bonds, in turn making bond and stock exposures in the replicating portfolio comparable in magnitude. Capital gain strips, or gain strips for short, pay one risky cash flow at time $t+h$ equal to the realized ex-dividend price of the stock. We scale this cash flow by the current stock price. For example, a 20-quarter gain strip on

\footnotetext{
${ }^{2}$ Note that under this assumption, the net present value of deployed capital may differ from $\$ 1$. Our methodology can handle capital calls. In that case, the replicating portfolio would mimic not only the distribution cash flows but also the call cash flows. The calls would be treated as negative bond strip positions.
} 
the aggregate stock market bought at time $t$ pays the single cash flow $P_{t+20}^{m} / P_{t}^{m}=1.05$ at time $t+20$, if the realized cumulative capital gain on the stock market over this 20-quarter investment horizon is $5 \%$. The reason for including gain strips in the replicating portfolio is that PE cash flows during the harvesting period are likely to reflect asset dispositions. These dispositions take place at prices that reflect all future cash flows on those assets. It is conceivable that these late-life distributions are more highly correlated with publicly listed equity prices (future equity dividends) than with current equity dividends.

Denote the $H K \times 1$ price vector for strips by $\boldsymbol{P}_{t, h}$. The first $H \times 1$ elements of this price vector are the prices of nominal zero-coupon bonds of maturities $h=1, \cdots, H$, which we denote by $\boldsymbol{P}_{t, h}(1)=\boldsymbol{P}_{t, h}^{\$}$. Let the one-period stochastic discount factor (SDF) be $M_{t+1}$, then the $h$-period SDF is:

$$
M_{t, t+h}=\prod_{j=1}^{h} M_{t+j} .
$$

The (vector of) strip prices satisfy the (system of) Euler equation:

$$
\boldsymbol{P}_{t, h}=\mathbb{E}_{t}\left[M_{t, t+h} \boldsymbol{F}_{t, t+h}\right]
$$

Strip prices reflect expectations of the SDF and cash flows.

The second step of our approach is to obtain the cash-flow replicating portfolio of strips for the PE cash-flow distributions. Denote the cash flow on the replicating portfolio by $\boldsymbol{\beta}_{t, h}^{i} \boldsymbol{F}_{t, t+h}$, where the $1 \times H K$ vector $\boldsymbol{\beta}_{t, h}^{i}$ denotes the exposure of PE fund $i$ to the $H K$ assets in the replicating portfolio. We estimate the exposures from a projection of cashflows realized at time $t+h$ of PE funds started at time $t$ on the cash-flows of the risk-free and risky strips:

$$
X_{t+h}^{i}=\boldsymbol{\beta}_{t, h}^{i} \boldsymbol{F}_{t, t+h}+e_{t+h}^{i} .
$$

where $e$ denotes the idiosyncratic cash-flow component, orthogonal to $F_{t, t+h}$. The vector $\beta_{t, h}^{i}$ describes how many units of each strip are in the replicating portfolio for the fund cash-flows. Equation (1) is estimated on a sample of all funds in a given category, all vintages $t$, and all horizons $h$. We impose cross-equation restrictions on this estimation, as explained below.

Expected Returns The expected return on private equity fund is given by:

$$
\mathbb{E}_{t}\left[R^{i}\right]=\sum_{h=1}^{H} \sum_{k=1}^{K} \boldsymbol{w}_{t, h}^{i}(k) \mathbb{E}_{t}\left[\boldsymbol{R}_{t+h}(k)\right]
$$


where $w^{i}$ is a $1 \times H K$ vector of replicating portfolio weights with generic element $w_{t, h}^{i}(k)=$ $\beta_{t, h}^{i}(k) P_{t, h}(k)$. The $H K \times 1$ vector $\mathbb{E}_{t}[\boldsymbol{R}]$ denotes the expected returns on the $K$ traded asset strips at each horizon $h$, obtained by the asset pricing model. Time variation in strip expected returns combines with the time variation coming from $\boldsymbol{\beta}_{t, h}^{i}$ to induce time variation in the expected return on the private equity fund. Equation (2) decomposes the risk premium into compensation for exposure to the various risk factors, horizon by horizon. The expected return is measured over the life of the fund (not annualized). It can be annualized by taking into account the maturity of the fund. Akin to a Macauley duration, we define the maturity of the fund, expressed in years (rather than quarters), as:

$$
\delta_{t}^{i}=\frac{1}{4} \sum_{h=1}^{H} \sum_{k=1}^{K} \tilde{w}_{t, h}^{i}(k) h,
$$

where the weights $\tilde{w}_{t, h}^{i}(k)$ are the original weights $w_{t, h}^{i}(k)$ rescaled to sum to 1 . The annualized expected fund return is then:

$$
\mathbb{E}_{t}\left[R_{\text {ann }}^{i}\right]=\left(1+\mathbb{E}_{t}\left[R^{i}\right]\right)^{1 / \delta_{t}^{i}}-1
$$

Risk-Adjusted Profit Performance evaluation of PE funds requires quantifying the LP's profit on a particular PE investment, after taking into account its riskiness. This ex-post realized, risk-adjusted profit is the second main object of interest. Under the maintained assumption that all the relevant sources of systematic risk are captured by the replicating portfolio, the PE cash-flows consist of one component that reflects compensation for risk and a risk-adjusted profit (RAP) equal to the discounted value of the idiosyncratic cashflow component. For fund $i$ in vintage $t$, we redefine the idiosyncratic component of fund cash-flows as $e^{i}$ :

$$
e_{t+h}^{i}=X_{t+h}^{i}-\boldsymbol{\beta}_{t, h}^{i} \boldsymbol{F}_{t, t+h} .
$$

We define the RAP as:

$$
\begin{aligned}
R A P_{t}^{i} & =\underbrace{\left(\sum_{h=1}^{H} X_{t+h}^{i} P_{t, h}^{\$}-1\right)}_{\sim \text { TVPI }}-\left(\sum_{h=1}^{H} \sum_{k=1}^{K} \beta_{t, h}^{k} \boldsymbol{F}_{t, t+h} P_{t, h}^{\$}-\beta_{t, h}^{k} \boldsymbol{P}_{t, h}\right) \\
& =\sum_{h=1}^{H} e_{t+h}^{i} P_{t, h}^{\$}+\sum_{h=1}^{H} \sum_{k=1}^{K} \beta_{t, h}^{k} \boldsymbol{P}_{t, h}-1 .
\end{aligned}
$$

The risk-adjusted profit compares the returns on the PE fund against the returns on the 
replicating portfolio. The returns of the PE fund are the future cash flows of the PE fund, discounted at the risk-free term structure of interest rates (recall nominal bond prices are $\left.P_{t, h}^{\$}\right)$, minus the $\$ 1$ of capital committed to the fund. Except for the discounting component, this measure is similar to a traditional TVPI measure. The second term measures the return from the replicating portfolio: the discounted value of all realized cash flows minus the cost of purchasing the replicating portfolio. Rewriting, we can express the RAP as the discounted sum of the idiosyncratic cash-flows, and the difference between the purchase price of the replicating portfolio of strips and one. Since the idiosyncratic cash-flow components are orthogonal to the priced cash-flow shocks, they are discounted at the risk-free interest rate. Since the term structure of risk-free bond prices $P_{t, h}^{\$}$ is known at time $t$, there is no measurement error involved in the discounting. The null hypothesis of no outperformance is $\mathbb{E}\left[R A P_{t}^{i}\right]=0$, where the expectation is taken on average across funds. This is because the idiosyncratic cash-flows average to zero, and our null hypothesis is that purchasing a portfolio of strips that has the same systematic risk as the PE fund will have the same cost as the PE fund, namely $\$ 1$. Our approach credits PE funds with out-performance to the extent they are able to deliver factor exposure at an (afterfee) expense lower than that of existing publicly traded assets. It does not credit the GP for factor timing, i.e., an unexpectedly high realization of the factors.

A fund with strong asset selection skills picks investment projects with payoffs superior to the payoffs on traded assets and will have a positive RAP. Additionally, a fund with market timing skills, which invests at the right time (within the investment period) and sells at the right time (within the harvesting period) will have positive risk-adjusted profit. $^{3}$ If capital lock-up in the PE fund structure enables managers to earn an illiquidity premium, we would also expect this to be reflected in a positive RAP on average. Like any other performance metric in the PE literature, our approach does not allow us to disentangle true skill from this illiquidity premium. To the best of our knowledge there is no hard evidence of the existence of an illiquidity premium. Many institutional investors such as pension funds value the fact that PE investments do not have to be marked-tomarket. Given that public pensions make up the largest asset allocator to private equity, ${ }^{4}$ then the illiquidity premium could in fact be negative. Regardless of the sign, our RAP

\footnotetext{
${ }^{3}$ The fund's horizon is endogenous because it is correlated with the success of the fund. As noted by Korteweg and Nagel (2016), this endogeneity does not pose a problem as long as cash-flows are observed. They write: "Even if there is an endogenous state-dependence among cash-flows, the appropriate valuation of a payoff in a certain state is still the product of the state's probability and the SDF in that state."

${ }^{4}$ See data from Preqin: https://www.preqin.com/insights/blogs/an-analysis-of-usbasedpublic-pension-fund-allocations-to-private-equity-june-2015/11528.
} 
does incorporate illiquidity (either as a discount or premium).

To assess the performance of PE funds, we report both the distribution of risk-adjusted profits across all funds in the sample, as well as the equal-weighted average RAP by vintage. When calculating our RAP measure (and only then), we exclude vintages after 2010 for which we are still missing a substantial fraction of the cash flows.

\subsection{Identifying and Estimating Cash-Flow Betas}

The replicating portfolio must be rich enough that it spans all priced (aggregate) sources of risk, yet it must be parsimonious enough that its exposures can be estimated with sufficient precision. Allowing every fund in every category and vintage to have its own unrestricted cash-flow beta profile for each risk factor leads to parameter proliferation and lack of identification. We impose cross-equation restrictions to aid identification.

Identifying Assumptions Identification is achieved both from the cross-section and from the time series. We make four assumptions. First, the cash-flows $X_{t+h}^{i \in c}$ of all funds $i$ in the same category $c$ (category superscripts are omitted for ease of notation) and vintage $t$ have the same risk factor exposures at horizon $h, \beta_{t, h}$. We have $N_{f} \times T \times H$ fund cashflow observations, where $T$ reflects the number of different vintages and $N_{f}$ the average number of funds in a category c per vintage. Second, the risk exposures $\beta_{t, h}^{k}$ for each factor $k$ are the sum of a vintage effect $a_{t}^{k}$ and a horizon effect $b_{h}^{k}$. Third, horizon effects are constant for the four quarters within the same calendar year. This reduces the number of horizon effects that need to be estimated for each factor from $H=64$ to $H / 4=16$. Fourth, the vintage effects depend on the price-dividend ratio on the aggregate stock market in the quarter of fund inception. The vintage effects thus captures dependence on the overall investment climate at the time of $\mathrm{PE}$ fund origination. The choice of the $p d_{t}^{m}$ ratio is also motivated by the asset pricing model of Section 3, where the $p d_{t}^{m}$ ratio is one of the key state variables driving time variation in risk premia. ${ }^{5}$ To simplify the time dimension, we categorize vintages $t$ by the quartile of the $p d_{t}^{m}$ ratio in the vintage quarter; quartile breakpoints are based on the same 1974-2017 sample. The vintage effects are normalized to be zero on average across quartiles, so that 3 vintage coefficients need to be estimated for each factor. To summarize, with $K$ factors, we estimate $(16+3) \times K$ risk exposures, rather than $H \times T \times K$ coefficients in an unrestricted model.

\footnotetext{
${ }^{5}$ Haddad, Loualiche, and Plosser (2017) emphasizes the importance of P/D ratios and aggregate equity premia in explaining Buyout activity.
} 
Two-factor Model We start with a model in which all private equity cash-flows are assumed to have bond and aggregate stock market exposure. We refer to this as the twofactor model $(K=2)$. This model extends not only the PME approach of Kaplan and Schoar (2005), which assumes a stock market beta of 1 for all PE funds, but also the GPME approach of Korteweg and Nagel (2016), which assumes a constant stock market beta (different from 1). Our approach allows for exposures to both bonds and stocks be horizon dependent as well as vintage-specific. Korteweg and Nagel (2016)'s two-factor model has 2 exposure coefficients while we estimate 38 coefficients. Another difference is that the GPME approach uses the realized SDF while we use strip prices, which are expectations of the SDF (multiplied by risky cash flow realization in the case of equity strips).

Fund cash-flows for the two-factor model can be expressed as:

$$
\begin{aligned}
X_{t+h}^{i \in c} & =\beta_{t, h}^{\text {bond }}+\beta_{t, h}^{\text {equity }} F_{t, t+h}^{\text {equity }}+e_{t+h}^{i} \\
& =a_{p d_{t}}^{\text {bond }}+b_{h}^{\text {bond }}+\left(a_{p d_{t}}^{\text {equity }}+b_{h}^{\text {equity }}\right) F_{t, t+h}^{\text {equity }}+e_{t+h}^{i} .
\end{aligned}
$$

We include all available vintages that have at least eight quarters of cash flows because the extra information from recent vintages may be useful to better identify the first few elements of $b_{h}$. We estimate equation (6) by OLS.

$K$-factor Model Our main model is a $K$-factor model in which we allow for $K-2$ additional cross-sectional equity market factors (beyond the two factors from the previous model) to better capture the systematic risk in PE fund cash flows. PE fund cash flows are modeled as:

$$
\begin{aligned}
X_{t+h}^{i \in c} & =\beta_{t, h}^{\text {bond }}+\sum_{k=2}^{K} \beta_{t, h}^{k} F_{t, t+h}^{k}+e_{t+h}^{i} \\
& =a_{t}^{\text {bond }}+b_{h}^{\text {bond }}+\sum_{k=2}^{K}\left(a_{t}^{k}+b_{h}^{k}\right) F_{t, t+h}^{k}+e_{t+h}^{i} .
\end{aligned}
$$

In the empirical implementation, $K=15$. The factors are bond strips, and both dividend strips and capital gain strips on seven equity factors: the aggregate stock market, small stocks, growth stocks, value stocks, REITs, infrastructure stocks, and natural resource stocks. Under our identifying assumptions, we estimate $3 K=45$ vintage coefficients and $K H / 4=240$ horizon coefficients for a total of 285 coefficients.

Because of the large number of coefficients to estimate, we use an Elastic Net ap- 
proach that constrains all penalized coefficients to be non-negative, and imposes additional shrinkage penalties on parameters. This second approach follows a recent literature on Machine Learning in asset pricing (e.g., Gu, Kelly, and Xiu, 2018; Kozak, Nagel, and Santosh, 2017) and aims to shrink the dimensionality of the factors that enter the PE fund-replicating portfolio. This estimation offers two key economic advantages. First, it constrains the replicating portfolio to long positions only, which avoids costs and difficulties related to short positions. Second, the Elastic Net model will set to zero many possible factor and horizon terms in the replicating portfolio. This avoids having to take a stance on the identity of a small number of factors, a problem with the OLS approach. The Elastic Net simplifies the resulting replicating positions considerably (both through the ridge regression and Lasso penalties). The Elastic Net estimation of equation (1) can be written as:

$$
\hat{\beta}_{\text {ElasticNet }}=\arg \min _{\beta \in \mathbf{R}^{K H}}\left\|X_{t+h}^{i}-\beta_{t, h}^{i} \boldsymbol{F}_{t, t+h}\right\|_{2}^{2}+\lambda_{0} \mathbf{1}\{\beta>0\}+\lambda_{1}\|\beta\|_{1}+\lambda_{2}\|\beta\|^{2}
$$

We set the hyper-parameter $\lambda_{0}=\infty$, which ensures only positive coefficients. We use cross-validation to tune the parameters $\lambda_{1}$, which governs the Lasso parameter zeroing out a subset of coefficients (factor selection), and the $\lambda_{2}$ ridge regression penalty which shrinks the magnitude of coefficient estimates closer to zero, for each fund category separately.

\section{Asset Pricing Model}

The second main step is to price the replicating portfolio. If the only sources of risk were fluctuations in the term structure of interest rates, this step would be straightforward. After all, we can infer the prices of zero-coupon bonds of all maturities from the observed yield curve at each date. However, fluctuations in interest rates are not the only and not even the main source of risk in the cash-flows of private equity funds as we will show. If fluctuations in the aggregate stock market were the only other source of aggregate risk, then we could use price information from dividend strips. Those prices can either be observed directly from dividend strip futures markets (van Binsbergen, Hueskes, Koijen, and Vrugt, 2013) or inferred from options and stock markets (van Binsbergen, Brandt, and Koijen, 2012). However, the available time series is too short for our purposes, strips are not available for horizons beyond seven years and do not come in one-quarter horizon 
increments. Most importantly, the only dividend strip data are for the aggregate stock market. There are no strip data for the additional traded factors we wish to include in our analysis such as publicly listed real estate or infrastructure assets, a small stock, value stock, or growth stock index. Finally, we do not observe expected returns on the available strips, only realized returns. Expected returns are difficult to infer from short time series of realized returns. For all these reasons, we need an asset pricing model to generate the time series of strip prices, $\boldsymbol{P}_{t, h}$ and the corresponding expected returns for each strip. But we impose that the asset pricing model is consistent with the available aggregate dividend strip data in addition to the standard asset pricing moments.

We propose a reduced-form stochastic discount factor (SDF) model rather than a structural asset pricing model, since it is more important for our purposes to price the replicating portfolio of publicly traded assets correctly than to understand the fundamental sources of risk that underly the pricing of stocks and bonds. Our approach builds on Lustig, Van Nieuwerburgh, and Verdelhan (2013), who price a claim to aggregate consumption and study the properties of the price-dividend ratio of this claim, the wealthconsumption ratio. A virtue of the reduced-form model is that it can accommodate a substantial number of risk factors. We argue that it is important to go beyond the aggregate stock and bond markets to capture the risk embedded in PE fund cash flows.

As in Korteweg and Nagel (2016), the objective here is not to test the asset pricing model but rather to investigate whether a potential PE investment adds value to an investor who already has access to securities whose sources of risk are captured by the SDF.

\subsection{Setup}

\subsubsection{State Variable Dynamics}

Time is denoted in quarters. We assume that the $N \times 1$ vector of state variables follows a Gaussian first-order VAR:

$$
z_{t}=\Psi z_{t-1}+\Sigma^{\frac{1}{2}} \varepsilon_{t}
$$

with shocks $\varepsilon_{t} \sim$ i.i.d. $\mathcal{N}(0, I)$ whose variance is the identity matrix. The companion matrix $\Psi$ is a $N \times N$ matrix. The vector $z$ is demeaned. The covariance matrix of the innovations to the state variables is $\Sigma$; the model is homoscedastic. We use a Cholesky decomposition of the covariance matrix, $\Sigma=\Sigma^{\frac{1}{2}} \sum^{\frac{1}{2}}$, which has non-zero elements only on and below the diagonal. The Cholesky decomposition of the residual covariance matrix allows us to interpret the shock to each state variable as the shock that is orthogonal to 
the shocks of all state variables that precede it in the VAR. We discuss the elements of the state vector and their ordering below. For now, we note that the (demeaned) one-month bond nominal yield is one of the elements of the state vector: $y_{t, 1}^{\$}=y_{0,1}^{\$}+e_{y n}^{\prime} z_{t}$, where $y_{0,1}^{\$}$ is the unconditional average 1-quarter nominal bond yield and $e_{y n}$ is a vector that selects the element of the state vector corresponding to the one-quarter yield. Similarly, the (demeaned) inflation rate is part of the state vector: $\pi_{t}=\pi_{0}+e_{\pi}^{\prime} z_{t}$ is the (log) inflation rate between $t-1$ and $t$. Lowercase letters denote logs.

\subsubsection{Stochastic Discount Factor}

We specify an exponentially affine SDF, similar in spirit to the no-arbitrage term structure literature (Ang and Piazzesi, 2003). The nominal SDF $M_{t+1}^{\$}=\exp \left(m_{t+1}^{\$}\right)$ is conditionally log-normal:

$$
m_{t+1}^{\$}=-y_{t, 1}^{\$}-\frac{1}{2} \Lambda_{t}^{\prime} \Lambda_{t}-\Lambda_{t}^{\prime} \varepsilon_{t+1} .
$$

Note that $y_{t, 1}^{\$}=-\mathbb{E}_{t}\left[m_{t+1}^{\$}\right]-0.5 \mathbb{V}_{t}\left[m_{t+1}^{\$}\right]$. The real log SDF $m_{t+1}=m_{t+1}^{\$}+\pi_{t+1}$ is also conditionally Gaussian. The innovations in the vector $\varepsilon_{t+1}$ are associated with a $N \times 1$ market price of risk vector $\Lambda_{t}$ of the affine form:

$$
\Lambda_{t}=\Lambda_{0}+\Lambda_{1} z_{t}
$$

The $N \times 1$ vector $\Lambda_{0}$ collects the average prices of risk while the $N \times N$ matrix $\Lambda_{1}$ governs the time variation in risk premia. Asset pricing amounts to estimating the market prices of risk $\left(\Lambda_{0}, \Lambda_{1}\right)$. We specify the moment conditions to identify the market prices of risk below.

\subsubsection{Bond Pricing}

Proposition 1 in Appendix A shows that nominal bond yields of maturity $\tau$ are affine in the state variables:

$$
y_{t, \tau}^{\$}=-\frac{1}{\tau} A_{\tau}^{\$}-\frac{1}{\tau}\left(B_{\tau}^{\$}\right)^{\prime} z_{t}
$$

The scalar $A^{\$}(\tau)$ and the vector $B_{\tau}^{\$}$ follow ordinary difference equations that depend on the properties of the state vector and on the market prices of risk. The appendix also calculates the real term structure of interest rates, the real bond risk premium, and the inflation risk premium on bonds of various maturities. We will price a large cross-section 
of nominal bonds that differ by maturity, paying special attention to matching the time series of one- and twenty-quarter bond yields since those bond yields are part of the state vector $z_{t}$.

\subsubsection{Equity Pricing}

The present-value relationship says that the price of a stock equals the present-discounted value of its future cash-flows. By value-additivity, the price of the stock, $P_{t}^{m}$, is the sum of the prices to each of its future cash-flows $D_{t}^{m}$. These future cash-flow claims are the so-called dividend strips or zero-coupon equity (Wachter, 2005). Dividing by the current dividend $D_{t}^{m}$ :

$$
\begin{array}{r}
\frac{P_{t}^{m}}{D_{t}^{m}}=\sum_{\tau=1}^{\infty} P_{t, \tau}^{d} \\
\exp \left(\overline{p d}+e_{p d^{m}}^{\prime} z_{t}\right)=\sum_{\tau=0}^{\infty} \exp \left(A_{\tau}^{m}+B_{\tau}^{m \prime} z_{t}\right),
\end{array}
$$

where $P_{t, \tau}^{d}$ denotes the price of a $\tau$-period dividend strip divided by the current dividend. Proposition 2 in Appendix A shows that the log price-dividend ratio on each dividend strip, $p_{t, \tau}^{d}=\log \left(P_{t, \tau}^{d}\right)$, is affine in the state vector and provides recursions for the coefficients $\left(A_{\tau}^{m}, \boldsymbol{B}_{\tau}^{m}\right)$. Since the log price-dividend ratio on the stock market is an element of the state vector, it is affine in the state vector by assumption. Equation (12) restates the present-value relationship from equation (11). It articulates a non-linear restriction on the coefficients $\left\{\left(A_{\tau}^{m}, B_{\tau}^{m}\right)\right\}_{\tau=1}^{\infty}$ at each date (for each state $z_{t}$ ), which we impose in the estimation. Analogous present value restrictions are imposed for the other traded equity factors, whose price-dividend ratios and dividend growth rates are also included in the state vector.

If dividend growth were unpredictable and its innovations carried a zero risk price, then dividend strips would be priced like real zero-coupon bonds. The strips' dividendprice ratios would equal yields on real bonds with the coupon adjusted for deterministic dividend growth. All variation in the price-dividend ratio would reflect variation in the real yield curve. In reality, the dynamics of real bond yields only account for a small fraction of the variation in the price-dividend ratio, implying large prices of risk associated with shocks to dividend growth that are orthogonal to shocks to bond yields. 


\subsubsection{Dividend Futures}

The model readily implied the price of a futures contract that received the single realized nominal dividend at some future date, $D_{t+k}^{\$}$. That futures price, $F_{t, \tau}^{d}$, scaled by the current nominal dividend $D_{t}^{\$}$, is:

$$
\frac{F_{t, \tau}^{d}}{D_{t}^{\$}}=P_{t, \tau}^{d} \exp \left(\tau y_{t, \tau}^{\$}\right),
$$

The one-period realized return on this futures contract for $k>1$ is:

$$
R_{t+1, \tau}^{f u t, d}=\frac{F_{t+1, \tau-1}^{d}}{F_{t, \tau}^{d}}-1
$$

Appendix A shows that $\log \left(1+R_{t+1, \tau}^{f u t, d}\right)$ is affine in the state vector $z_{t}$ and in the shocks $\varepsilon_{t+1}$. It is straightforward to compute average realized returns over any subsample, and for any portfolio of futures contracts.

\subsection{Estimation}

\subsubsection{State Vector Elements}

The state vector contains the following 18 variables, in order of appearance: (1) GDP price inflation, (2) real per capita GDP growth, (3) the nominal short rate (3-month nominal Treasury bill rate), (4) the spread between the yield on a five-year Treasury note and a three-month Treasury bill, (5) the log price-dividend ratio on the CRSP value-weighted stock market, (6) the log real dividend growth rate on the CRSP stock market. Elements 7, $9,11,13,15$, and 17 are the log price-dividend ratios on the REIT index of publicly listed real estate companies, a listed infrastructure index (infra), the first size quintile of stocks (small), the first book-to-market quintile of stocks (growth), natural resource stocks (nr), and the fifth book-to-market quintile of stocks (value). Elements 8, 10, 12, 14, 16, and 18 are the corresponding log real dividend growth rates:

$$
\begin{aligned}
z_{t}=\quad & {\left[\pi_{t}, x_{t}, y_{t, 1}^{\$}, y_{t, 20}^{\$}-y_{t, 1}^{\$}, p d_{t}^{m}, \Delta d_{t}^{m}, p d_{t}^{\text {reit }}, \Delta d_{t}^{\text {reit }}, p d_{t}^{\text {infra }}, \Delta d_{t}^{\text {infra }},\right.} \\
& \left.p d_{t}^{\text {small }}, \Delta d_{t}^{\text {small }}, p d_{t}^{\text {growth }}, \Delta d_{t}^{\text {growth }}, p d_{t}^{n r}, \Delta d_{t}^{\text {nr }}, p d_{t}^{\text {value }}, \Delta d_{t}^{\text {value }}\right]^{\prime} .
\end{aligned}
$$

This state vector is observed at quarterly frequency from 1974.Q1 until 2017.Q4 (176 observations). This is the longest available time series for which all variables are avail- 
able. ${ }^{6}$ Our PE cash flow data starts shortly thereafter in the early 1980s. While most of our PE fund data are after 1990, we deem it advantageous to use the longest possible sample to more reliably estimate the VAR dynamics and especially the market prices of risk. All state variables are demeaned with the observed full-sample mean.

The VAR is estimated by OLS in the first stage of the estimation. We recursively zero out all elements of the companion matrix $\Psi$ whose $t$-statistic is below 1.96. Appendix B contains the resulting point estimates for $\Psi$ and $\Sigma^{\frac{1}{2}}$.

\subsubsection{Market Prices of Risk}

The state vector contains both priced sources of risk as well as predictors of bond and stock returns. We estimated 12 non-zero parameters in the constant market price of risk vector $\Lambda_{0}$ and 92 non-zero elements of the matrix $\Lambda_{1}$ which governs the dynamics of the risk prices. The point estimates are listed in Appendix B.2. We use the following target moments to estimate the market price of risk parameters.

First, we match the time-series of nominal bond yields for maturities of one quarter, one year, two years, five years, ten years, twenty years, and thirty years. They constitute about $7 \times T$ moments, where $T=176$ quarters. ${ }^{7}$

Second, we impose restrictions that we exactly match the average five-year bond yield and its dynamics. This delivers 19 additional restrictions:

$$
-A_{20}^{\$} / 20=y_{0,20}^{\$} \quad \text { and } \quad-B_{20}^{\$} / 20=[0,0,1,1,0,0,0,0,0,0,0,0,0,0,0,0,0,0]
$$

Because the five-year bond yield is the sum of the third and fourth element in the state vector, the market prices of risk must be such that $-B_{20}^{\$} / 20$ has a one in the third and fourth place and zeroes everywhere else.

Third, we match the time-series of log price-dividend ratios on the stock market, real estate stocks, infrastructure stocks, small stocks, growth stocks, natural resource stocks,

\footnotetext{
${ }^{6}$ The model is quarterly. We use the average of daily Constant Maturity Treasury yields within the quarter. The REIT index is the NAREIT All Equity index, which excludes mortgage REITs. The first observation for REIT dividend growth is in 1974.Q1. All dividend series are deseasonalized by summing dividends across the current month and past 11 months. This means we lose the first 8 quarters of data in 1972 and 1973 when computing dividend growth rates. The infrastructure stock index is measured as the valueweighted average of the eight relevant Fama-French industries (Aero, Ships, Mines, Coal, Oil, Util, Telcm, Trans). The natural resource index is measured from the Alerian Master Limited Partnership from 1996.Q1 onwards and as the Oil industry index beforehand.

${ }^{7}$ The 20-year bond yield is missing prior to 1993.Q4 while the 30-year bond yield data is missing from 2002.Q1-2005.Q4. In total 107 observations are missing, so that we have $1232-107=1125$ bond yields to match.
} 
and value stocks. The model-implied price-dividend ratios are built up from 3,500 quarterly dividend strips according to equation (11). We impose these present-value relationships in each quarter, delivering $7 \times T$ moments.

Fourth, we impose that the time series of risk premia for the seven stock indices in the model match the risk premia implied by the VAR, i.e., from the data. As usual, the expected excess return in logs (including a Jensen adjustment) must equal minus the conditional covariance between the log SDF and the log return. For example, for the overall stock market:

$$
\begin{aligned}
& E_{t}\left[r_{t+1}^{m, \$}\right]-y_{t, 1}^{\$}+\frac{1}{2} V_{t}\left[r_{t+1}^{m, \$}\right]=-\operatorname{Cov}_{t}\left[m_{t+1}^{\$} r_{t+1}^{m, \$}\right] \\
& r_{0}^{m}+\pi_{0}-y_{0}^{\$}(1)+\left[\left(e_{\text {divm }}+\kappa_{1}^{m} e_{p d}+e_{\pi}\right)^{\prime} \Psi-e_{p d}^{\prime}-e_{y n}^{\prime}\right] z_{t} \\
&+\frac{1}{2}\left(e_{\text {divm }}+\kappa_{1}^{m} e_{p d}+e_{\pi}\right)^{\prime} \Sigma\left(e_{\text {divm }}+\kappa_{1}^{m} e_{p d}+e_{\pi}\right)=\left(e_{\text {divm }}+\kappa_{1}^{m} e_{p d}+e_{\pi}\right)^{\prime} \Sigma^{\frac{1}{2}} \Lambda_{t}
\end{aligned}
$$

The left-hand side is given by the VAR (data), while the right-hand side is determined by the market prices of risk $\Lambda_{0}$ and $\Lambda_{1}$ (model). This provides $(N+1) \times 7=133$ additional restrictions. These moments help identify the 6 th, 8 th, 10th, 12th, 14th, 16th, and 18th elements of $\Lambda_{0}$ and corresponding rows of $\Lambda_{1}$ (together with the present-value restrictions).

Fifth, we price a claim that pays the next eight quarters of realized nominal dividends on the aggregate stock market. The value of this claim is the sum of the prices to the nearest eight dividend strips. Data for the price-dividend ratio on this claim and the share it represents in the overall stock market (S\&P500) for the period 1996.Q1-2009.Q3 (55 quarters) are obtained from van Binsbergen, Brandt, and Koijen (2012). This delivers $2 \times 55$ moments. We also ensure that the model is consistent with the high average realized returns on short-horizon dividend futures, first documented by van Binsbergen, Hueskes, Koijen, and Vrugt (2013). Table 1 in van Binsbergen and Koijen (2017) reports the observed average monthly return on one- through seven-year U.S. SPX dividend futures over the period Nov 2002 - Jul 2014. That average portfolio return is $8.71 \%$ per year. We construct an average return for the same short maturity futures portfolio (paying dividends 2 to 29 quarters from now) in the model:

$$
R_{t+1}^{f u t, p o r t f}=\frac{1}{28} \sum_{\tau=2}^{29} R_{t+1, \tau}^{f u t, d}
$$

We evaluate the realized return on this dividend futures portfolio at the state variables observed between 2003.Q1 and 2014.Q2, average it, and annualize it. This results in one 
additional restriction. We free up the market price of risk associated with the market price-dividend ratio (fifth element of $\Lambda_{0}$ and first six elements of the fifth row of $\Lambda_{1}$ ) to help match the dividend strip evidence.

Sixth, we impose a good deal bound on the standard deviation of the log SDF, the maximum Sharpe ratio, in the spirit of Cochrane and Saa-Requejo (2000).

Seventh, we impose regularity conditions on bond yields. We impose that very longterm real bond yields have average yields that weakly exceed average long-run real GDP growth, which is $1.65 \%$ per year in our sample. Long-run nominal yields must exceed long-run real yields by $2 \%$, an estimate of long-run average inflation. These regularity conditions are satisfied at the final solution.

Not counting the regularity conditions, we have 2,620 moments to estimate 104 market price of risk parameters. The estimation is massively over-identified.

\subsubsection{Model Fit}

Figure 1 plots the bond yields on bonds of maturities 1 quarter, 1 year, 5 years, and 10 years. Those are the most relevant horizons for the private equity cash-flows. The model matches the time series of bond yields in the data closely for the horizons that matter for PE funds (below 15 years). It matches nearly perfectly the 1-quarter and 5-year bond yield which are part of the state space.

The top panels of Figure 2 show the model's implications for the average nominal (left panel) and real (right panel) yield curves at longer maturities. These long-term yields are well behaved. The bottom left panel shows that the model matches the dynamics of the nominal bond risk premium, defined as the expected excess return on five-year nominal bonds. The compensation for interest rate risk varies substantially over time, both in data and in the model. The bottom right panel shows a decomposition of the yield on a fiveyear nominal bond into the five-year real bond yield, annual expected inflation over the next five years, and the five-year inflation risk premium. On average, the $5.7 \%$ five-year nominal bond yield is comprised of a $1.7 \%$ real yield, a $3.3 \%$ expected inflation rate, and a $0.8 \%$ inflation risk premium. The importance of these components fluctuates over time.

Figures 3 and 4 show the equity risk premium, the expected excess return, in the left panels and the price-dividend ratio in the right panels. The various rows cover the seven stock indices we price. The dynamics of the risk premia in the data are dictated by the VAR. The model chooses the market prices of risk to fit these risk premium dynamics as 
closely as possible. ${ }^{8}$ The price-dividend ratios in the model are formed from the pricedividend ratios on the strips of maturities ranging from 1 to 3500 quarters, as explained above. The figure shows an excellent fit for price-dividend levels and a good fit for risk premium dynamics. Some of the VAR-implied risk premia have outliers which the model does not fully capture. This is in part because the good deal bounds restrict the SDF from becoming too volatile and extreme. We note large level differences in valuation ratios across the various stock factors, as well as big differences in the dynamics of risk premia and price levels, which the model is able to capture well.

\subsection{Temporal Pricing of Risk}

The first key input from the model into the private equity valuation exercise are the prices of nominal zero-coupon bonds and of the various dividend strips. Figure 5 plots these strip prices, scaled by the current quarter dividend. For readability, we plot only three maturities: one, five, and ten years. The model implies substantial variation in strip prices over time, across maturities, as well as across risky assets. If the replicating portfolio for VC funds originated in the year 2000 loads heavily on growth strips, when growth strips are expensive, then the risk-adjusted performance of vintage-2000 VC funds will be high, all else equal.

As part of the estimation, the model fits several features of traded dividend strips on the aggregate stock market. Figure 6 shows the observed time series of the pricedividend ratio on a claim to the first 8 quarters of dividends (red line, left panel), as well as the share of the total stock market value that these first eight quarters of dividends represent (red line, right panel). The blue line is the model. The model generates the right level for the price-dividend ratio for the short-horizon claim. For the same 55 quarters for which the data are available, the average is 7.75 in the model and 7.65 in the data. The first 8 quarters of dividends represent $3.4 \%$ of the overall stock market value in the data and $4.5 \%$ in the model, over the period in which there are data. The model mimics the observed dynamics of the short-horizon value share quite well, including the sharp decline in 2000.Q4-2001.Q1 when the short-term strip value falls by more than the overall stock market. This reflects the market's perception that the recession would be shortlived. In contrast, the share of short-term strips increases in the Great Recession, both in

\footnotetext{
${ }^{8}$ The quarterly risk premia are annualized (multiplied by 4) for presentational purposes only. The VAR does not restrict risk premia to remain positive. The VAR-implied market equity risk premium is negative in $21 \%$ of the quarters.
} 
the data and in the model, in recognition of the persistent nature of the crisis.

The second key input from the model into the private equity valuation exercise are the expected excess return on the bond and stock strips of horizons of 1-60 quarters. After all, the expected return of the PE fund is a linear combination of these expected returns; recall equation (2). Figure 7 plots the average risk premium on nominal zero coupon bond yields (top left panel) and on all dividend strips (other panels). Risk premia on nominal bonds are increasing with maturity from 0 to $3.5 \%$. The second panel shows the risk premia on dividend strips on the overall stock market (solid blue line). It also plots the dividend futures risk premium (red line). The difference between the spot and futures risk premium is approximately equal to the nominal bond risk premium. The unconditional dividend futures risk premium is downward sloping in maturity at the short end of the curve, and then flattens out. The graph also plots the model-implied dividend futures risk premium, averaged over the period 2003.Q1-2014.Q2 (yellow line). It is substantially more downward sloping at the short end than the risk premium averaged over the entire 1974-2017 sample. In fact, the model matches the realized portfolio return on dividend futures of maturities 1-7 years over the period 2003.Q1-2014.Q2, which is $8.7 \%$ in the data and $8.7 \%$ in the model. ${ }^{9}$

The remaining panels of Figure 7 show the dividend strip risk spot and future premia for the other cross-sectional factors. There are interesting differences in the levels of future risk premia especially at shorter horizons and in the shape of term structures. Average futures risk premia are generally declining to flat in maturity. Heterogeneity in risk premia by asset class, by horizon, and over time will give rise to heterogeneity in the risk premia on the PE-replicating portfolios.

Figure 8 plots the time series of expected returns on bonds and on both dividend and gain strips for the seven equity factors; the maturity of all strips is 20 quarters. Expected returns are annualized. We note rich cross-sectional heterogeneity in levels and dynamics across panels, a low-frequency decline over time in the level of expected returns common across most panels, and high pairwise correlation between dividend and capital gain strip expected returns in each panel.

Appendix $C$ provides further insight into how the model prices risk at each horizon using tools developed by Hansen and Scheinkman (2009) and Borovička and Hansen (2014). The shock price elasticities measure how the model prices risk exposure to each

\footnotetext{
${ }^{9}$ As an aside, the conditional risk premium, which is the expected return on the dividend futures portfolio over the 2003.Q1-2014.Q2 period is $6.0 \%$ per year in the model. The unconditional risk premium on the dividend futures portfolio (over the full sample) is $5.2 \%$.
} 
VAR innovation at various horizons. The shock exposure elasticities measure how cash flow (dividend) growth on each of the seven listed equity factors responds to an impulse in inflation, GDP growth, short rates, the slope of the term structure, and shocks to the cash flows themselves. It makes clear that the various equity factors have very different risk exposures from each other, and at various horizons.

\section{Expected Returns and Risk-adjusted Profits in PE Funds}

In this section, we combine the cash-flow exposures from section 2 with the asset prices from section 3 to obtain risk-adjusted profits on private equity funds.

\subsection{Summary Statistics}

Our fund data cover the period January 1981 until December 2017. Our main data source is Preqin, but we also replicate our analysis using data from Burgiss in Appendix F. ${ }^{10}$ We group private equity funds into eight categories: Buyout (LBO), Venture Capital (VC), Real Estate (RE), Infrastructure (IN), Natural Resources (NR), Fund of Funds (FF), Debt Funds (DF), and Restructuring (RS). Our FF category contains the Preqin categories Fund of Funds, Hybrid Equity, and Secondaries. The Buyout category is commonly referred to as Private Equity, whereas we use the PE label to refer to the combination of all investment categories.

We include all funds with non-missing cash-flow information. We group funds by their vintage, defined as the quarter in which they make their first capital call. The last vintage we consider in the analysis is 2017.Q4. Table 1 reports the number of funds and the aggregate AUM in each vintage-category pair. In total, we have 4,219 funds in our analysis and an aggregate of $\$ 4.1$ trillion in assets under management. There is clear business cycle variation in when funds funds get started as well as in their size (AUM). Buyout is the largest category by AUM, followed by Real Estate, and then Venture Capital. The last column of the table shows the quartile of the price/dividend ratio on the stock market, which we use to estimate vintage effects. The table reports the average pd-quartile across of the four vintages (quarters) in the calendar year.

\footnotetext{
${ }^{10}$ One possible limitation of the Preqin data is it is substantially sourced by FOIA requests made to public pensions, who may have differential pricing terms in side letters and "Most Favored Nation" clauses. However, Da Rin and Phalippou (2017) suggests that public pensions are not statistically different from other investors in their access to these clauses. Burgiss data is sourced instead from a more representative set of institutional investors.
} 
Figure 9 shows the average cash-flow profile in each category for distribution events, pooling all funds and vintages together and equally weighting them. For this graph, we combine all monthly cash-flows into one yearly cash-flow for each fund, and then average across funds within the category. The first 15 orange bars are for the first 15 years since the first capital call. The last bar (in green) represents the discounted sum of cash flows that occur after year $15 .{ }^{11}$ The literature often treats PE vehicles as lasting for about ten years. While we observe that the majority of distribution cash-flows occur between years 5 and 10 , cash flows after year 10 account for a substantial portion of the total cash received by LPs, and we therefore incorporate them in our analysis. ${ }^{12}$ All cash flows are net of fees imposed by the GPs.

Figure 10 zooms in on the four investment categories of most interest to us: LBO, VC, $\mathrm{RE}$, and IN. The figure shows the average cash-flow profile for each vintage. Since there are few LBO and VC funds prior to 1990 and few RE and IN funds prior to 2000, we start the former two panels with vintage year 1990 and the latter two panels with vintage year 2000. The figure shows that there is substantial variation in cash-flows across vintages, even within the same investment category. This variation will allow us to identify vintage effects. The figure also highlights that there is a lot of variation in cash-flows across calendar years. VC funds started in the mid- to late-1990s vintages realized very high average cash-flows around calendar year 2000 and a sharp drop thereafter. Since the stock market also had very high cash-flow realizations in the year 2000 and a sharp drop thereafter, this type of variation will help the model identify a high stock market beta for VC funds. This is an important distinction with other methods, such as the PME, which assume constant risk exposure and so would attribute high cash flow distributions in this period to excess returns. Appendix Figure D.1 shows cash-flow profiles for the remaining fund categories.

\footnotetext{
${ }^{11}$ We discount at the risk free rate produced by the Asset Pricing model. For infrastructure, we have a few outliers in years 14 and 15. To avoid overfitting in the OLS model, we discount these cash flows (but do not discard them) to the thirteenth year, which improves ease of interpretability but does not affect our conclusion.

${ }^{12}$ Industry publications have also noted the increasing lifespan of private equity funds. For instance, a Preqin report from 2016 remarks: "The average lifespan of funds across the whole private capital industry is increasing beyond the typical 10 years... older funds of vintages 2000-2005 still hold a substantial \$204bn worth of investments, equating to $7.2 \%$ of total unrealized assets" (Preqin, 2016). We also estimate our results on a subsample of funds which only distribute $10 \%$ or less of their cash after 10 years, and find comparable results.
} 


\subsection{Factor Estimation in OLS and Elastic Net}

We compare the results of two estimation approaches, run separately for each fund category. The first is a two-factor model (bond and aggregate stock dividend strips) estimated by OLS; recall equation (6). The second is an Elastic Net model estimated on the full set of fifteen factors (bonds strips, and dividend and capital gains strips for: aggregate stock index, small stocks, growth stocks, value stocks, REITs, infrastructure stocks, and natural resource stocks); recall equations (7) and (8). The estimated parameters are the factor exposures across horizon, $b_{h^{\prime}}^{k}$ and how these exposures shift by vintage (pd quartile), captured by the $a_{t}^{k}$. Their sum, $a_{t}^{k}+b_{h}^{k}$, measures the number of units of factor strip $k$ with maturity $h$ that the PE-replicating portfolio buys.

This Elastic Net approach has the main benefit that it results in substantial dimension reduction of our estimation problem (through its two regularization terms), which is essential in estimating a large number of parameters across a variety of horizons, factors, and vintage states. Absent this dimensionality reduction, we simply would be unable to estimate an asset pricing model with a rich set of possible factors given the limited number of PE fund observations. The end result is a parsimonious replicating portfolio consisting of long positions in a modest number of strips (factor-horizon combinations).

Figure 11 contrasts our resulting factor exposures along the dimension of horizon $\widehat{b}_{h}$ obtained through both the 2-factor OLS model (left) and the Elastic Net model using the full set of factors (right). Each row corresponds to one of the four main PE categories. Appendix Figure D.2 contains these estimates for the other four PE categories. Appendix Figures D. 3 and D.4 contain these estimates for the PD-quartile effects $\widehat{a}_{t}$.

Buyout In Panel A of Figure 11, we find substantial stock exposures throughout most of the life of the fund. The replicating portfolio contains short positions in bonds, exception for the middle years (7-12) and the terminal cash flow represented by year 16 . This terminal cash exposure is captured by a mix of stock and bond strips.

The Elastic Net model on the right differs in several respects. First, all positions are positive, which ensures that PE cash flows are replicable through long-only positions. Second, the two factors in the OLS model for find little weight in the Elastic Net model. This suggests that other cross-sectional factors better capture the systematic risk in Buyout funds. The regularization in the Elastic Net approach ensures sufficient dimension reduction in order to produce a sparse portfolio of replicating positions. We uncover a pattern of dividend strip (solid lines) and capital gain strip (dotted lines) exposures that 
is rich and complex. While we have not constrained our estimation to require that adjacent years have similar exposures, we frequently find that factors have some periodic tendencies with rising and falling exposures over the fund's life cycle.

Early on in fund life, PE fund cash flows tend to look more like aggregate stocks, value stocks, and small stocks. Closer to to the end of the fund life, we estimate a much more substantial growth exposure. This suggests that the early cash flows, when portfolio companies have been purchased and are either quickly re-sold or harvested for operating profits, have exposures which look like small, value, and general stock market. By the end of the fund life, the exposure looks closer to the capital realization of growth stocks. This overall pattern generally corresponds to Buyout fund activities which consist of purchasing a broad range of companies, restructuring the operations, harvesting some initial cash flows (for instance through dividend recapitalization), and ultimately reselling these assets on public markets. We also find some moderate evidence for non-standard dividend cash flows (such as from REITs around year 8, and infrastructure in years 9-11 of fund life). To minimize over-fitting, we rely on a cross-validation exercise in which we use a leave-out sample to fit $\lambda_{1}$ and $\lambda_{2}$ parameters.

The takeaway from the analysis on Buyout funds is that these vehicles do not simply take on bond and equity exposure in the cross-section, as is commonly assumed. Our best estimate for fund cash flow fit features a much richer factor exposure structure across different equity factor categories and horizons. This factor exposure is relevant for LPs who invest in Buyout vehicles. Portfolio management of PE within institutional investor portfolios should take into account the rich risk and return dynamics of PE funds.

Venture Capital We see further evidence of the importance of considering a broad crosssection of factor exposures in Panel B of Figure 11, which examines Venture Capital funds. Our OLS 2-factor model in the left panel places some positive weight on the equity dividend factor both early and late in fund life, but finds that a bond position best fits cash distributions for the most active middle part of the funds' life.

Instead, our Elastic Net model (right panel) indicates that the single factor which contributes most to the fit of VC cash flows for the first nine years of fund life is gains strips on growth stocks. VC cash flows are akin to the cash flows obtained from selling firms in the bottom quintile of the book-to-market distribution. Appendix Figure D.3 suggests that this loading is even higher in periods when the market has a higher pd ratio.

Our findings for VC funds carry an important economic intuition. While Buyout funds 
acquire a range of companies which may differ in their underlying factor exposures; VC funds concentrate on early-stage and rapidly expanding entrepreneurial companies and distribute little cash prior to their exits from these funds. Further VC funds, unlike Buyout (or Real Estate, or Infrastructure funds) typically harvest few cash flows during fund operations prior to deal exits. Correspondingly, we find that the bulk of VC fund cash flow exposure can be accounted for by growth gains strips.

Real Estate Panel C repeats our estimation for Real Estate funds. Stock dividend strips have a positive loading throughout fund horizon in the OLS model. Bond positions are negative except for some of the middle years. Again, our Elastic Net model picks up additional cross-sectional exposures which crowd out the exposure to aggregate stock and bond market strips from the two-factor model. Reassuringly, REIT dividends and REIT gains strips are important components of the replicating portfolio. The early cash flow distributions also load on value and small stock gain strips. In the later years, REPE fund cash flows are exposed to the same risk as infrastructure dividends strips and growth gains strips. These results suggest that Real Estate funds take on a distinct factor exposure profile from Buyout and VC funds, while sharing at least some of the same factor exposures.

Infrastructure Panel D studies Infrastructure funds. Here, too, we find a strong role for sector-specific factors, such as infrastructure dividend strips, natural resource gains strips, and REIT gains strips which point to the role of underlying asset characteristics in driving the fund-level asset pricing profile. ${ }^{13}$ Interestingly, the infrastructure category tends to place greater weight on dividend strips, as opposed to capital gains strips; suggesting that the cash flows in this sector are more like dividends than like realized prices.

Take-aways These rich dynamics across horizon, price-to-dividend ratios, and factors have important asset pricing implications. The risk loadings on PE funds broadly cannot be assumed to be static either in the time-series or across fund age (maturity). Rather, a broad set of risk factor exposures is relevant across all PE fund categories. We provide the first systematic analysis of the asset pricing properties of these some of these alternative fund categories (RE, IN, NR), and find that they carry important sector-specific asset exposures. These exposures are frequently concentrated in the first half of the fund's

\footnotetext{
${ }^{13}$ Similarly, Natural Resource funds, which we examine in the Appendix, have greater natural resource strip exposure.
} 
life. Our estimation approach allows us to translate these complex risk dynamics into the expected return for different fund categories and to revisit the question of performance evaluation. We turn to expected returns next.

\subsection{Expected Return}

With the replicating portfolio of zero-coupon bonds and dividend strips in hand (expressions are detailed in Appendix A), we can calculate the expected return on PE funds in each investment category using equation (2). Figure 12 plots the time-series of the expected return for the four main PE categories. It aggregates over all of the different horizon effects and annualizes the resulting expected return as per equation (4). The left panels of this figure are for the 2-factor OLS model; the right panels for the Elastic Net model with 15 factors. Appendix Figure D.5 reports the results for other 4 PE categories. Generally, the Elastic Net delivers expected returns that look more reasonable in levels and dynamics than the two-factor OLS model.

Time variation in the factor exposures coming through dependence on the pd-quartile of the vintage combines with time variation in expected returns on dividend and gain strips driven by the state variables of the VAR to generate time variation in the expected return on PE funds. The annualized expected returns that investors can anticipate on their PE investments as compensation for systematic risk has seen large variation over time, with a declining pattern at low frequencies. The low-frequency decline is inherited from a low-frequency decline in strip expected returns; recall Figure 8.

At higher frequencies we note the low expected return around the year 2000, when the stock market peaked, and an increase in risk premia during the Great Recession. Since then, expected returns have lowered substantially, especially for Buyout, VC, and Infrastructure. In the RE category, we observe higher expected returns since the Great Recession than in the other categories.

\subsection{Performance Evaluation}

Next, we turn to performance evaluation. Figure 13 plots the histogram of Risk-Adjusted Profits (RAP) for the two-factor OLS (gray) and 15-factor Elastic Net (yellow) models for Buyout, VC, RE, and IN. The four alternate PE categories are shown in Figure D.6. Recall from equation (5) that the RAP for each fund compares the realized cash flow distributions against the realized payoffs from the replicating portfolio, as well as the 
difference in the purchase price of the replicating portfolio and the $\$ 1$ commitment in the PE fund. A kernel density is estimated from the discrete histogram.

In Buyout, RE, and IN, the entire profit distribution is shifted to the left under the Elastic Net model. PE funds are less profitable on a risk-adjusted basis once we account for a richer cross-section of factor exposures through our Elastic Net model. As a result, an LP using traditional approaches (TVPI) and even a flexible two-factor model would attribute a fund's performance to outperformance, which the Elastic Net model would instead attribute much of the profit as compensation for risk.

This reduction in apparent outperformance is strongest in the Buyout category. While the risk-adjusted profits are positive under the two-factor model, they are negative on average in our benchmark Elastic Net model, at -21 cents per dollar invested. This average RAP masks substantial cross-sectional dispersion. Around a quarter of funds outperform by at least $10 \%$ in the full model. We find a similar pattern in VC: the average RAP for VC funds with our full elastic net model is is -11 center per dollar invested; also about a quarter of VC funds generate greater than 10 cents in RAP.

The results for RE look similar to those for Buyout. The extra risk exposure shifts the RAP distribution to the left. Average RAP is -17 cents and $22 \%$ of funds have a RAP greater than $10 \%$. The average IN fund fares slightly better with an average RAP of -10 cents and $27 \%$ of funds generating more than 10 cents in risk-adjusted profit.

Figure 14 plots the average RAP by vintage for both the OLS (left) and Elastic Net (right) models. Appendix Figure D.7 plots these estimates for alternate fund categories. While the general time-series for profits are similar across both sets of models, there are also notable differences. For instance, in the Buyout category, we observe positive profits continuing through the most recent vintages in the OLS model. By contrast, our Elastic Net model estimates positive profits for a few historic vintages, but largely negative average profits for vintages since 1995.

While we observe extremely high profits for VC funds originated in the mid-1990s, these profits fall by a factor of two in the Elastic Net model. Recent VC vintages have generated negative RAPs. Real estate funds started just before the Great Recession (20042006) have performed very poorly, losing 30 cents on a risk-adjusted basis. The last vintage we consider in this graph (2010) is faring much better. 


\subsection{Model Comparison}

It is instructive to benchmark our results across other approaches pursued in the literature. Figure 15 graphically compares the results from the Elastic Net model for our main PE categories against two commonly used PE fund performance metrics: IRR and PME. Appendix Figure D.8 repeats the analysis for the additional categories. The left panels plot fund-level IRR against our fund-level RAP measure; the right panels plot fund-level PME against fund-level RAP. The key takeaway from this comparison is a similar ranking of fund performance. Our measure of RAP generally correlates between $70 \%$ and $90 \%$ with the IRR and PME measures in the cross-section of funds. The correlation is higher with the PME than with the IRR measure in the Buyout and VC categories for which we have the most data. This is reasonable as the PME approach also incorporates a role for public market assets. The similarity lends credibility to our measure of RAP. The measures are not identical, however, so that there are funds which conventional measures assess to be high-performing but our estimates suggest only offer fair (or even too little) compensation for factor risk exposure.

Table 2 compares average outperformance. Panel A shows results from Preqin, our primary data source. We repeat our analysis on the Burgiss data set, which has broader coverage of 7,193 PE funds, in Panel B. We show complete results from Burgiss in Appendix F. We discuss the Preqin results first. The first three rows of Panel A reflect standard measures to evaluate PE funds: the TVPI, IRR, and PME. The next two rows display our two-factor OLS and 15-factor Elastic Net models. The columns report the $R^{2}$ from the factor model estimation, the average RAP, and the cross-sectional standard deviation of the RAP. We focus on the four main fund categories.

For Buyout funds, the two-factor Elastic Net model has an $\mathrm{R}^{2}$ of 0.156 , and an average risk-adjusted profit of 29 cents per dollar invested. Relative to the average PME of 36 cents, the lower RAP estimate reflects the refined equity exposure estimate, compared with the PME which assumes that all funds have an equity beta of one.

Next, we add additional factors and estimate the impact on model fit and RAP. For Buyout, the model fit of the Elastic Net improves to 0.160. In addition to the improvement in model fit, we observe substantially different profit estimates. The average RAP for the Buyout category is -17.6 cents for the Elastic Net model compared with 29.1 for the two-factor model. Under the richer model of systematic risk, we obtain a lower estimate of risk-adjusted outperformance. In other words, while the cash flow estimation improves modestly when adding more equity factors, the systematic risk exposure of the 
PE funds can now be replicated more cheaply and so results in a substantially lower estimate of PE fund profit. The Elastic Net model also results in a tighter distribution (lower cross-sectional standard deviation) of RAP. The last row reports the results for a model where the cash flows of all funds in a particular fund category-vintage pair are aggregated, and then an Elastic Net model is estimated on the aggregate cash flows. It generally shows higher $R^{2}$, suggesting that there is substantial idiosyncratic risk in individual fund returns (just like there is in individual stocks). The average RAP estimates obtained on aggregated fund cash flows are similar. To better assess the role of idiosyncratic risk; in Appendix E we perform our analysis on public equities. We find similarly moderate $R^{2}$ when we fit dividend strips against individual stocks; but substantially higher $R^{2}$ when we fit our model on portfolios.

The message for the other fund categories is similar. Richer risk adjustment results is much lower average RAPs and a tighter distribution. The full-factor Elastic Net results in an average RAP that is 23 cents lower than that predicted by the two-factor OLS model for VC funds, 14 cents lower for RE funds, and 39 cents for IN funds. We also note the much wider cross-sectional dispersion in VC fund performance compared to the other PE categories.

Next, we examine the persistence of the various performance metrics, defined as the correlation between profits across the different measures between adjacent funds from the same PE firm. We use fund vintages to examine the autocorrelation of returns between the current fund and the immediately preceding fund in the sequence. In the first three rows of Panel A, we report persistence for the traditional performance metrics such as TVPI, IRR, and PME. Consistent with prior research (Harris, Jenkinson, Kaplan, and Stucke, 2014), we find substantial persistence in performance across funds originated within the same firm across time. However, we tend to observe less persistence when we include additional factor controls. For example, the persistence of PME for VC funds is 0.43 while the persistence according to the Elastic Net model is only 0.15. Similarly, the persistence of REPE funds falls from 0.40 to 0.20 . This result sheds new light on the puzzle of excess persistence in PE fund outperformance. A portion of this persistence is due to some firms specializing in strategies that have a common risk factor exposure across the funds under their management. Accounting for this factor exposure lowers the measure of persistence. $^{14}$

\footnotetext{
${ }^{14}$ We also examine the persistence of factor exposure across funds within the same firm family and find persistence in factor exposures estimated on the first fund started by firms, and subsequent funds estimated through separate regressions. This also suggests our factor exposure measure results in a robust measure
} 
Panel B of Table 2 repeats the analysis on the Burgiss data which has more expansive coverage in general, but especially in the VC and infrastructure categories. Examining this data set allows us to address possible sample selection issues in the Preqin data set. Reassuringly, we find very similar results across the two data sets. In particular, we find that average RAPs are generally estimated to be negative using our full-factor approach. The model fit for aggregated cash flows (last row) tends to be higher in the Burgiss than in the Preqin data. In the VC category, Burgiss has better coverage of certain high-performing funds which do not report to Preqin. Indeed, we find that average TVPI if 53 cents in Burgiss and 35 cents in Preqin. However, we continue to find negative estimates of risk-adjusted profits for VC: -7.4 cents in Burgiss versus -11.4 cents in Preqin. Similarly, the better coverage of infrastructure PE funds does not overturn the finding of negative average RAP. In fact the average RAP from the Elastic Net model is - 21 cents in Burgiss compared to -10 cents in Preqin.

Our pervasive finding of negative average RAP stands in contrast to previous literature in private equity which has generally found evidence of fund outperformance (Brown, Harris, Jenkinson, Kaplan, and Robinson, 2015; Kaplan and Sensoy, 2015; Harris, Jenkinson, and Kaplan, 2014). The difference is made apparent when comparing standard performance metrics in the first three rows, which tend to show more favorable performance statistics. Even the two-factor model generally shows positive profits. Our more negative conclusion about excess returns in the private equity industry is a natural consequence of risk-adjustment due to cross-sectional factor exposure. Similar risk adjustments in the mutual fund (Fama and French, 2010) or hedge fund space (Fung, Hsieh, Naik, and Ramadorai, 2008) tend to substantially lower outperformance. We find the same is true for private equity funds, a point that has surprisingly not been made before. We also find evidence for substantial cross-sectional dispersion in RAPs, as well as sizable persistence in risk-adjusted performance over time. This suggests that there may be a subset of PE managers that consistently delivers outsized returns. This finding is consistent with Kacperczyk, Van Nieuwerburgh, and Veldkamp $(2014,2016)$ who find that a small right tail of mutual fund managers consistently outperforms, although the earlier mutual fund literature has been skeptical of skill in any part of the fund distribution (Fama and French, 2010).

Similar findings of limited excess returns across different categories of delegated asset managers are suggestive of similar economic forces at work. First, investors may find it of fund risk attributes. 
difficult to replicate complex factor strategies on their own, and so may be willing to pay managers to generate factor strategies. Second, superior performance tends to be associated with higher fund flows, leading to increased capital commitments which diminish returns in the presence of decreasing returns to scale, along the lines of Berk and Green (2004). As the PE industry has grown substantially, there may be insufficient economies of scale to adequately manage a growing asset base to generate the same outsize returns of previous periods. Finally, delegated asset managers charge sizable management and performance fees especially when financial products are more opaque and complex (Célérier and Vallée, 2015) as they are in PE. This lowers post-fee returns for investors further.

\section{Conclusion}

We provide a novel valuation method for private equity cash-flows that decomposes the cash-flow at each horizon into a systematic component that reflects exposure to various sources of aggregate risk, priced in listed securities markets, and an idiosyncratic component which reflects the risk-adjusted profit to the PE investor. The systematic component represents a portfolio of stock and bond strips paying safe or risky cash flows at horizons over which PE funds make cash flow distributions. A state-of-the-art no-arbitrage asset pricing model estimates prices and expected returns for these strips, fitting the time series of bond yields and stock prices, including dividend strips. It provides the first estimates of the term structure of risk and return in the cross-section of equity factors.

Using both OLS and Elastic Net approaches, we estimate rich heterogeneity in PE fund risk exposures across horizons, in the cross-section, and in the time-series. PE funds' risk exposure is best modeled not only using bonds and the aggregate stock market, but is improved with the addition of sector-specific equity factor exposures. The estimated exposures are sensible given the nature of underlying nature of PE assets, and indicate an important role for growth and small stocks in Venture Capital and for REITs in real estate funds. In the time series, we find that expected returns on PE funds have been declining substantially since the 1980s and especially since the Great Recession, reflecting declining risk premia in public markets.

On average, PE funds considerably underperform their replicating portfolio benchmark, suggesting that while PE funds offer investors access to complex risk exposures, they do so at a more expensive price than offered in public markets. While our resulting profit measures correlate well with existing measures of outperformance in the cross- 
section of funds, they suggest both lower average performance and less performance persistence.

Our analysis highlights the value of a methodological advance in the assessment of risk and return for unlisted assets, which are an increasing component of the total investable universe for many institutional investors. While Private Equity is an especially important application of our approach, given its size, our method can be applied more broadly to study the asset pricing characteristics of any other cash-flowing asset that is not listed on the capital markets. Individual real estate or infrastructure investment projects are a key application left for future work. 


\section{References}

Ammar, S. B., and M. Eling, 2015, "Common risk factors of infrastructure investments," Energy Economics.

Andonov, A., R. Kräussl, and J. Rauh, 2018, “The Subsidy to Infrastructure as an Asset Class," Working Paper 25045, National Bureau of Economic Research.

Ang, A., B. Chen, W. N. Goetzmann, and L. Phalippou, 2017, “Estimating Private Equity Returns from Limited Partner Cash Flows," Netspar Discussion Paper No. 06/2014-021; Said Business School WP 2014-8.

Ang, A., and M. Piazzesi, 2003, "A No-Arbitrage Vector Autoregression of Term Structure Dynamics with Macroeconomic and Latent Variables," Journal of Monetary Economics, $50,745-787$.

Berk, J. B., and R. C. Green, 2004, "Mutual Fund Flows and Performance in Rational Markets," Journal of Political Economy, 112(6), 1269-1295.

Bökberg, A., J. Carrellas, A. Chau, and C. Duane, 2019, "Private markets come of age McKinsey Global Private Markets Review," working paper, McKinsey Global Institute.

Borovička, J., and L. P. Hansen, 2014, "Examining Macroeconomic Models through the Lens of Asset Pricing," Journal of Econometrics, 183(1), 67-90.

Brown, G., R. Harris, T. Jenkinson, S. N. Kaplan, and D. Robinson, 2015, “What Do Different Commercial Data Sets tell Us About Private Equity Performance?," Working Paper University of North Carolina Kenan Institute.

Campbell, J. Y., 1991, “A Variance Decomposition for Stock Returns,” Economic Journal, $101,157-179$.

_ , 1993, "Intertemporal Asset Pricing Without Consumption Data," American Economic Review, 83(3), 487-511.

— , 1996, “Understanding Risk and Return," The Journal of Political Economy, 104(2), 298-345.

Campbell, J. Y., and R. J. Shiller, 1991, "Yield Spreads and Interest Rate Movements: A Bird's Eye View," Review of Economic Studies, 58, 495-514. 
Célérier, C. M., and B. Vallée, 2015, “The Motives for Financial Complexity: An Empirical Investigation," SSRN, (2289890).

Cochrane, J. H., 2005, "The risk and return of venture capital," Journal of Financial Economics, $75,3-52$.

Cochrane, J. H., and M. Piazzesi, 2006, “Decomposing the Yield Curve," Working Paper, University of Chicago.

Cochrane, J. H., and J. Saa-Requejo, 2000, “Beyond Arbitrage: 'Good deal' asset price bounds in incomplete markets," Journal of Political Economy, 108, 79-119.

Cox, J., J. Ingersoll, and S. Ross, 1985, “An Intertemporal General Equilibrium Model of Asset Pricing," Econometrica, 53, 363-384.

Da Rin, M., and L. Phalippou, 2017, “The importance of size in private equity: Evidence from a survey of limited partners," Journal of Financial Intermediation, 31, 64-76.

Dai, Q., and K. J. Singleton, 2000, "Specification Analysis of Affine Term Structure Models," Journal of Finance, 55, 1943-1978.

Driessen, J., T.-C. Lin, and L. Phalippou, 2012, "A new method to estimate risk and return of nontraded assets from cash flows: The case of private equity funds," Journal of Financial and Quantitative Analysis, 47(3), 511-535.

Duffie, D., and R. Kan, 1996, “A Yield Factor Model of Interest Rates," Mathematical Finance, 6, 379-406.

Ewens, M., C. M. Jones, and M. Rhodes-Kropf, 2013, “The Price of Diversifiable Risk in Venture Capital and Private Equity," Review of Financial Studies, 26, 1854-1889.

Fama, E. F., and K. R. French, 1992, "The Cross-Section of Expected Stock Returns," The Journal of Finance, 47(2), 427-465.

_ 2010, "Luck versus Skill in the Cross-section of Mutual Fund Returns," The Journal of Finance, 65(5), 1915-1947.

Fung, W., D. A. Hsieh, N. Y. Naik, and T. Ramadorai, 2008, “Hedge Funds: Performance, Risk, and Capital formation," The Journal of Finance, 63(4), 1777-1803. 
Gompers, P. A., and J. Lerner, 1997, “Risk and Reward in Private Equity Investments: The Challenge of Performance Assessment," Journal of Private Equity, 1, 5-12.

Gu, S., B. Kelly, and D. Xiu, 2018, "Empirical Asset pricing via Machine Learning," National Bureau of Economic Research Working Paper No. 25398.

Haddad, V., E. Loualiche, and M. Plosser, 2017, “Buyout activity: The impact of aggregate discount rates," The Journal of Finance, 72(1), 371-414.

Hansen, L. P., and J. Scheinkman, 2009, "Long-Term Risk: An Operator Approach," Econometrica, 77 (1), 177-234.

Harris, R. S., T. Jenkinson, and S. N. Kaplan, 2014, “Private Equity Performance: What Do We Know?," Journal of Finance, 69(5).

Harris, R. S., T. Jenkinson, S. N. Kaplan, and R. Stucke, 2014, “Has Persistence Persisted in Private Equity? Evidence from Buyout and Venture Capital Funds," .

Kacperczyk, M., S. Van Nieuwerburgh, and L. Veldkamp, 2014, “Time-Varying Fund Manager Skill," Journal of Finance, 69, 1455-1484.

— , 2016, "Rational Attention Allocation over the Business Cycle," Econometrica, 84, $571-626$.

Kaplan, S., and B. Sensoy, 2015, “Private Equity Performance: A Survey," Annual Review of Financial Economics, 7, 597-614.

Kaplan, S. N., and A. Schoar, 2005, "Private equity performance: Returns, persistence, and capital flows," Journal of Finance, 60(4), 1791-1823.

Koijen, R. S. J., H. Lustig, and S. Van Nieuwerburgh, 2017, “The Cross-Section and TimeSeries of Stock and Bond Returns," Journal of Monetary Economics, 88, 50-69.

Korteweg, A., and S. Nagel, 2016, "Risk-Adjusting the Returns to Venture Capital," Journal of Finance, 71(3), 1437-1470.

Korteweg, A., and M. Sorensen, 2010, "Risk and return characteristics of venture capitalbacked entrepreneurial companies," Review of Financial Studies, 23(10), 3738-3772.

_ 2017, "Skill and Luck in Private Equity Performance," Journal of Financial Economics, 0 . 
Kozak, S., S. Nagel, and S. Santosh, 2017, "Shrinking the Cross Section," National Bureau of Economic Research Working Paper No. 24070.

Lettau, M., and J. Wachter, 2011, “The Term Structures of Equity and Interest Rates," Journal of Financial Economics, 101 (1), 90-113.

Ljungqvist, A., and M. Richardson, 2003, "The cash flow, return and risk characteristics of private equity," Working Paper, NYU Stern.

Lustig, H., S. Van Nieuwerburgh, and A. Verdelhan, 2013, "The Wealth-Consumption Ratio," Review of Asset Pricing Studies, 3(1), 38-94., Review of Asset Pricing Studies.

Metrick, A., and A. Yasuda, 2010, "The economics of private equity funds," Review of Financial Studies, 23(6), 2303-2341.

Peng, L., 2001, “Building a Venture Capital Index,” Working Paper.

_ , 2016, "The risk and return of commercial real estate: A property level analysis," Real Estate Economics, 44(3), 555-583.

Phalippou, L., and O. Gottschalg, 2009, "The performance of private equity funds," Review of Financial Studies, 22(4), 1747-1776.

Preqin, 2016, “The 2016 Preqin Global Private Equity and Venture Capital Report," Preqin, London, UK.

Robinson, D. T., and B. A. Sensoy, 2011, "Cyclicality, Performance Measurement, and Cash Flow Liquidity in Private Equity," Working Paper.

Sagi, J. S., 2017, "Asset-level risk and return in real estate investments," Working Paper, UNC Kenan-Flagler Business School.

Sorensen, M., and R. Jagannathan, 2015, "The Public Market Equivalent and Private Equity Performance," Financial Analysts Journal, 71(4), 43-50.

Sorensen, M., N. Wang, and J. Yang, 2014, "Valuing private equity," Review of Financial Studies, 27(7), 1977-2021.

van Binsbergen, J., M. Brandt, and R. Koijen, 2012, "On the Timing and Pricing of Dividends," American Economic Review, 102(4), 1596-1618. 
van Binsbergen, J. H., W. H. Hueskes, R. Koijen, and E. B. Vrugt, 2013, "Equity Yields," Journal of Financial Economics, 110(3), 503-519.

van Binsbergen, J. H., and R. Koijen, 2017, “The Term Structure of Returns: Facts and Theory," Journal of Financial Economics, 124(1), 1.

Van Nieuwerburgh, S., 2019, "Why Are REITs Currently So Expensive?," Real Estate Economics, 47(1), 18-65.

Wachter, J., 2005, "Solving Models with External Habit," Finance Research Letters, 2, 210226.

Woodward, S., 2009, “Measuring Risk for Venture Capital and Private Equity Portfolios," Working Paper. 


\section{FIGURE 1: Dynamics of the Nominal Term Structure of Interest Rates}

The figure plots the observed and model-implied 1-, 4-, 20-, 40-quarter nominal bond yields.
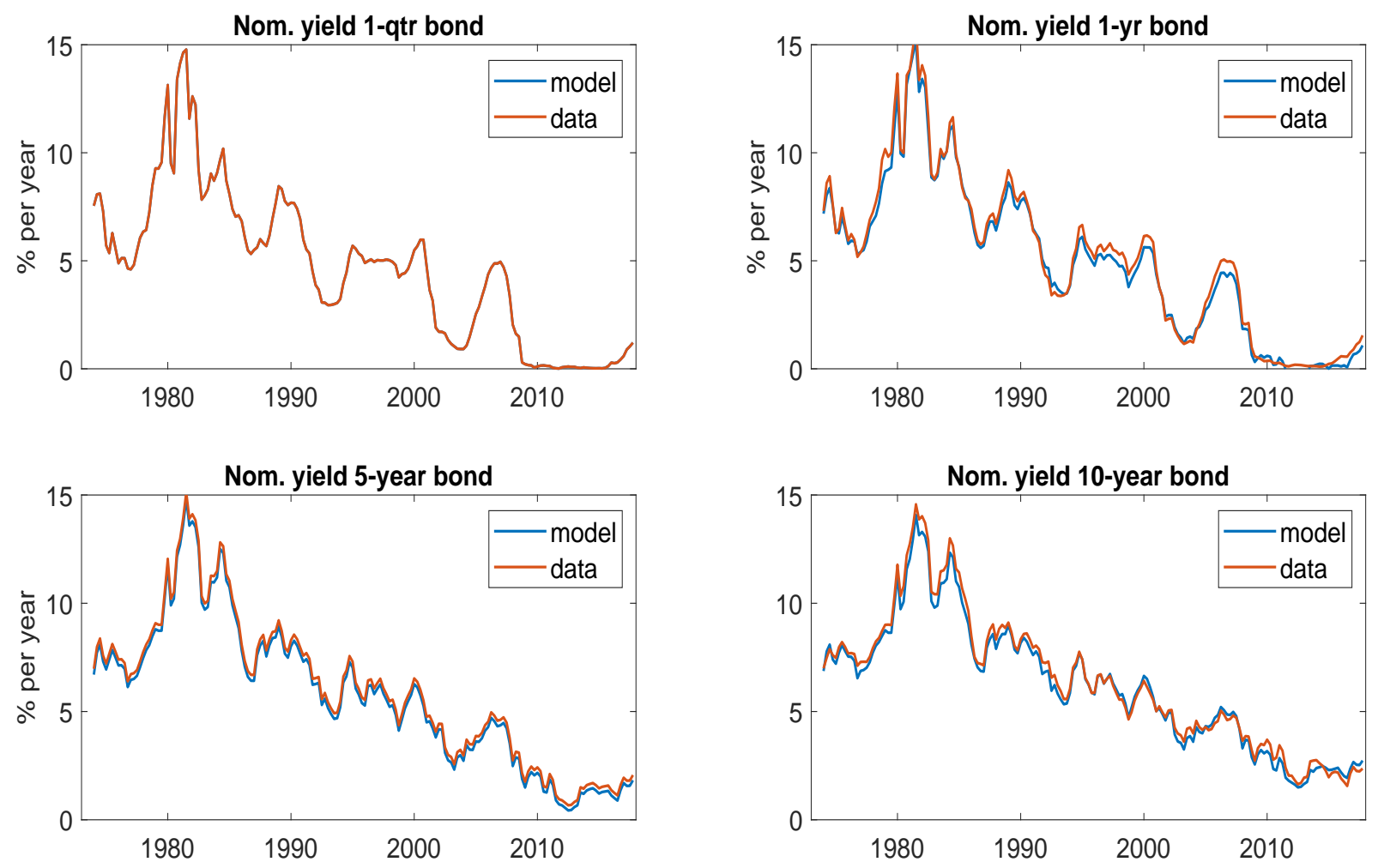


\section{FIGURE 2: Long-term Yields and Bond Risk Premia}

The top panels plot the average bond yield on nominal (left panel) and real (right panel) bonds for maturities ranging from 1 quarter to 200 quarters. The bottom left panel plots the nominal bond risk premium in model and data. The bottom right panel decomposes the model's five-year nominal bond yield into the five-year real bond yield, the five-year inflation risk premium and the five-year real risk premium.
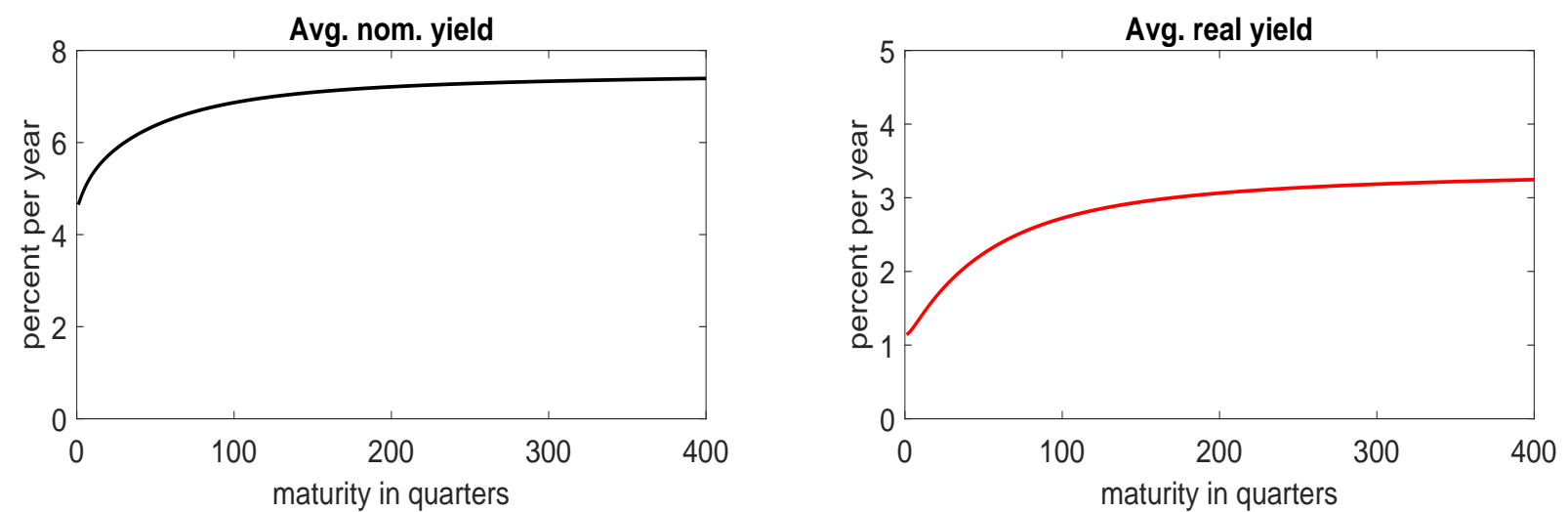

Risk Premium 5-yr nom. bond
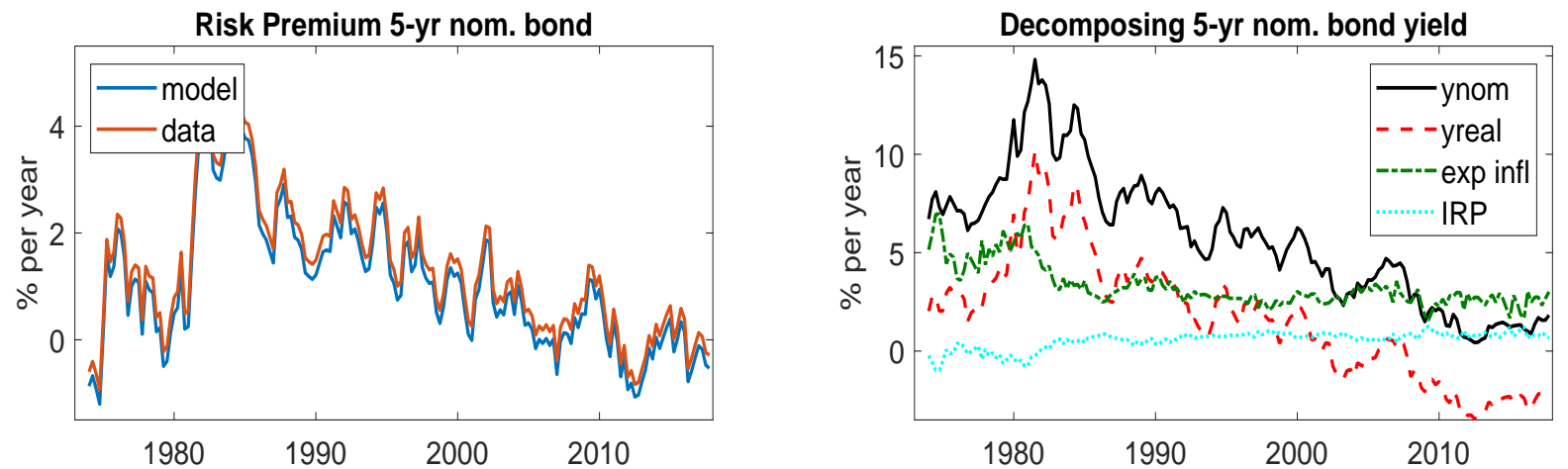
FIGURE 3: Equity Risk Premia and Price-Dividend Ratios (part 1)

The figure plots the observed and model-implied equity risk premium on the overall stock market, small stocks, growth stocks, and value stocks, in the left panels, as well as the corresponding price-dividend ratio in the right panels. The model is the blue line, the data are the red line.
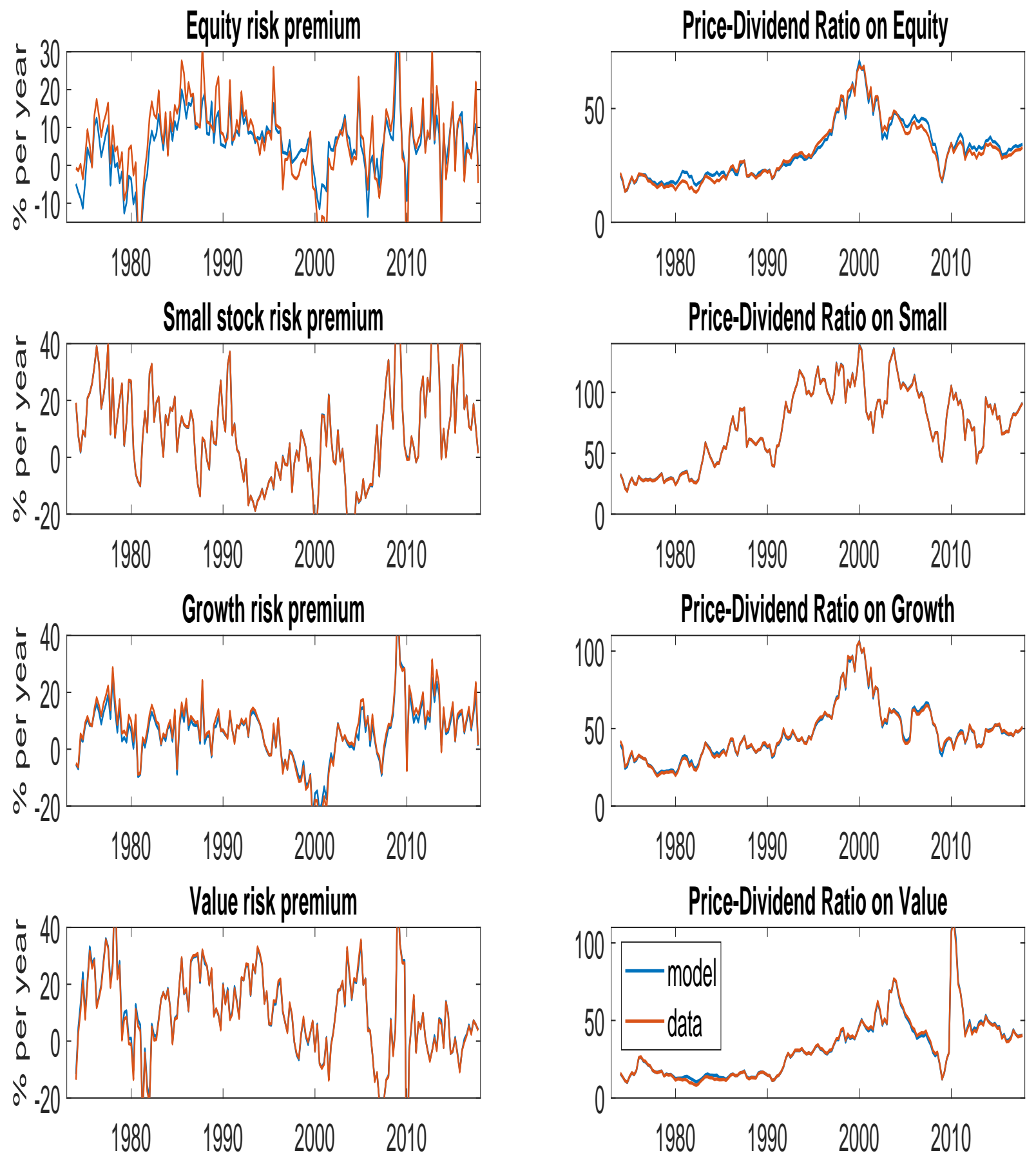
FIGURE 4: Equity Risk Premia and Price-Dividend Ratios (part 2)

The figure plots the observed and model-implied equity risk premium on REIT stocks, infrastructure stocks, and natural resource stocks, in the left panels, as well as the corresponding price-dividend ratio in the right panels. The model is the blue line, the data are the red line.
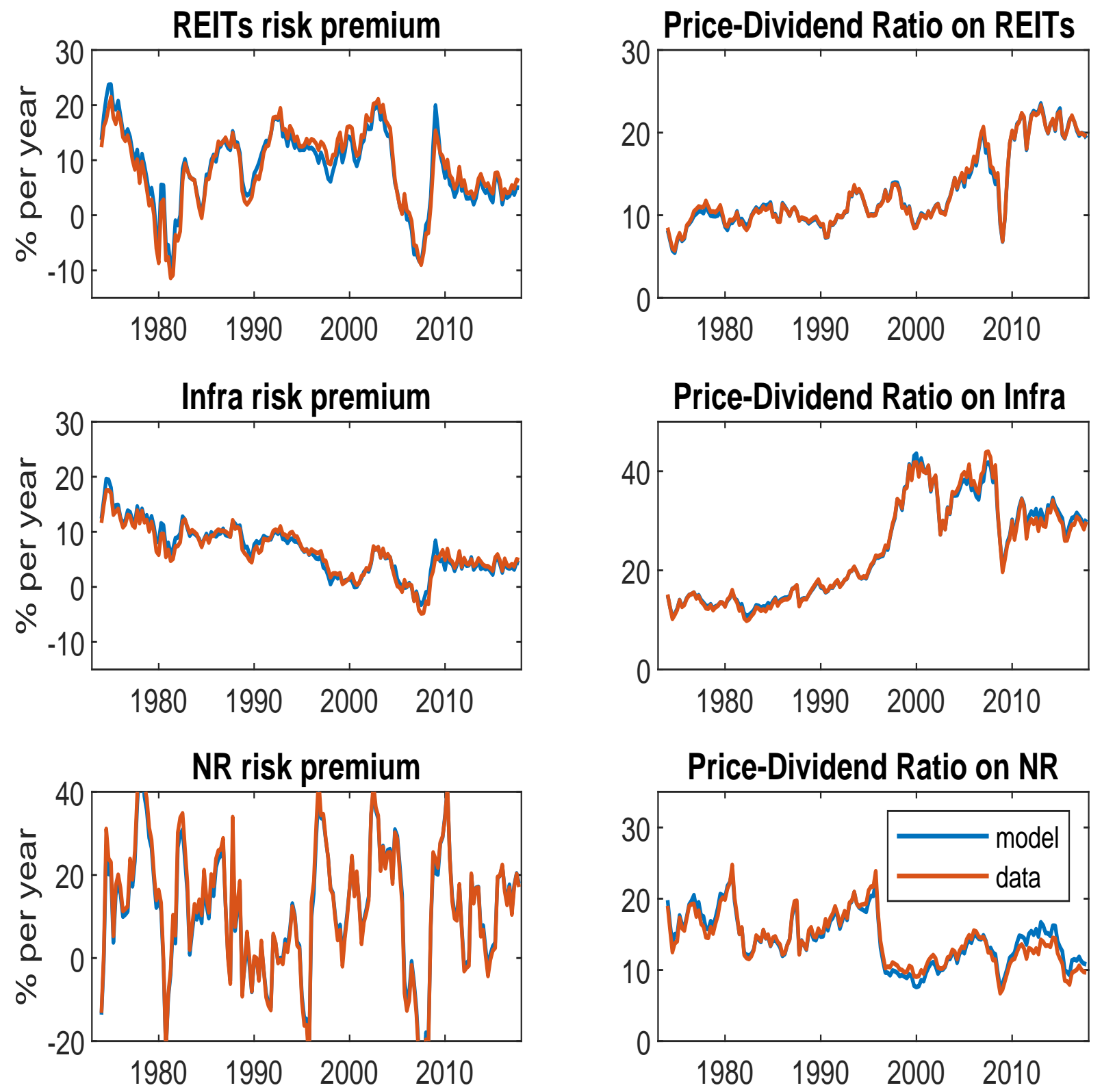


\section{FIGURE 5: Zero Coupon Bond Prices and Dividend Strip Prices}

The figure plots the model-implied prices on zero-coupon Treasury bonds in the first panel, and price-dividend ratios for dividend strips on the overall stock market, small stocks, growth stocks, value stocks, REIT market stocks, infrastructure stocks, and natural resources stocks in the next seven panels, for maturities of 4,20 , and 40 quarters. The prices/price-dividend ratios are expressed in levels and each claim pays out a single cash flow.

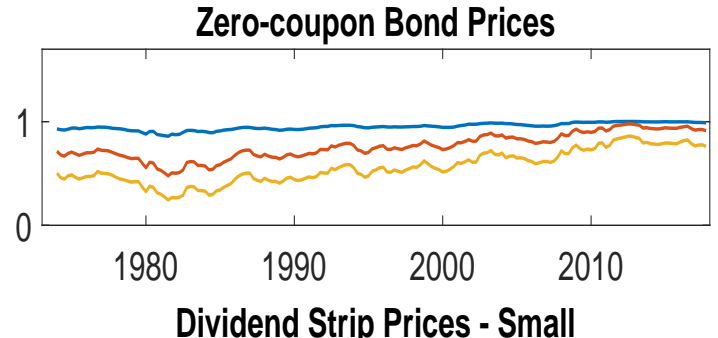

Dividend Strip Prices - Small

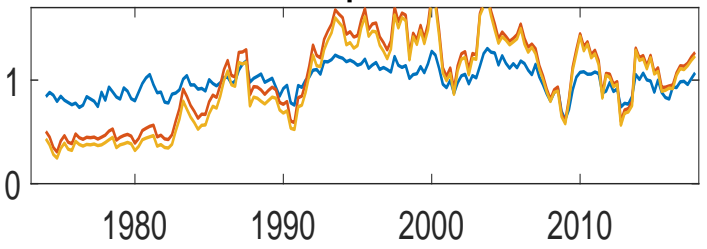

Dividend Strip Prices - Value

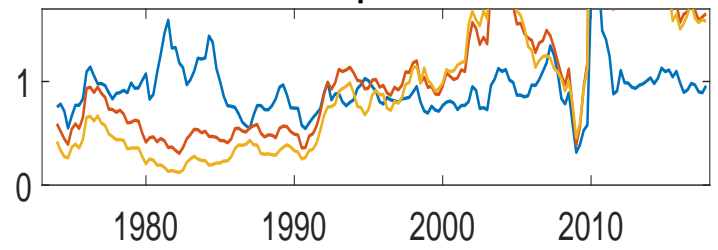

Dividend Strip Prices - Infrastructure

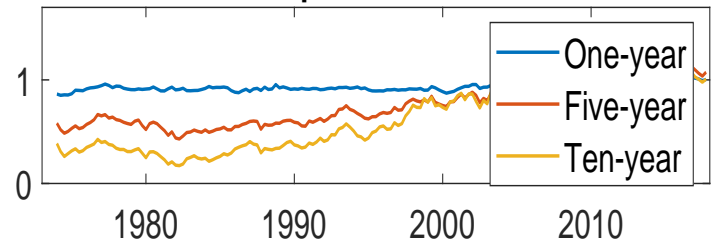

Dividend Strip Prices - Stock Market

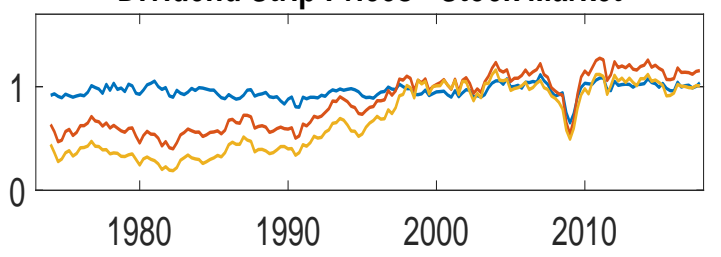

Dividend Strip Prices - Growth

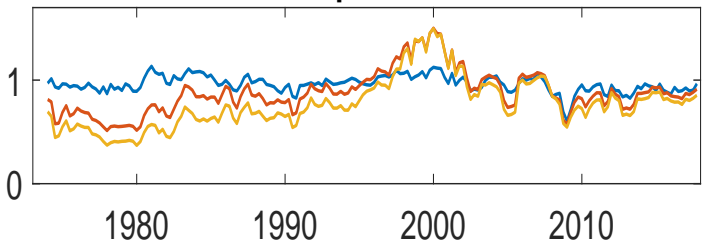

Dividend Strip Prices - REITS

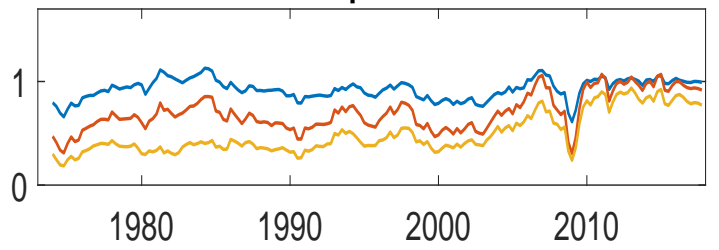

Dividend Strip Prices - Nat. Res.

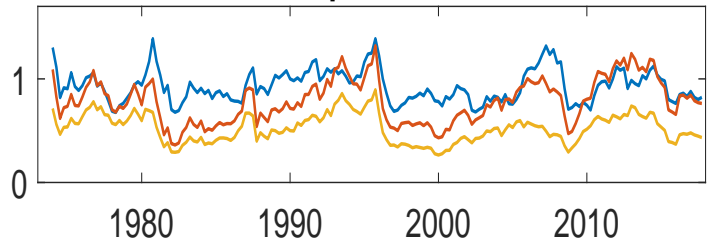




\section{FIGURE 6: Short-run Cumulative Dividend Strips}

The left panel plots the model-implied price-dividend ratio on a claim that pays the next eight quarters of dividends on the aggregate stock market. The right panel plots the share that this claim represents in the overall value of the stock market. The data are from van Binsbergen, Brandt, and Koijen (2012) and available from 1996.Q1-2009.Q3.
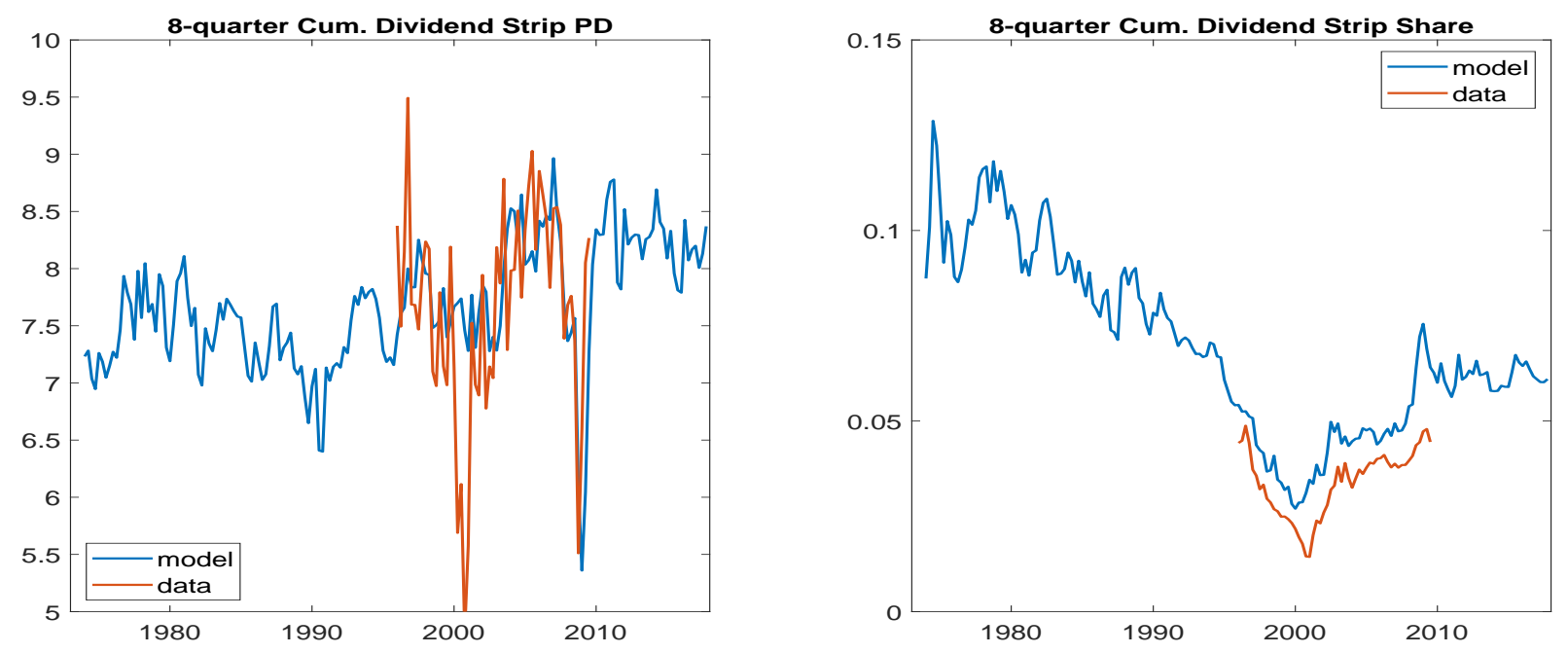


\section{FIGURE 7: Strip Expected Returns by Horizon}

The figure plots the model-implied average risk premia on nominal zero-coupon Treasury bonds in the first panel, and on dividend strips on the overall stock market, small stocks, growth stocks, value stocks, REITs, infrastructure stocks, and natural resource stocks in the next seven panels, for maturities ranging from 1 to 64 quarters.
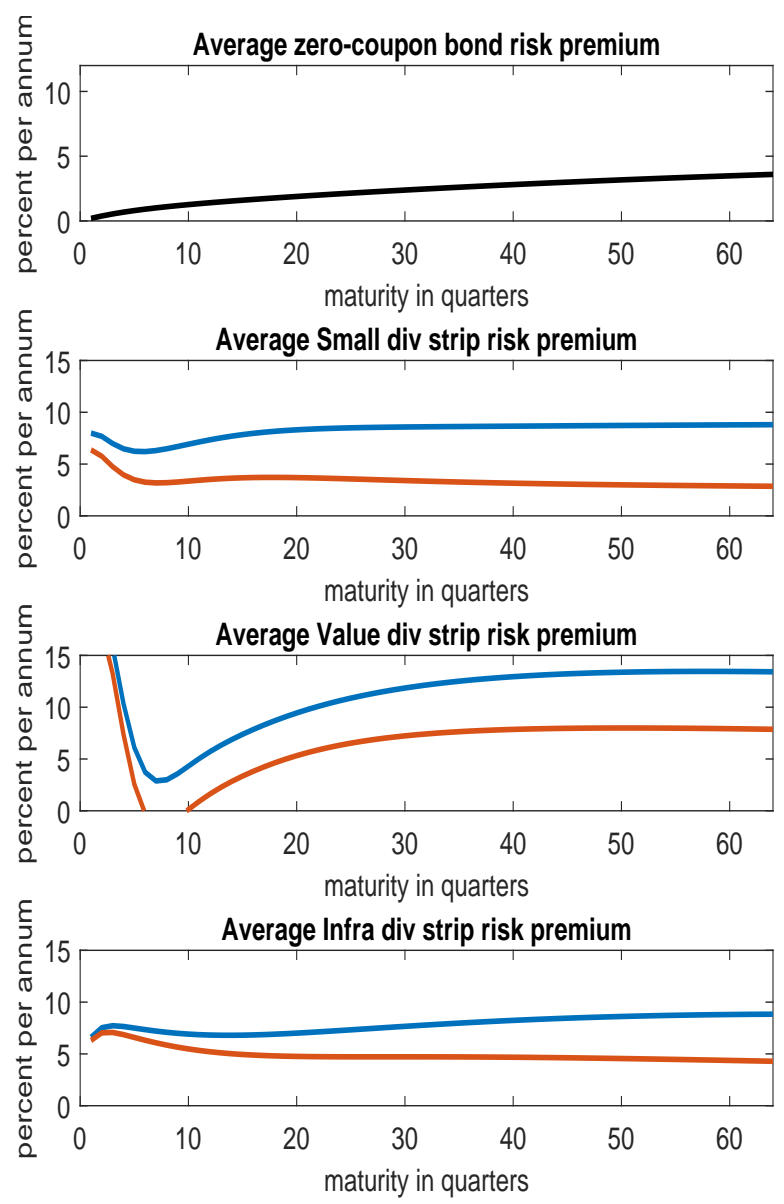
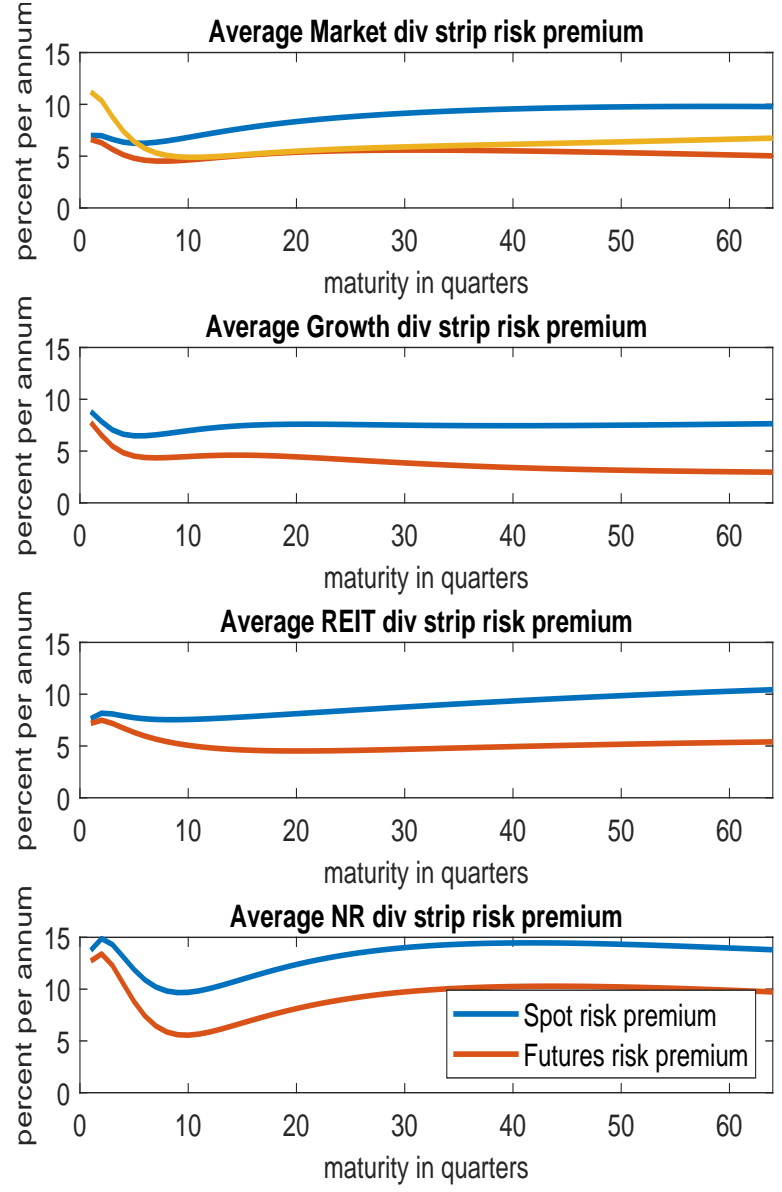


\section{FIGURE 8: Strip Expected Returns in the Time Series}

The figure plots the model-implied time series of risk premia on nominal zero-coupon Treasury bonds in the first panel, and on dividend and capital gains strips on the overall stock market, small stocks, growth stocks, value stocks, REITs, infrastructure stocks, and natural resource stocks in the next seven panels. The maturity for each strip that is plotted is 5 years (20 quarters).

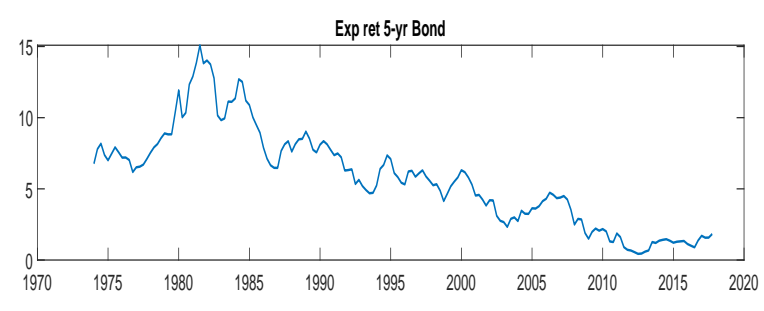

Exp ret Small Strip

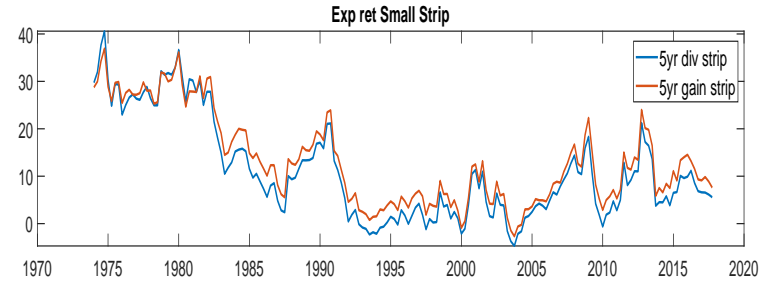

Exp ret Value Strip
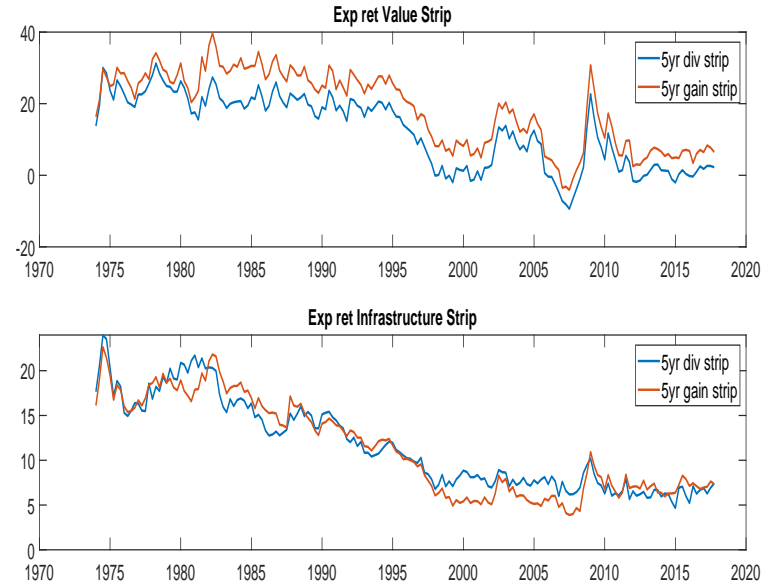
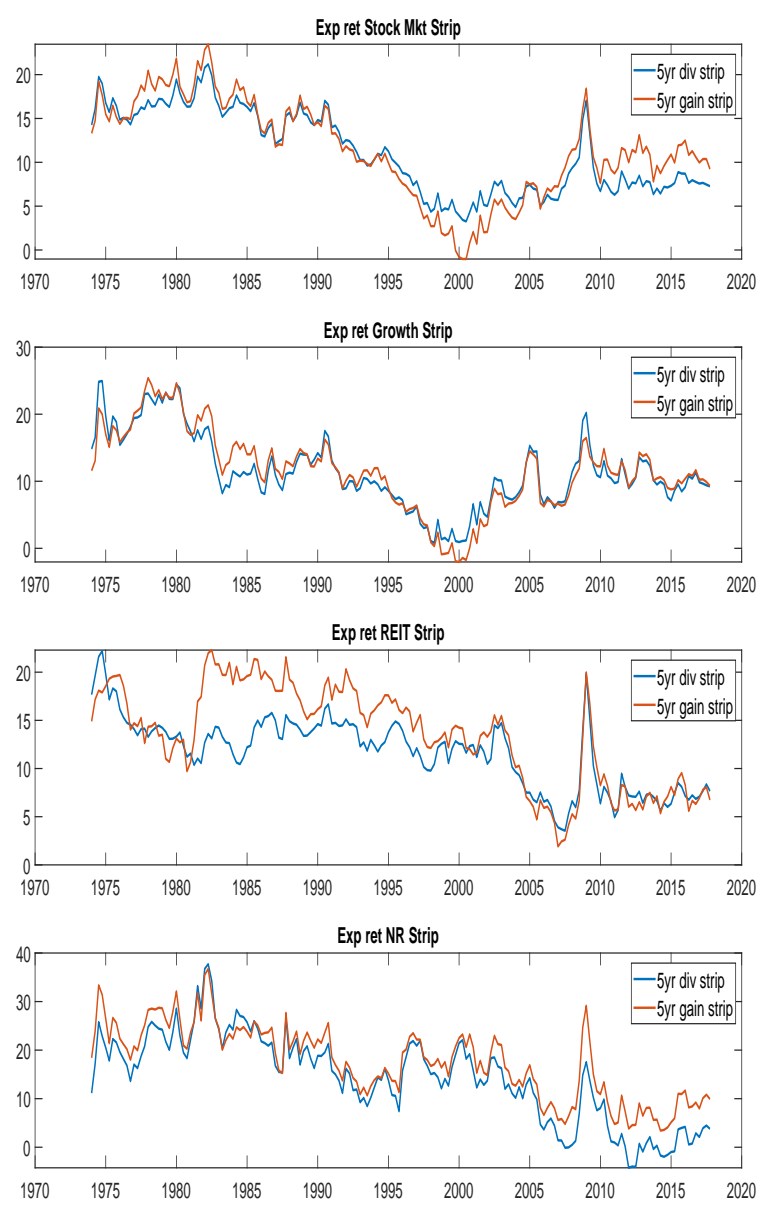
FIGURE 9: Distribution Cash-flow Profiles
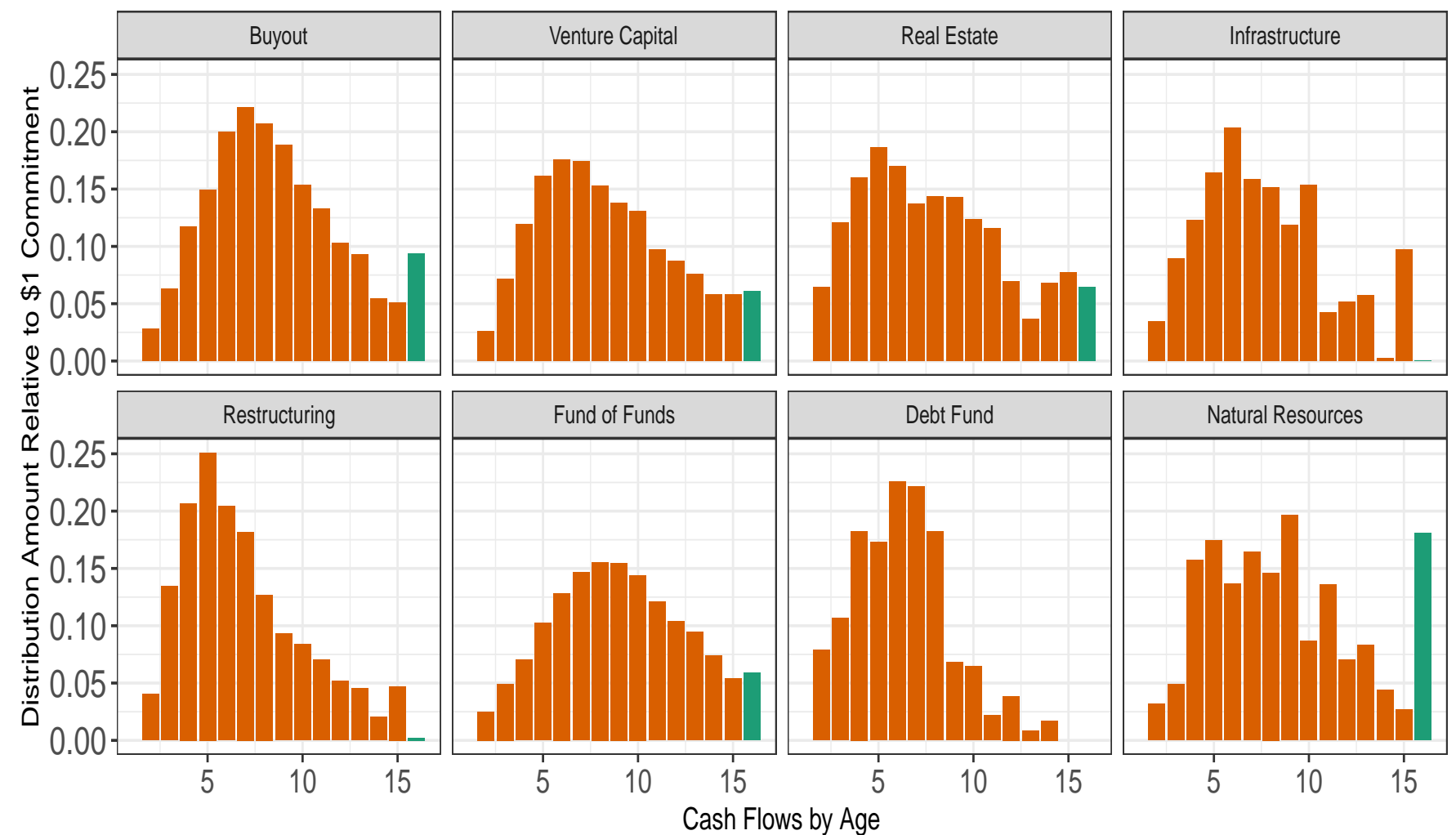


\section{FIGURE 10: Cash-flows by Vintage}

Panel A: Buyout
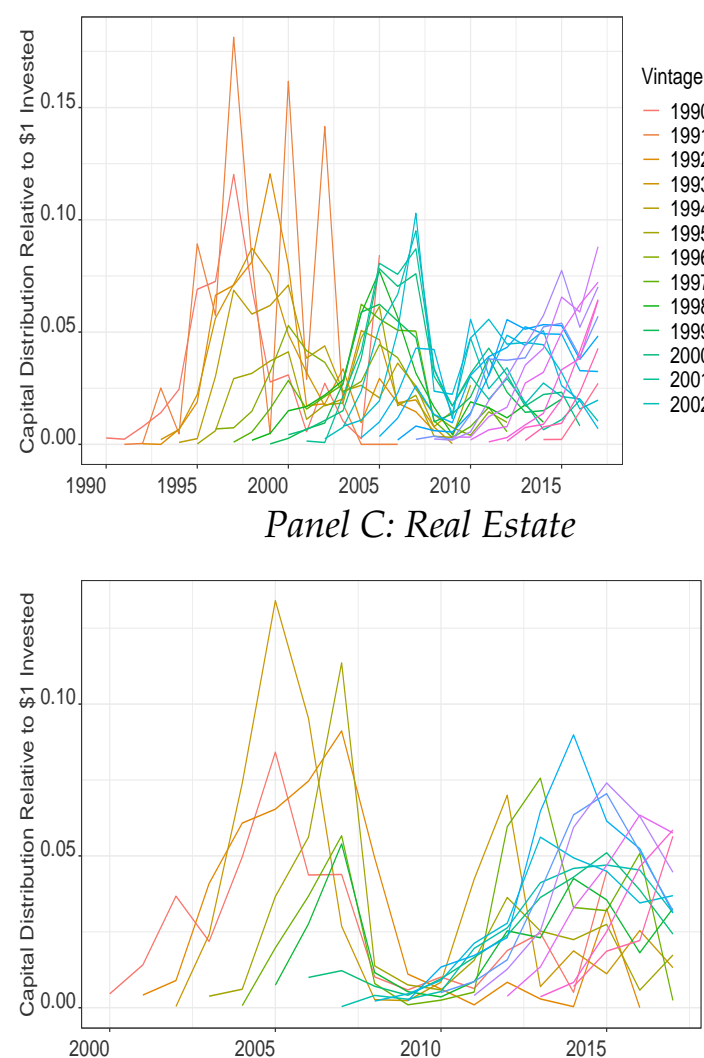

Panel B: Venture Capital
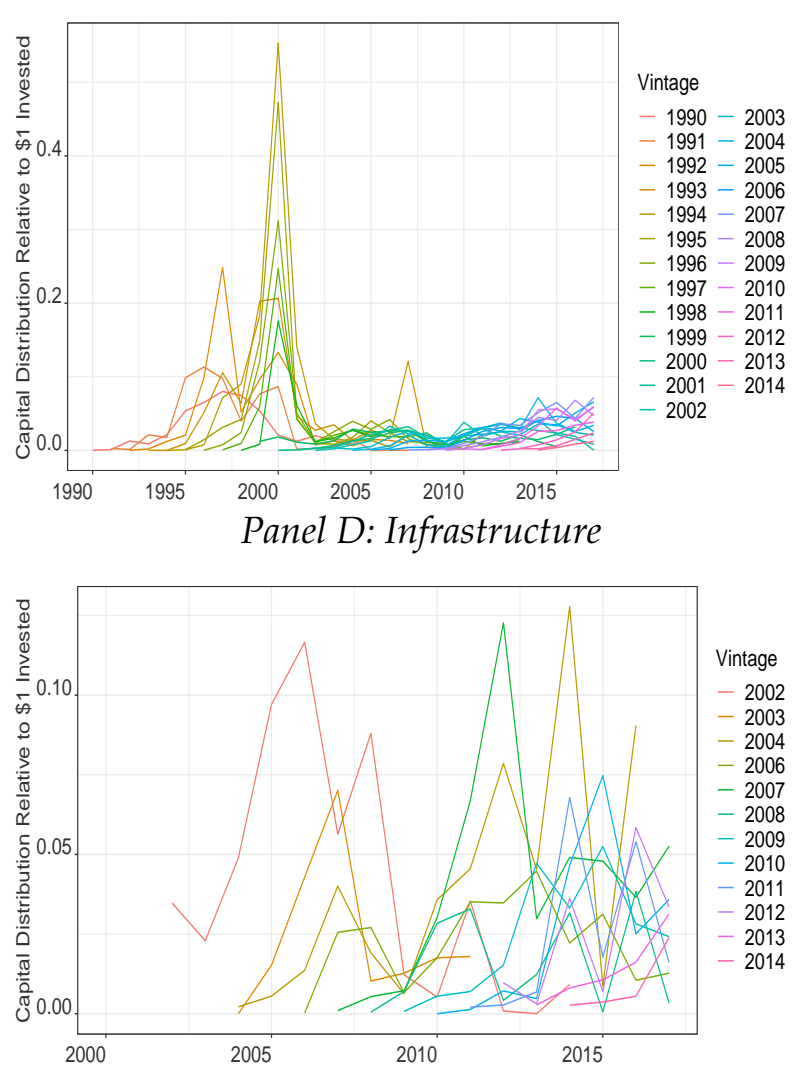


\section{FIGURE 11: Factor Exposure over Fund Horizon}

\section{2-Factor}

\section{Elastic Net}

\section{Panel A: Buyout}
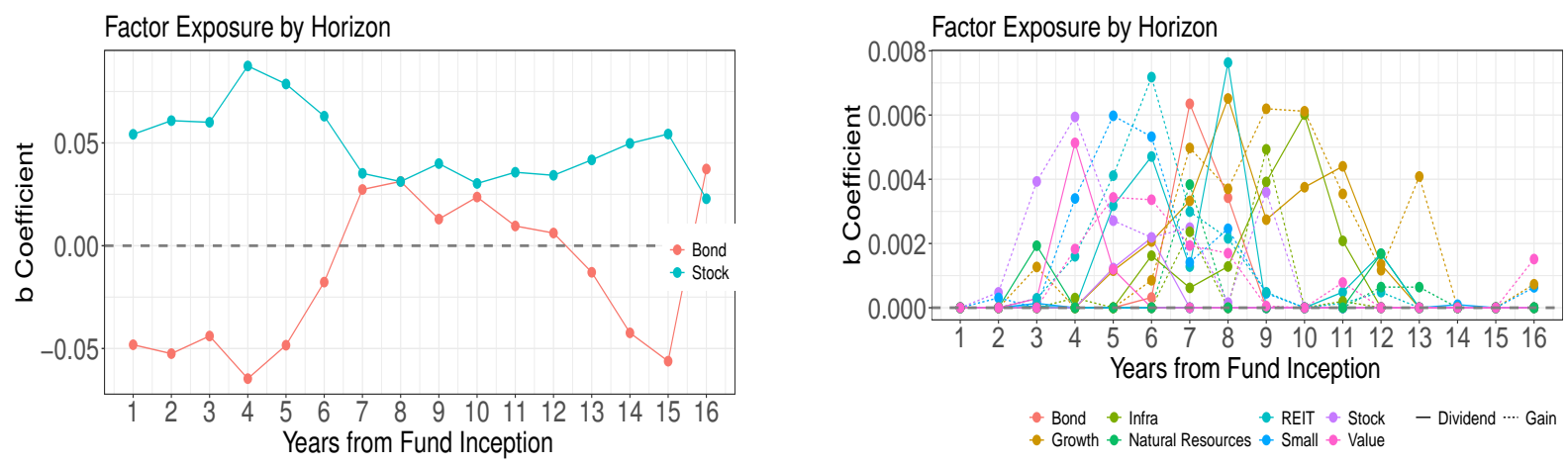

Panel B: Venture Capital
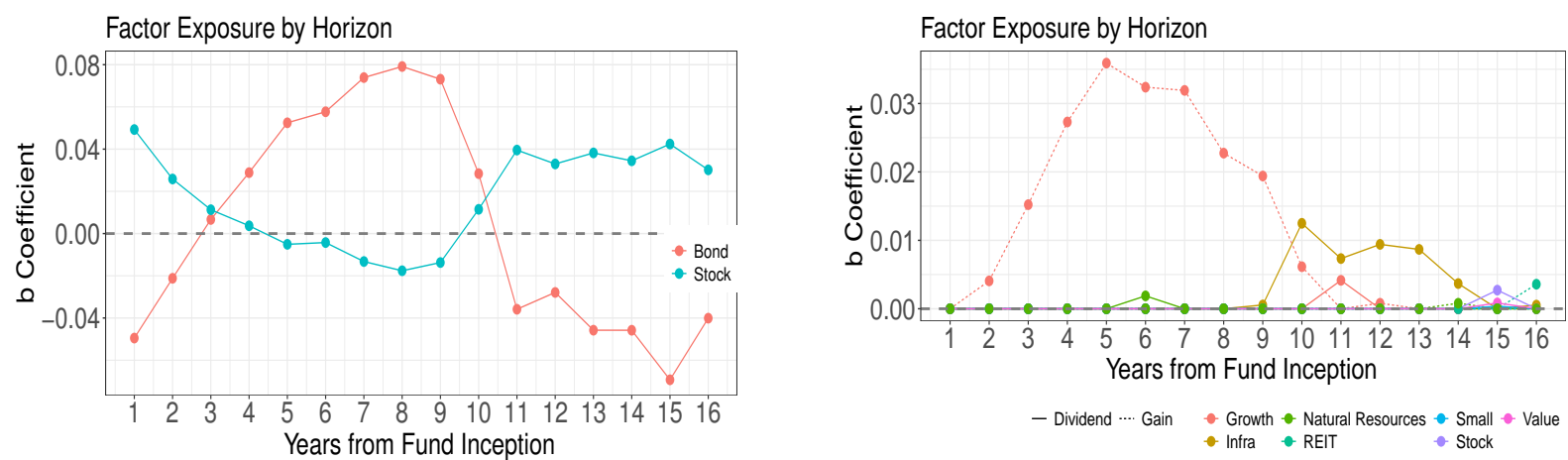

Panel C: Real Estate
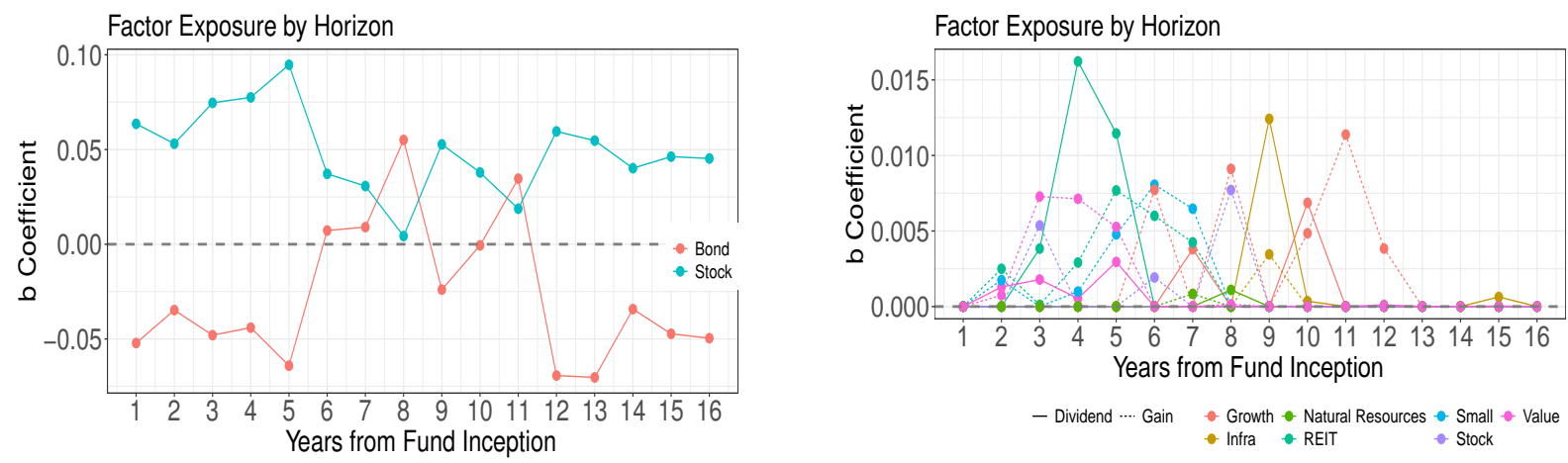

\section{Panel D: Infrastructure}
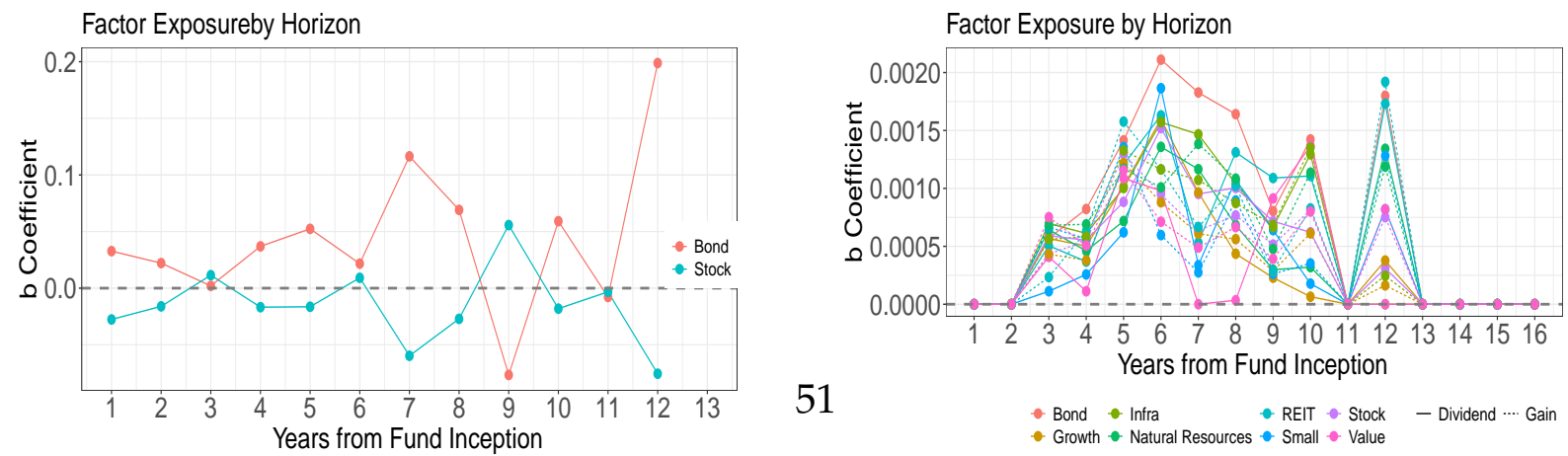
FIGURE 12: Expected Returns by Vintage

2-Factor

Elastic Net

Panel A: Buyout
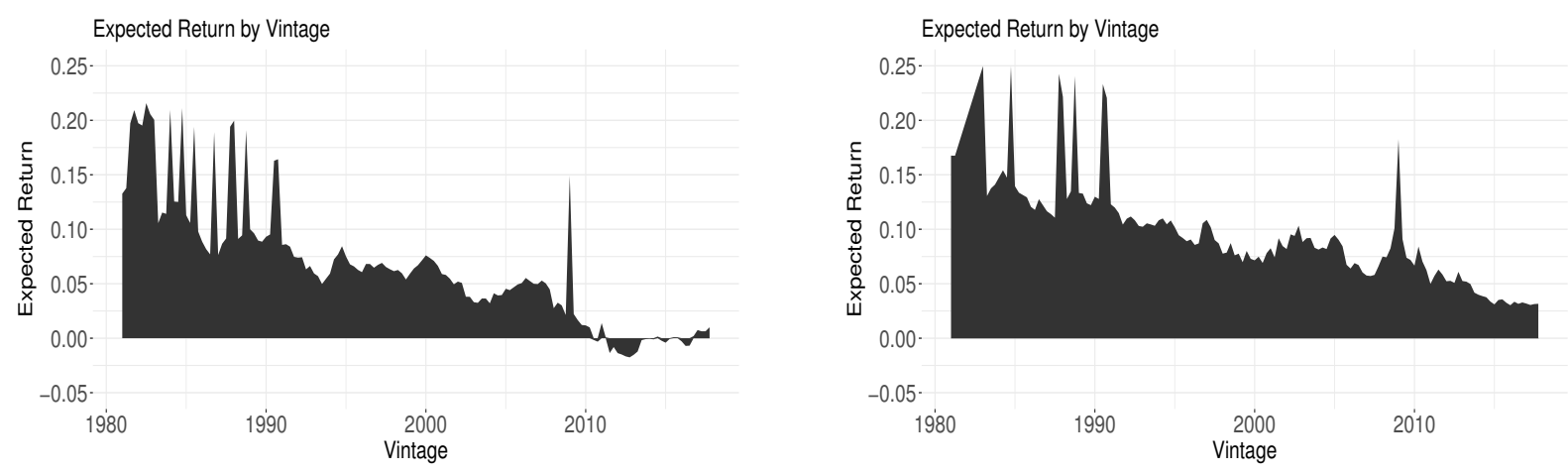

Panel B: Venture Capital
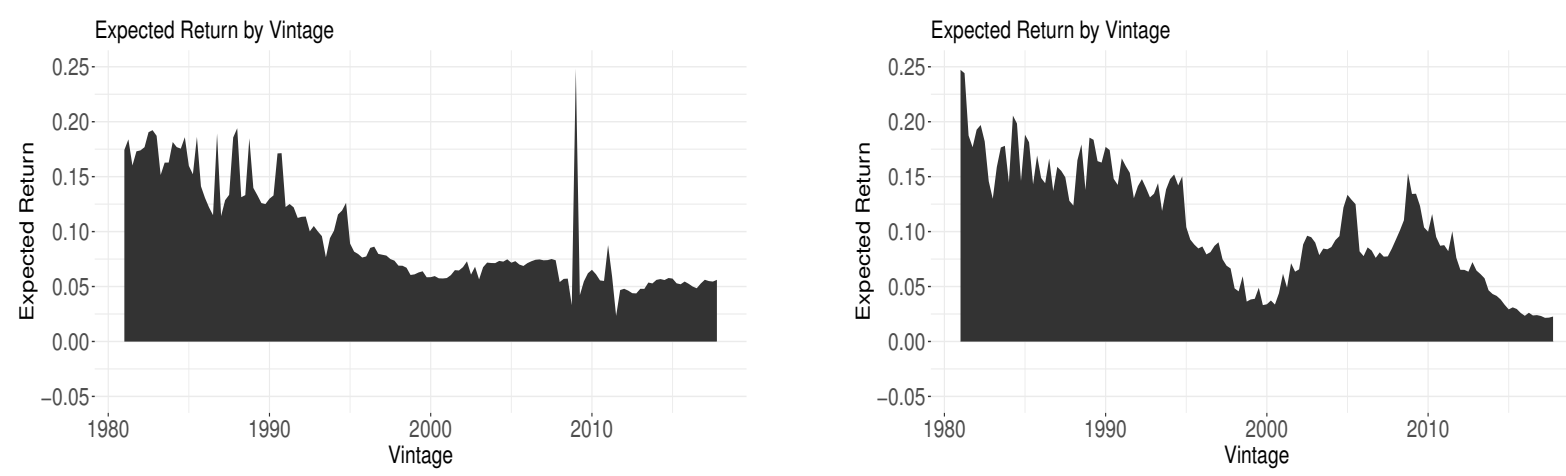

Panel C: Real Estate
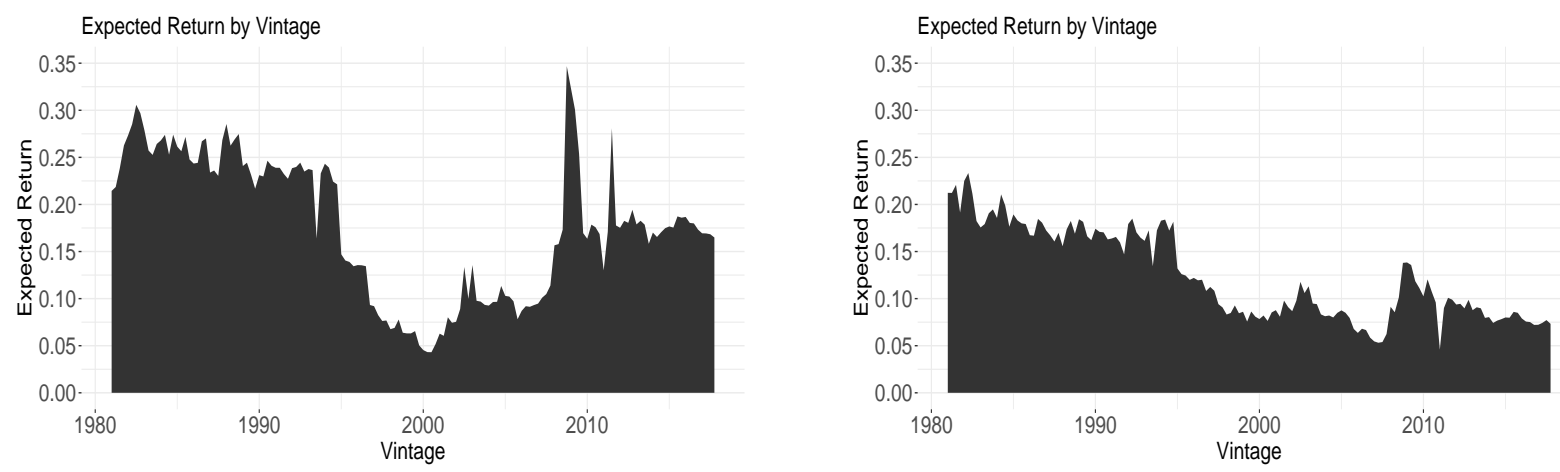

Panel D: Infrastructure
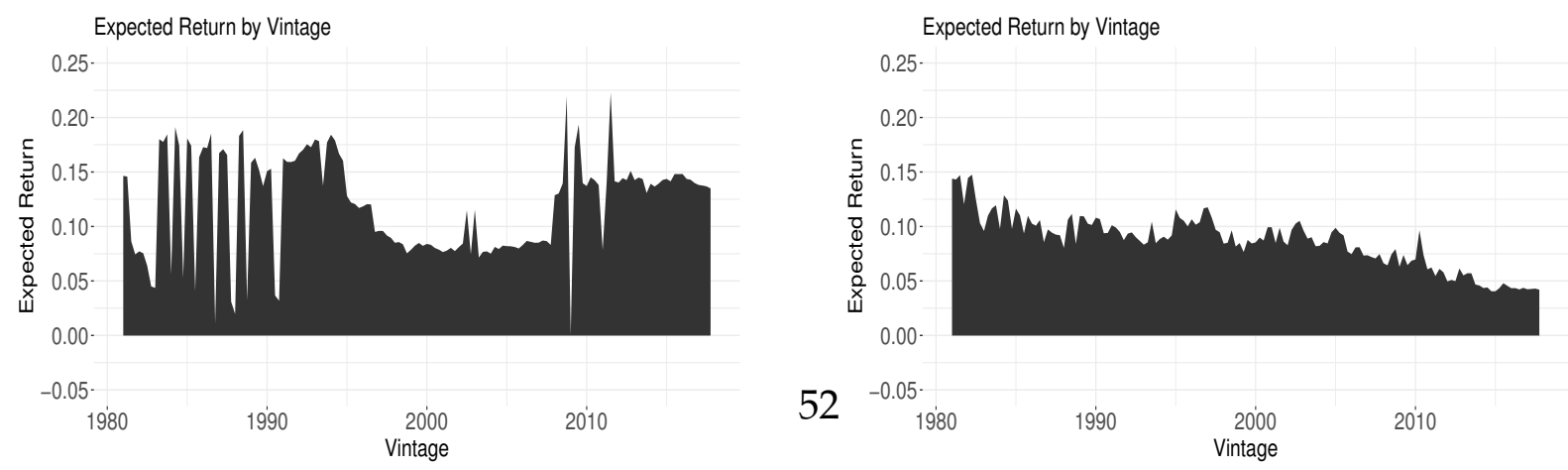


\section{FIGURE 13: Profit Comparison}

\section{2-Factor}

Panel A: Buyout
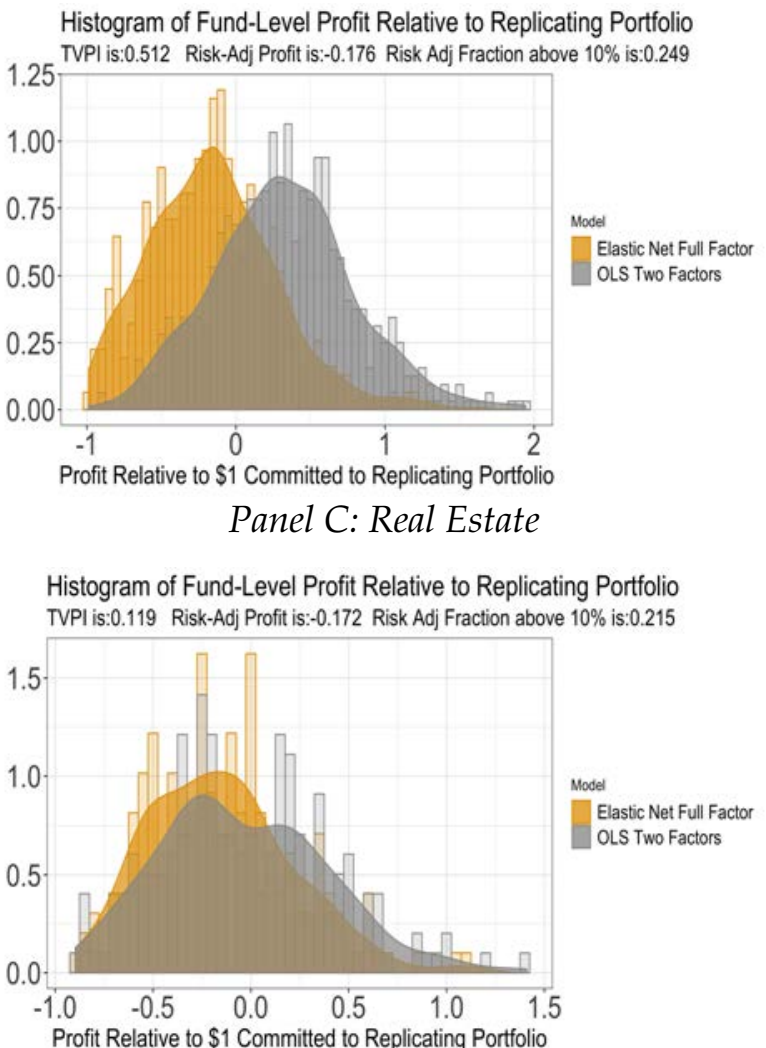

\section{Elastic Net}

\author{
Panel B: Venture Capital
}
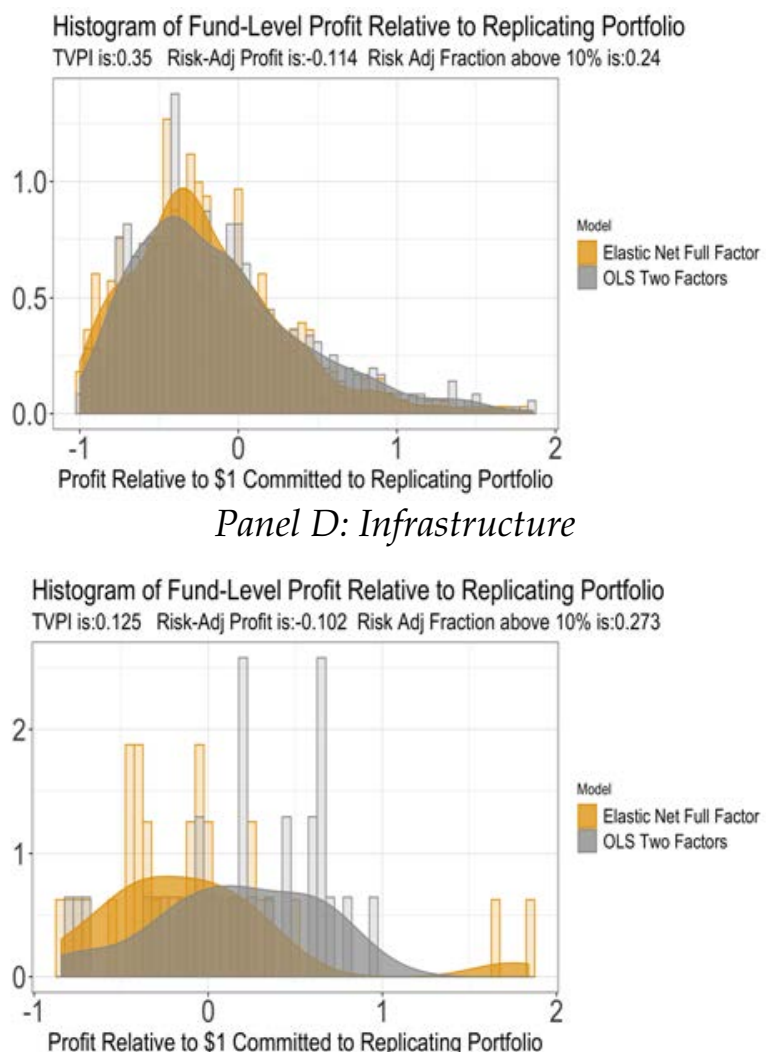


\section{FIGURE 14: Profits Over Time}

\section{2-Factor}

Panel A: Buyout
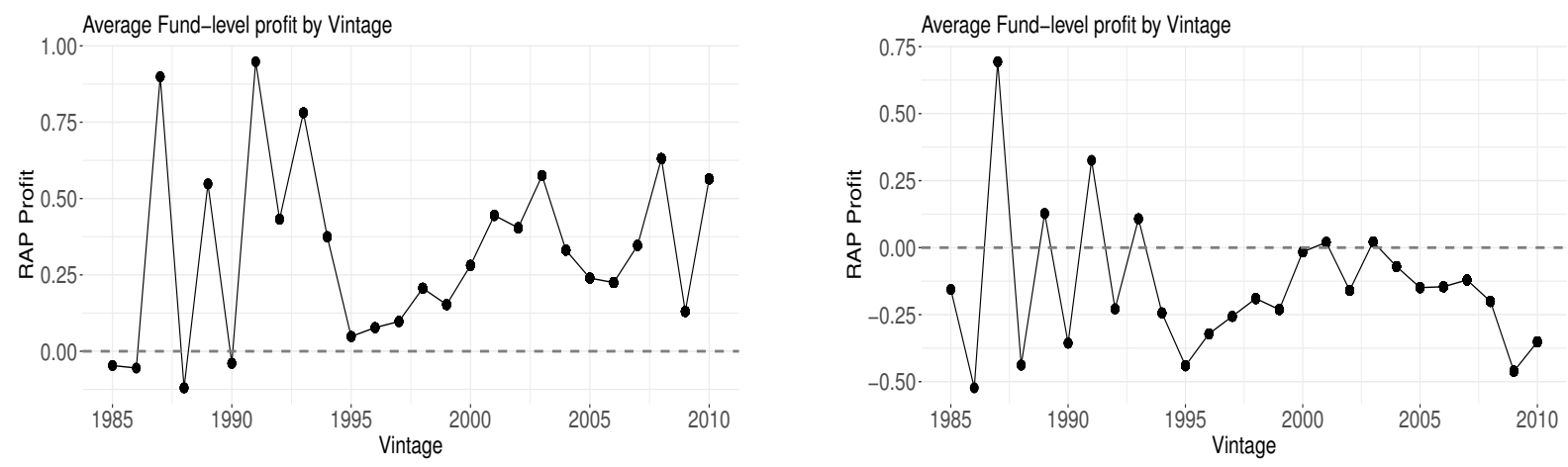

Panel B: Venture Capital
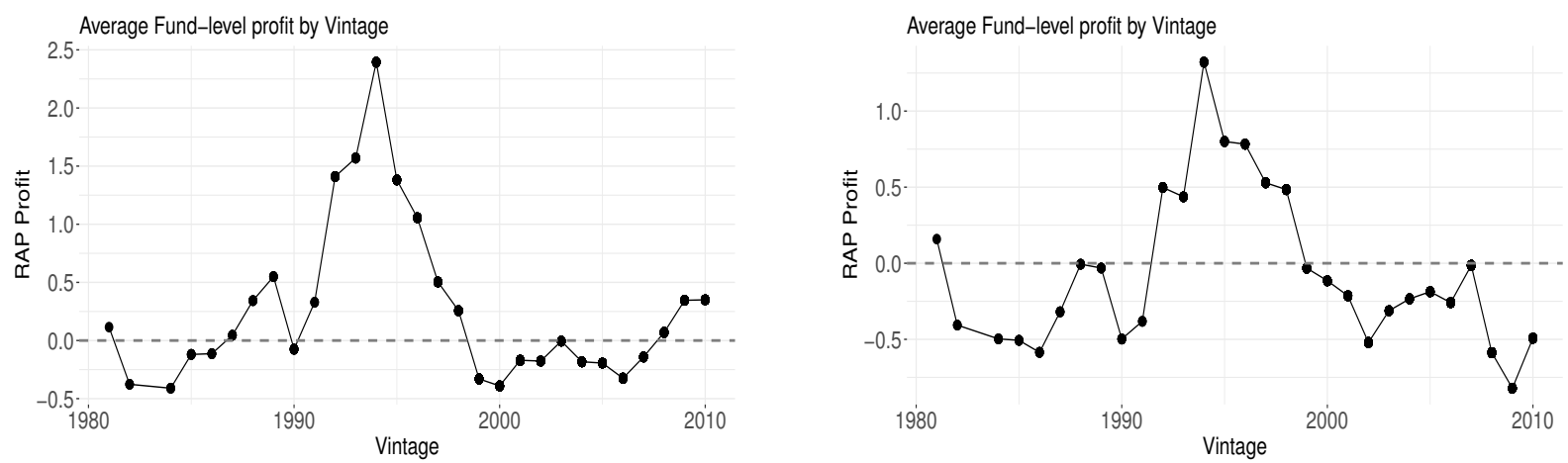

Panel C: Real Estate
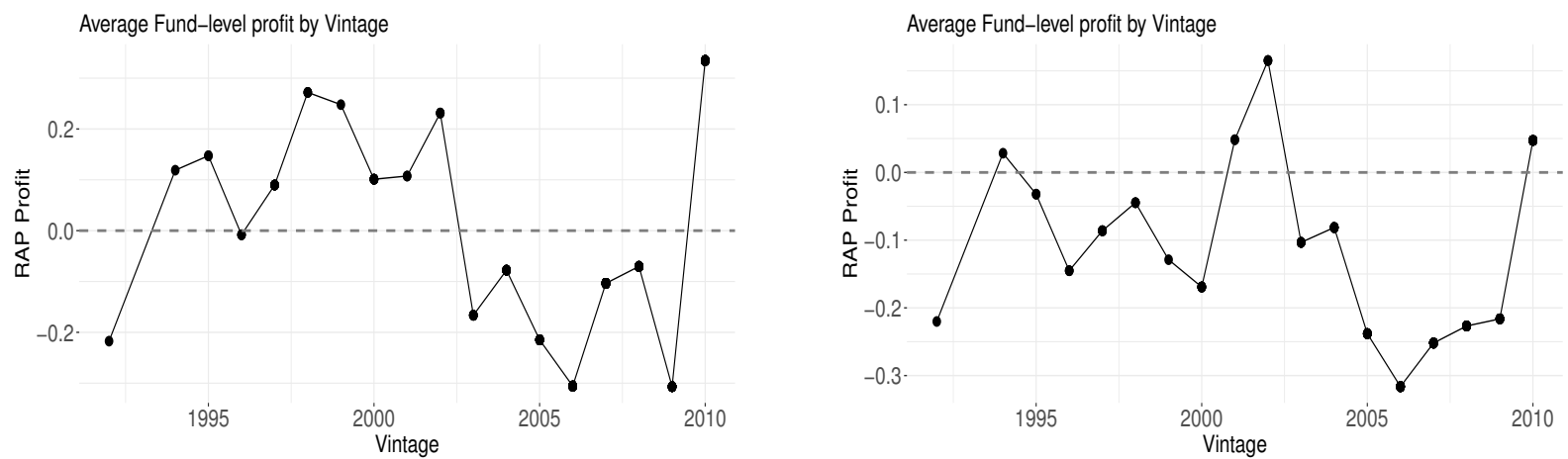

Panel D: Infrastructure
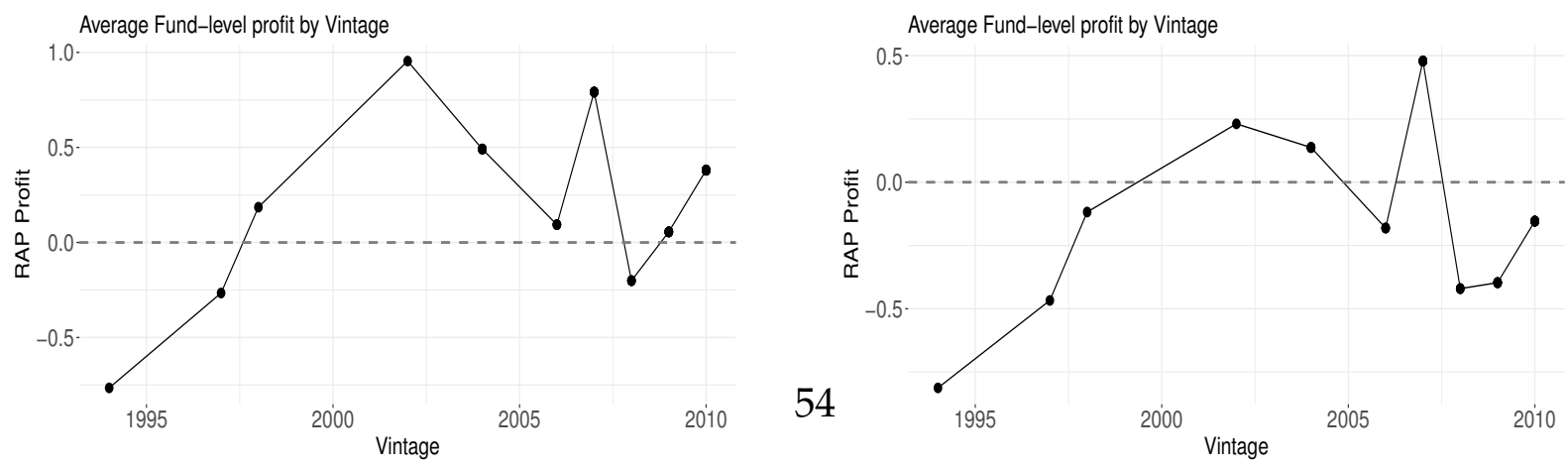


\section{FIGURE 15: Elastic Net Alternative Approach Comparison}

\section{Panel A: Buyout}
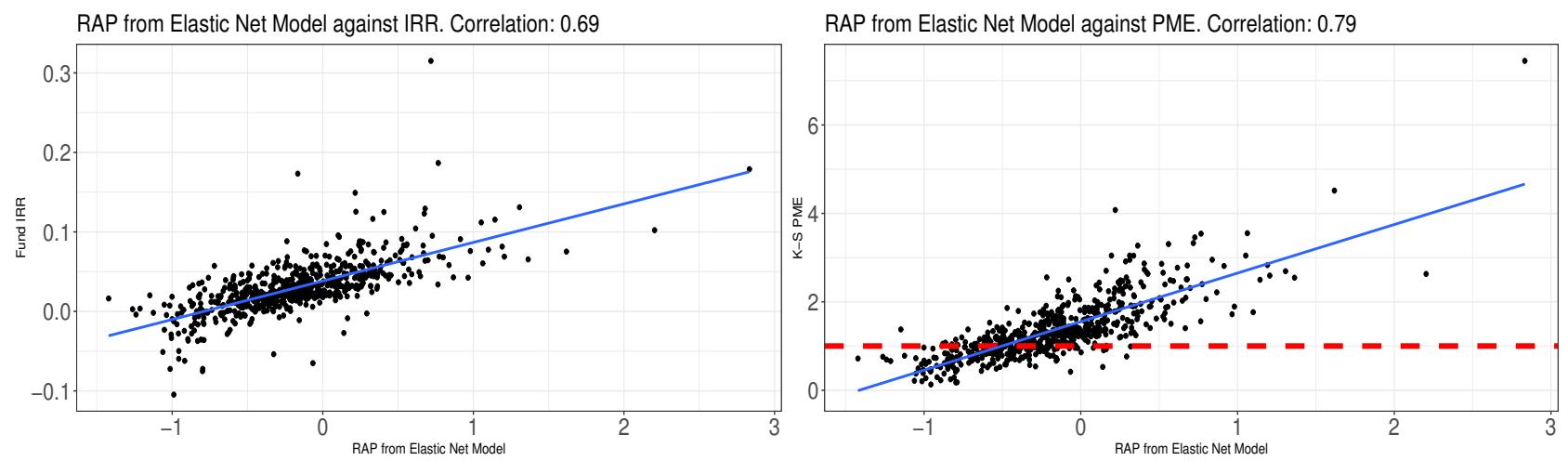

Panel B: Venture Capital
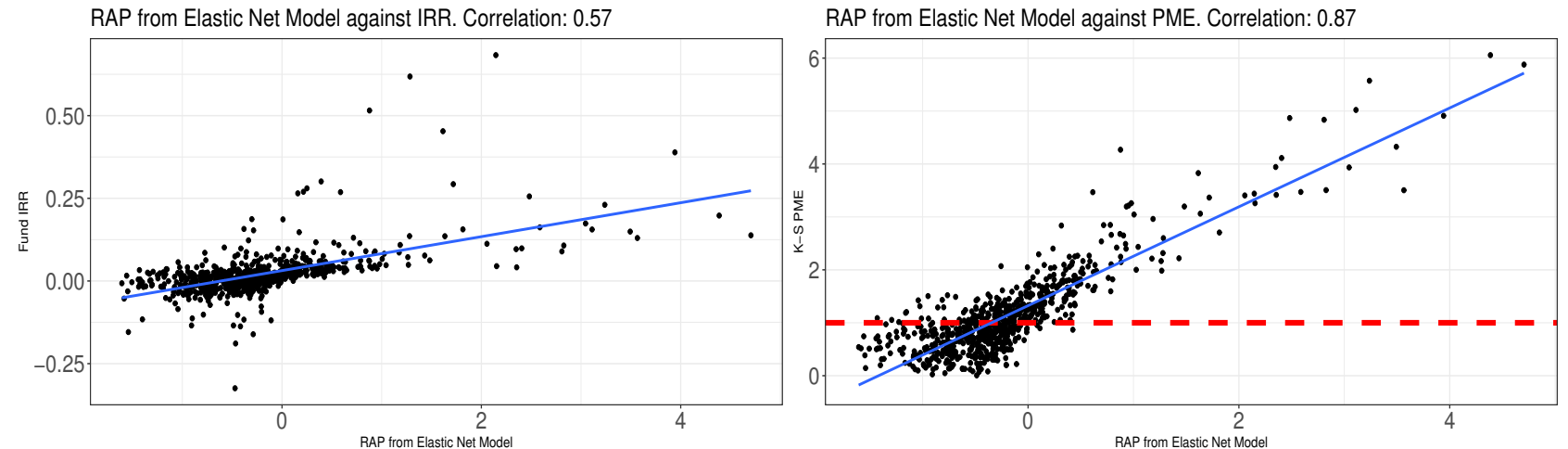

Panel C: Real Estate
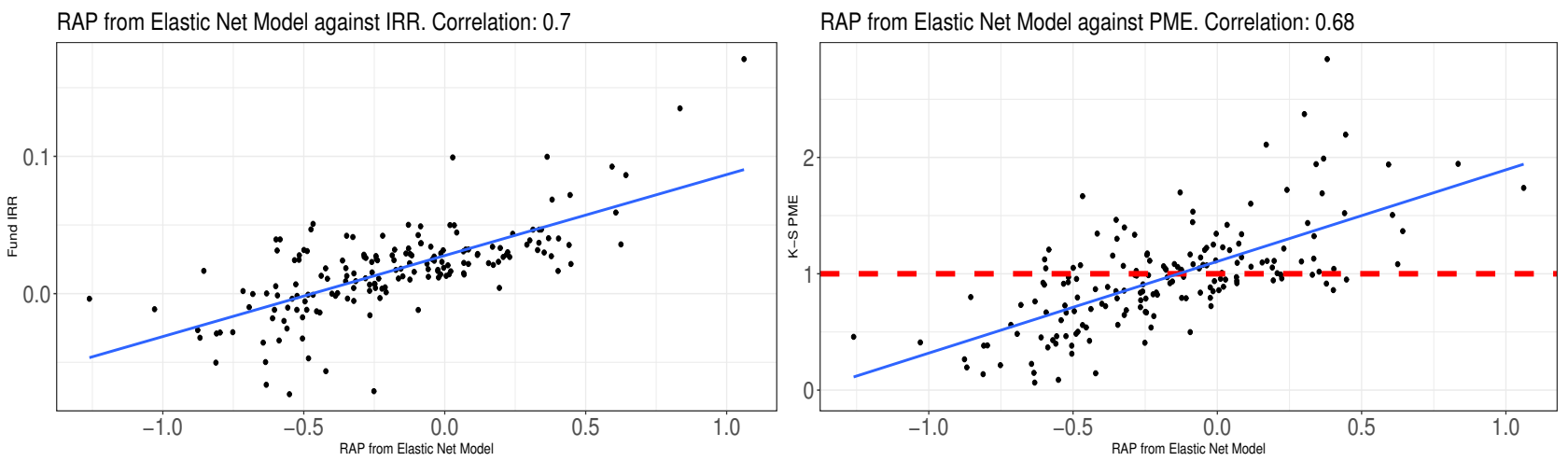

Panel D: Infrastructure
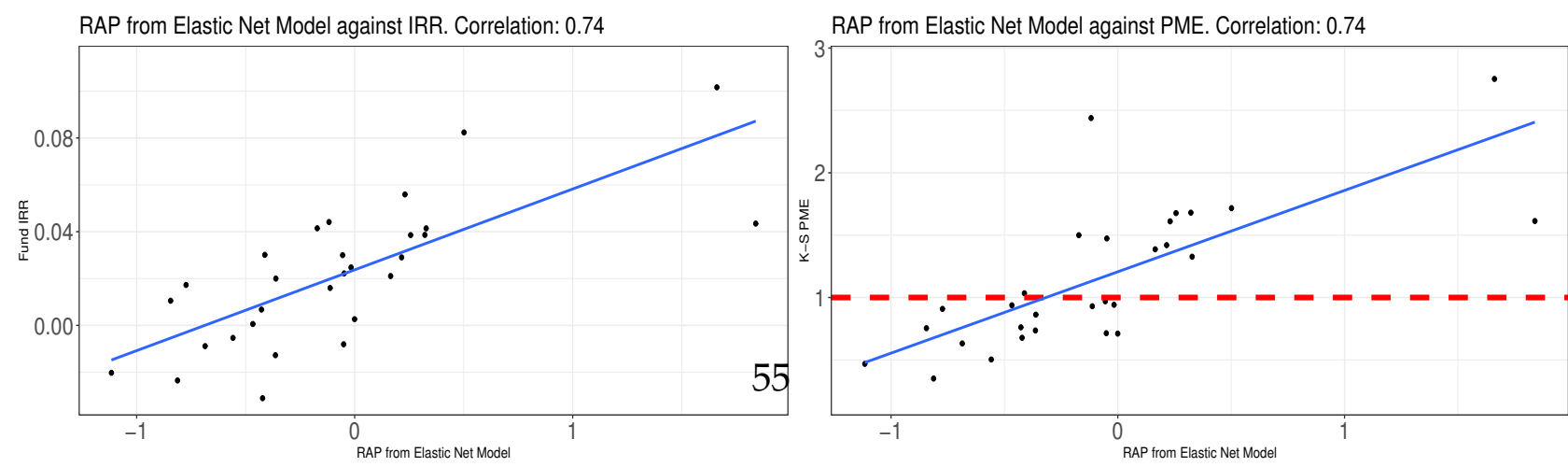
TABLE 1: Summary Statistics

Panel A: Fund Count

\begin{tabular}{|c|c|c|c|c|c|c|c|c|c|c|}
\hline Vintage & Buyout & Venture Capital & Real Estate & Infrastructure & Restructuring & Fund of Funds & Debt Fund & Natural Resources & Total & PD Ratio \\
\hline 1981 & 0 & 1 & 0 & 0 & 0 & 0 & 0 & 0 & 1 & 1 \\
\hline 1982 & 0 & 3 & 0 & 0 & 0 & 0 & 0 & 0 & 3 & 1 \\
\hline 1983 & 0 & 1 & 0 & 0 & 0 & 1 & 0 & 0 & 2 & 1 \\
\hline 1984 & 0 & 3 & 0 & 0 & 0 & 0 & 0 & 0 & 3 & 1 \\
\hline 1985 & 4 & 6 & 0 & 0 & 0 & 0 & 0 & 0 & 10 & 1.6 \\
\hline 1986 & 2 & 7 & 0 & 0 & 0 & 3 & 0 & 0 & 12 & 1.6 \\
\hline 1987 & 5 & 5 & 0 & 0 & 0 & 0 & 0 & 0 & 10 & 1.7 \\
\hline 1988 & 7 & 4 & 0 & 0 & 0 & 1 & 0 & 0 & 12 & 1.5 \\
\hline 1989 & 3 & 5 & 0 & 0 & 0 & 0 & 0 & 1 & 9 & 2 \\
\hline 1990 & 7 & 8 & 0 & 0 & 1 & 2 & 0 & 0 & 18 & 1.4 \\
\hline 1991 & 2 & 4 & 0 & 0 & 2 & 1 & 0 & 0 & 9 & 2 \\
\hline 1992 & 9 & 12 & 1 & 0 & 2 & 0 & 0 & 1 & 25 & 2.0 \\
\hline 1993 & 9 & 11 & 0 & 0 & 0 & 2 & 0 & 0 & 23 & 2.2 \\
\hline 1994 & 15 & 12 & 1 & 1 & 1 & 1 & 0 & 1 & 32 & 2.1 \\
\hline 1995 & 14 & 17 & 2 & 0 & 0 & 5 & 0 & 1 & 39 & 3 \\
\hline 1996 & 20 & 21 & 3 & 1 & 3 & 1 & 0 & 0 & 51 & 3.3 \\
\hline 1997 & 23 & 26 & 6 & 0 & 2 & 4 & 0 & 1 & 63 & 4 \\
\hline 1998 & 40 & 32 & 3 & 1 & 1 & 11 & 0 & 3 & 91 & 4 \\
\hline 1999 & 31 & 47 & 2 & 0 & 3 & 9 & 1 & 1 & 94 & 4 \\
\hline 2000 & 33 & 84 & 6 & 0 & 3 & 17 & 2 & 0 & 145 & 4 \\
\hline 2001 & 21 & 55 & 2 & 0 & 5 & 19 & 0 & 1 & 103 & 3.9 \\
\hline 2002 & 24 & 29 & 3 & 1 & 3 & 13 & 1 & 2 & 76 & 3.8 \\
\hline 2003 & 18 & 20 & 7 & 1 & 4 & 12 & 1 & 1 & 64 & 3.8 \\
\hline 2004 & 27 & 33 & 11 & 4 & 2 & 19 & 1 & 2 & 99 & 4 \\
\hline 2005 & 55 & 49 & 19 & 0 & 6 & 33 & 2 & 5 & 169 & 4 \\
\hline 2006 & 71 & 59 & 32 & 4 & 11 & 51 & 1 & 4 & 233 & 4.0 \\
\hline 2007 & 72 & 72 & 35 & 6 & 13 & 48 & 1 & 7 & 254 & 3.9 \\
\hline 2008 & 65 & 62 & 31 & 2 & 11 & 61 & 5 & 8 & 246 & 2.7 \\
\hline 2009 & 27 & 26 & 12 & 6 & 8 & 30 & 2 & 3 & 114 & 1.8 \\
\hline 2010 & 39 & 39 & 28 & 8 & 8 & 38 & 4 & 10 & 174 & 3.0 \\
\hline 2011 & 53 & 49 & 46 & 9 & 12 & 64 & 2 & 10 & 248 & 3.0 \\
\hline 2012 & 63 & 44 & 36 & 4 & 12 & 54 & 3 & 12 & 231 & 3 \\
\hline 2013 & 63 & 53 & 59 & 10 & 20 & 66 & 15 & 7 & 295 & 3 \\
\hline 2014 & 68 & 67 & 46 & 12 & 16 & 67 & 12 & 14 & 302 & 3 \\
\hline 2015 & 72 & 76 & 73 & 13 & 18 & 72 & 16 & 7 & 348 & 3 \\
\hline 2016 & 91 & 72 & 59 & 14 & 10 & 78 & 13 & 17 & 355 & 3 \\
\hline 2017 & 47 & 60 & 61 & 14 & 7 & 39 & 20 & 7 & 256 & 3 \\
\hline
\end{tabular}

Panel B: Fund AUM (\$m)

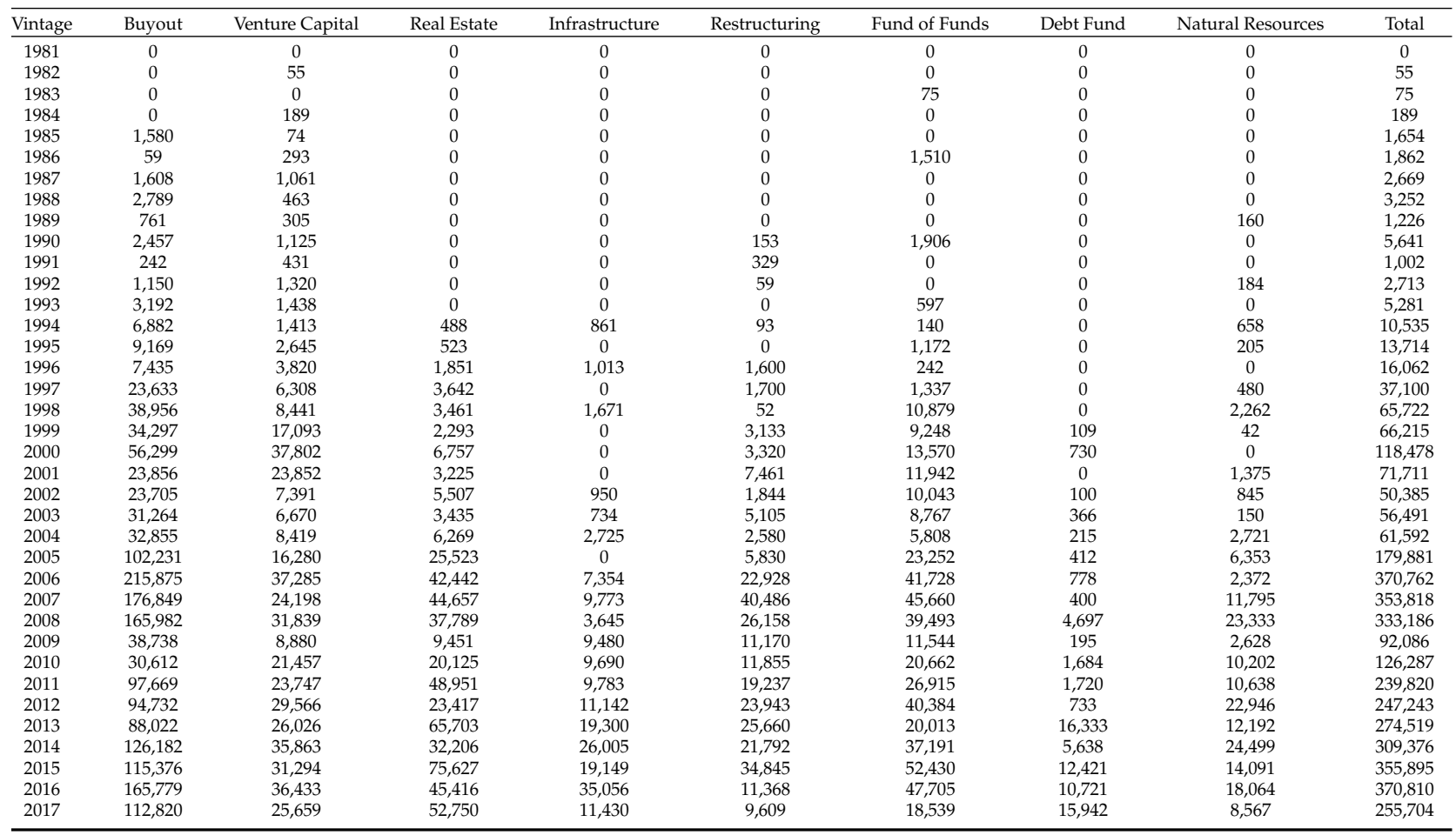




\section{TABLE 2: Model Comparison}

\section{Panel A: Preqin}

\begin{tabular}{|c|c|c|c|c|c|c|c|c|c|c|c|c|c|c|c|c|}
\hline \multirow[b]{2}{*}{ Model } & \multicolumn{4}{|c|}{ Buyout } & \multicolumn{4}{|c|}{$\mathrm{VC}$} & \multicolumn{4}{|c|}{ Real Estate } & \multicolumn{4}{|c|}{ Infrastructure } \\
\hline & $R^{2}$ & Profit & SD Profit & Persistence & $R^{2}$ & Profit & SD Profit & Persistence & $R^{2}$ & Profit & SD Profit & Persistence & $R^{2}$ & Profit & SD Profit & Persistence \\
\hline TVPI & - & 0.512 & $(0.756)$ & 0.31 & - & 0.35 & $(1.886)$ & 0.39 & - & 0.119 & $(0.513)$ & 0.27 & - & 0.125 & $(0.673)$ & 0.18 \\
\hline IRR (\%) & _ & 12.6 & $(13.1)$ & 0.25 & _ & 8.5 & $(22.4)$ & 0.25 & - & 7.9 & $(13.8)$ & 0.26 & - & 9.3 & (12) & -0.46 \\
\hline PME & - & 0.358 & $(0.669)$ & 0.22 & - & 0.24 & (1.587) & 0.43 & - & -0.04 & $(0.443)$ & 0.40 & - & 0.155 & $(0.571)$ & 0.10 \\
\hline Two-factor OLS & 0.158 & 0.385 & $(0.503)$ & 0.19 & 0.045 & 0.115 & (1.423) & 0.13 & 0.187 & -0.031 & $(0.443)$ & 0.14 & 0.094 & 0.292 & $(0.803)$ & -0.08 \\
\hline Two-factor Elastic Net & 0.156 & 0.291 & $(0.484)$ & 0.21 & 0.043 & 0.102 & $(1.42)$ & 0.14 & 0.184 & 0.139 & $(0.445)$ & 0.08 & 0.089 & 0.188 & $(0.598)$ & 0.17 \\
\hline Full factors & 0.160 & -0.176 & $(0.481)$ & 0.24 & 0.060 & -0.114 & (1.371) & 0.15 & 0.200 & -0.172 & $(0.392)$ & 0.18 & 0.090 & -0.102 & $(0.612)$ & 0.01 \\
\hline Elastic Net, Aggregated & 0.23 & -0.084 & $(0.386)$ & - & 0.19 & -0.051 & (0.911) & - & 0.26 & -0.098 & $(0.324)$ & - & 0.12 & -0.165 & $(0.419)$ & - \\
\hline
\end{tabular}

\section{Panel B: Burgiss}

\begin{tabular}{|c|c|c|c|c|c|c|c|c|c|c|c|c|c|c|c|c|}
\hline \multirow[b]{2}{*}{ Model } & \multicolumn{4}{|c|}{ Buyout } & \multicolumn{4}{|c|}{$\mathrm{VC}$} & \multicolumn{4}{|c|}{ Real Estate } & \multicolumn{4}{|c|}{ Infrastructure } \\
\hline & $R^{2}$ & Profit & SD Profit & Persistence & $R^{2}$ & Profit & SD Profit & Persistence & $R^{2}$ & Profit & SD Profit & Persistence & $R^{2}$ & Profit & SD Profit & Persistence \\
\hline TVPI & - & 0.53 & $(0.916)$ & 0.26 & - & 0.532 & (1.931) & 0.40 & - & 0.023 & $(0.575)$ & 0.34 & - & 0.188 & $(0.671)$ & 0.45 \\
\hline Two-factor Elastic Net & 0.125 & 0.248 & $(0.606)$ & 0.17 & 0.049 & 0.131 & $(1.45)$ & 0.24 & 0.096 & 0.033 & $(0.466)$ & 0.46 & 0.115 & 0.044 & $(0.522)$ & 0.29 \\
\hline Elastic Net & 0.13 & -0.187 & $(0.625)$ & 0.19 & 0.07 & -0.074 & (1.399) & 0.27 & 0.11 & -0.196 & $(0.48)$ & 0.41 & 0.13 & -0.207 & $(0.489)$ & 0.32 \\
\hline Elastic Net, Aggregated & 0.31 & -0.113 & $(0.364)$ & - & 0.27 & -0.047 & $(0.977)$ & - & 0.13 & -0.142 & $(0.445)$ & - & 0.23 & -0.182 & $(0.319)$ & - \\
\hline
\end{tabular}




\section{A Appendix: Asset Pricing Model}

\section{A.1 Risk-free rate}

The real short yield $y_{t, 1}$, or risk-free rate, satisfies $E_{t}\left[\exp \left\{m_{t+1}+y_{t, 1}\right\}\right]=1$. Solving out this Euler equation, we get:

$$
\begin{aligned}
y_{t, 1} & =y_{t, 1}^{\$}-\mathbb{E}_{t}\left[\pi_{t+1}\right]-\frac{1}{2} e_{\pi}^{\prime} \Sigma e_{\pi}+e_{\pi}^{\prime} \Sigma^{\frac{1}{2}} \Lambda_{t} \\
& =y_{0}(1)+\left(e_{y n}^{\prime}-e_{\pi}^{\prime} \Psi+e_{\pi}^{\prime} \Sigma^{\frac{1}{2}} \Lambda_{1}\right) z_{t} . \\
y_{0}(1) & \equiv y_{0,1}^{\$}-\pi_{0}-\frac{1}{2} e_{\pi}^{\prime} \sum_{\pi}+e_{\pi}^{\prime} \Sigma^{\frac{1}{2}} \Lambda_{0} .
\end{aligned}
$$

where we used the expression for the real SDF

$$
\begin{aligned}
m_{t+1} & =m_{t+1}^{\$}+\pi_{t+1} \\
& =-y_{t, 1}^{\$}-\frac{1}{2} \Lambda_{t}^{\prime} \Lambda_{t}-\Lambda_{t}^{\prime} \varepsilon_{t+1}+\pi_{0}+e_{\pi}^{\prime} \Psi z_{t}+e_{\pi}^{\prime} \Sigma^{\frac{1}{2}} \varepsilon_{t+1} \\
& =-y_{t, 1}-\frac{1}{2} e_{\pi}^{\prime} \Sigma e_{\pi}+e_{\pi}^{\prime} \Sigma^{\frac{1}{2}} \Lambda_{t}-\frac{1}{2} \Lambda_{t}^{\prime} \Lambda_{t}-\left(\Lambda_{t}^{\prime}-e_{\pi}^{\prime} \Sigma^{\frac{1}{2}}\right) \varepsilon_{t+1}
\end{aligned}
$$

The real short yield is the nominal short yield minus expected inflation minus a Jensen adjustment minus the inflation risk premium.

\section{A.2 Nominal and real term structure}

Proposition 1. Nominal bond yields are affine in the state vector:

$$
y_{t}^{\$}(\tau)=-\frac{A_{\tau}^{\$}}{\tau}-\frac{B_{\tau}^{\$ \prime}}{\tau} z_{t}
$$

where the coefficients $A_{\tau}^{\$}$ and $B_{\tau}^{\$}$ satisfy the following recursions:

$$
\begin{aligned}
A_{\tau+1}^{\$} & =-y_{0,1}^{\$}+A_{\tau}^{\$}+\frac{1}{2}\left(B_{\tau}^{\$}\right)^{\prime} \Sigma\left(B_{\tau}^{\$}\right)-\left(B_{\tau}^{\$}\right)^{\prime} \Sigma^{\frac{1}{2}} \Lambda_{0}, \\
\left(B_{\tau+1}^{\$}\right)^{\prime} & =\left(B_{\tau}^{\$}\right)^{\prime} \Psi-e_{y n}^{\prime}-\left(B_{\tau}^{\$}\right)^{\prime} \Sigma^{\frac{1}{2}} \Lambda_{1},
\end{aligned}
$$

initialized at $A_{0}^{\$}=0$ and $B_{0}^{\$}=0$.

Proof. We conjecture that the $t+1$-price of a $\tau$-period bond is exponentially affine in the state:

$$
\log \left(P_{t+1, \tau}^{\$}\right)=A_{\tau}^{\$}+\left(B_{\tau}^{\$}\right)^{\prime} z_{t+1}
$$

and solve for the coefficients $A_{\tau+1}^{\$}$ and $B_{\tau+1}^{\$}$ in the process of verifying this conjecture using the Euler 
equation:

$$
\begin{aligned}
P_{t, \tau+1}^{\$}= & \mathbb{E}_{t}\left[\exp \left\{m_{t+1}^{\$}+\log \left(P_{t+1, \tau}^{\$}\right)\right\}\right] \\
= & \mathbb{E}_{t}\left[\exp \left\{-y_{t, 1}^{\$}-\frac{1}{2} \Lambda_{t}^{\prime} \Lambda_{t}-\Lambda_{t}^{\prime} \varepsilon_{t+1}+A_{\tau}^{\$}+\left(B_{\tau}^{\$}\right)^{\prime} z_{t+1}\right\}\right] \\
= & \exp \left\{-y_{0,1}^{\$}-e_{y n}^{\prime} z_{t}-\frac{1}{2} \Lambda_{t}^{\prime} \Lambda_{t}+A_{\tau}^{\$}+\left(B_{\tau}^{\$}\right)^{\prime} \Psi z_{t}\right\} \times \\
& \mathbb{E}_{t}\left[\exp \left\{-\Lambda_{t}^{\prime} \varepsilon_{t+1}+\left(B_{\tau}^{\$}\right)^{\prime} \Sigma^{\frac{1}{2}} \varepsilon_{t+1}\right\}\right] .
\end{aligned}
$$

We use the log-normality of $\varepsilon_{t+1}$ and substitute for the affine expression for $\Lambda_{t}$ to get:

$$
P_{t, \tau+1}^{\$}=\exp \left\{-y_{0,1}^{\$}-e_{y n}^{\prime} z_{t}+A_{\tau}^{\$}+\left(B_{\tau}^{\$}\right)^{\prime} \Psi z_{t}+\frac{1}{2}\left(B_{\tau}^{\$}\right)^{\prime} \Sigma\left(B_{\tau}^{\$}\right)-\left(B_{\tau}^{\$}\right)^{\prime} \Sigma^{\frac{1}{2}}\left(\Lambda_{0}+\Lambda_{1} z_{t}\right)\right\} .
$$

Taking logs and collecting terms, we obtain a linear equation for $\log \left(p_{t}(\tau+1)\right)$ :

$$
\log \left(P_{t, \tau+1}^{\$}\right)=A_{\tau+1}^{\$}+\left(B_{\tau+1}^{\$}\right)^{\prime} z_{t}
$$

where $A_{\tau+1}^{\$}$ satisfies (16) and $B_{\tau+1}^{\$}$ satisfies (17). The relationship between log bond prices and bond yields is given by $-\log \left(P_{t, \tau}^{\$}\right) / \tau=y_{t, \tau}^{\$}$.

Define the one-period return on a nominal zero-coupon bond as:

$$
r_{t+1, \tau}^{b, \$}=\log \left(P_{t+1, \tau}^{\$}\right)-\log \left(P_{t, \tau+1}^{\$}\right)
$$

The nominal bond risk premium on a bond of maturity $\tau$ is the expected excess return corrected for a Jensen term, and equals negative the conditional covariance between that bond return and the nominal SDF:

$$
\begin{aligned}
\mathbb{E}_{t}\left[r_{t+1, \tau}^{b, \$}\right]-y_{t, 1}^{\$}+\frac{1}{2} \mathbb{V}_{t}\left[r_{t+1, \tau}^{b, \$}\right] & =-\mathbb{C}_{t}\left[m_{t+1}^{\$}, r_{t+1, \tau}^{b, \$}\right] \\
& =\left(B_{\tau}^{\$}\right)^{\prime} \Sigma^{\frac{1}{2}} \Lambda_{t}
\end{aligned}
$$

Real bond yields, $y_{t, \tau}$, denoted without the $\$$ superscript, are affine as well with coefficients that follow similar recursions:

$$
\begin{aligned}
& A_{\tau+1}=-y_{0,1}+A_{\tau}+\frac{1}{2} B_{\tau}^{\prime} \Sigma B_{\tau}-B_{\tau}^{\prime} \Sigma^{\frac{1}{2}}\left(\Lambda_{0}-\Sigma^{\frac{1}{2}} e_{\pi}\right), \\
& B_{\tau+1}^{\prime}=-e_{y n}^{\prime}+\left(e_{\pi}+B_{\tau}\right)^{\prime}\left(\Psi-\Sigma^{\frac{1}{2}} \Lambda_{1}\right) .
\end{aligned}
$$

For $\tau=1$, we recover the expression for the risk-free rate in (14)-(15). 


\section{A.3 Stock Market}

We define the real return on equity as $R_{t+1}^{m}=\frac{P_{t+1}^{m}+D_{t+1}^{m}}{P_{t}^{m}}$, where $P_{t}^{m}$ is the end-of-period price on the equity market. A log-linearization delivers:

$$
r_{t+1}^{m}=\kappa_{0}^{m}+\Delta d_{t+1}^{m}+\kappa_{1}^{m} p d_{t+1}^{m}-p d_{t}^{m} .
$$

The unconditional mean log real stock return is $r_{0}^{m}=\mathbb{E}\left[r_{t}^{m}\right]$, the unconditional mean dividend growth rate is $\mu^{m}=\mathbb{E}\left[\Delta d_{t+1}^{m}\right]$, and $\overline{p d^{m}}=\mathbb{E}\left[p d_{t}^{m}\right]$ is the unconditional average log price-dividend ratio on equity. The linearization constants $\kappa_{0}^{m}$ and $\kappa_{1}^{m}$ are defined as:

$$
\kappa_{1}^{m}=\frac{e^{\overline{p d^{m}}}}{e^{\overline{p d^{m}}}+1}<1 \text { and } \kappa_{0}^{m}=\log \left(e^{\overline{p d^{m}}}+1\right)-\frac{e^{\overline{p d^{m}}}}{e^{\overline{p d^{m}}}+1} \overline{p d^{m}}
$$

Our state vector $z$ contains the (demeaned) log real dividend growth rate on the stock market, $\Delta d_{t+1}^{m}-$ $\mu^{m}$, and the (demeaned) log price-dividend ratio $p d^{m}-\overline{p d^{m}}$.

$$
\begin{aligned}
p d_{t}^{m}(\tau) & =\overline{p d^{m}}+e_{p d}^{\prime} z_{t} \\
\Delta d_{t}^{m} & =\mu^{m}+e_{d i v m}^{\prime} z_{t}
\end{aligned}
$$

where $e_{p d}^{\prime}\left(e_{\text {divm }}\right)$ is a selector vector that has a one in the fifth (sixth) entry, since the log pd ratio (log dividend growth rate) is the fifth (sixth) element of the VAR.

We define the log return on the stock market so that the return equation holds exactly, given the time series for $\left\{\Delta d_{t}^{m}, p d_{t}^{m}\right\}$. Rewriting (20):

$$
\begin{aligned}
r_{t+1}^{m}-r_{0}^{m} & =\left[\left(e_{\text {divm }}+\kappa_{1}^{m} e_{p d}\right)^{\prime} \Psi-e_{p d}^{\prime}\right] z_{t}+\left(e_{\text {divm }}+\kappa_{1}^{m} e_{p d}\right)^{\prime} \Sigma^{\frac{1}{2}} \varepsilon_{t+1} . \\
r_{0}^{m} & =\mu^{m}+\kappa_{0}^{m}-\overline{p d^{m}}\left(1-\kappa_{1}^{m}\right) .
\end{aligned}
$$

The equity risk premium is the expected excess return on the stock market corrected for a Jensen term. By the Euler equation, it equals minus the conditional covariance between the log SDF and the log return:

$$
\begin{aligned}
1= & \mathbb{E}_{t}\left[M_{t+1} \frac{P_{t+1}^{m}+D_{t+1}^{m}}{P_{t}^{m}}\right]=E_{t}\left[\exp \left\{m_{t+1}^{\$}+\pi_{t+1}+r_{t+1}^{m}\right\}\right] \\
= & \mathbb{E}_{t}\left[\exp \left\{-y_{t, 1}^{\$}-\frac{1}{2} \Lambda_{t}^{\prime} \Lambda_{t}-\Lambda_{t}^{\prime} \varepsilon_{t+1}+\pi_{0}+e_{\pi}^{\prime} z_{t+1}+r_{0}^{m}+\left(e_{\text {divm }}+\kappa_{1}^{m} e_{p d}\right)^{\prime} z_{t+1}-e_{p d}^{\prime} z_{t}\right\}\right] \\
= & \exp \left\{-y_{0}^{\$}(1)-\frac{1}{2} \Lambda_{t}^{\prime} \Lambda_{t}+\pi_{0}+r_{0}^{m}+\left[\left(e_{\text {divm }}+\kappa_{1}^{m} e_{p d}+e_{\pi}\right)^{\prime} \Psi-e_{p d}^{\prime}-e_{y n}^{\prime}\right] z_{t}\right\} \\
& \times \mathbb{E}_{t}\left[\exp \left\{-\Lambda_{t}^{\prime} \varepsilon_{t+1}+\left(e_{\text {divm }}+\kappa_{1}^{m} e_{p d}+e_{\pi}\right)^{\prime} \Sigma^{\frac{1}{2}} \varepsilon_{t+1}\right]\right. \\
= & \exp \left\{r_{0}^{m}+\pi_{0}-y_{0}^{\$}(1)+\left[\left(e_{\text {divm }}+\kappa_{1}^{m} e_{p d}+e_{\pi}\right)^{\prime} \Psi-e_{p d}^{\prime}-e_{y n}^{\prime}\right] z_{t}\right\} \\
& \times \exp \left\{\frac{1}{2}\left(e_{\text {divm }}+\kappa_{1}^{m} e_{p d}+e_{\pi}\right)^{\prime} \Sigma\left(e_{\text {divm }}+\kappa_{1}^{m} e_{p d}+e_{\pi}\right)-\left(e_{\text {divm }}+\kappa_{1}^{m} e_{p d}+e_{\pi}\right)^{\prime} \Sigma^{\frac{1}{2}} \Lambda_{t}\right\}
\end{aligned}
$$


Taking logs on both sides delivers:

$$
\begin{aligned}
r_{0}^{m}+\pi_{0}-y_{0}^{\$}(1)+\left[\left(e_{\text {divm }}+\kappa_{1}^{m} e_{p d}+e_{\pi}\right)^{\prime} \Psi-e_{p d}^{\prime}-e_{y n}^{\prime}\right] z_{t} & \\
+\frac{1}{2}\left(e_{\text {divm }}+\kappa_{1}^{m} e_{p d}+e_{\pi}\right)^{\prime} \Sigma\left(e_{\text {divm }}+\kappa_{1}^{m} e_{p d}+e_{\pi}\right) & =\left(e_{\text {divm }}+\kappa_{1}^{m} e_{p d}+e_{\pi}\right)^{\prime} \Sigma^{\frac{1}{2}} \Lambda_{t} \\
\mathbb{E}_{t}\left[r_{t+1}^{m, \$}\right]-y_{t, 1}^{\$}+\frac{1}{2} \mathbb{V}_{t}\left[r_{t+1}^{m, \$}\right] & =-\mathbb{C}_{t}\left[m_{t+1}^{\$} r_{t+1}^{m, \$}\right]
\end{aligned}
$$

The left-hand side is the expected excess return on the stock market, corrected for a Jensen term, while the right-hand side is the negative of the conditional covariance between the (nominal) log stock return and the nominal log SDF. We refer to the left-hand side as the equity risk premium in the data, since it is

implied directly by the VAR. We refer to the right-hand side as the equity risk premium in the model, since it requires knowledge of the market prices of risk.

Note that we can obtain the same expression using the log real SDF and log real stock return:

$$
\begin{aligned}
\mathbb{E}_{t}\left[r_{t+1}^{m}\right]-y_{t, 1}+\frac{1}{2} \mathbb{V}_{t}\left[r_{t+1}^{m}\right] & =-\mathbb{C}_{t}\left[m_{t+1}, r_{t+1}^{m}\right] \\
r_{0}^{m}-y_{0}(1) & +\left[\left(e_{\text {divm }}+\kappa_{1}^{m} e_{p d}+e_{\pi}\right)^{\prime} \Psi-e_{p d}^{\prime}-e_{y n}^{\prime}-e_{\pi}^{\prime} \Sigma^{1 / 2} \Lambda_{1}\right] z_{t} \\
+\frac{1}{2}\left(e_{\text {divm }}+\kappa_{1}^{m} e_{p d}\right)^{\prime} \Sigma\left(e_{\text {divm }}+\kappa_{1}^{m} e_{p d}\right) & =\left(e_{\text {divm }}+\kappa_{1}^{m} e_{p d}\right)^{\prime} \Sigma^{1 / 2}\left(\Lambda_{t}-\left(\Sigma^{1 / 2}\right)^{\prime} e_{\pi}\right)
\end{aligned}
$$

We combine the terms in $\Lambda_{0}$ and $\Lambda_{1}$ on the right-hand side and plug in for $y_{0}(1)$ from (15) to get:

$$
\begin{aligned}
r_{0}^{m}+\pi_{0}-y_{0,1}^{\$}+\frac{1}{2} e_{\pi}^{\prime} \Sigma e_{\pi} & +\frac{1}{2}\left(e_{\text {divm }}+\kappa_{1}^{m} e_{p d}\right)^{\prime} \Sigma\left(e_{\text {divm }}+\kappa_{1}^{m} e_{p d}\right)+e_{\pi}^{\prime} \Sigma\left(e_{\text {divm }}+\kappa_{1}^{m} e_{p d}\right) \\
+\left[\left(e_{\text {divm }}+\kappa_{1}^{m} e_{p d}+e_{\pi}\right)^{\prime} \Psi-e_{p d}^{\prime}-e_{y n}^{\prime}\right] z_{t}= & \left(e_{\text {divm }}+\kappa_{1}^{m} e_{p d}\right)^{\prime} \Sigma^{1 / 2} \Lambda_{t}+e_{\pi}^{\prime} \Sigma^{\frac{1}{2}} \Lambda_{0}+e_{\pi}^{\prime} \Sigma^{1 / 2} \Lambda_{1} z_{t}
\end{aligned}
$$

This recovers equation (22).

\section{A.4 Dividend Strips}

\section{A.4.1 Affine Structure for Price-Dividend Ratio on Equity Strip}

Proposition 2. Log price-dividend ratios on dividend strips are affine in the state vector:

$$
p_{t, \tau}^{d}=\log \left(P_{t, \tau}^{d}\right)=A_{\tau}^{m}+B_{\tau}^{m \prime} z_{t},
$$

where the coefficients $A_{\tau}^{m}$ and $B_{\tau}^{m}$ follow recursions:

$$
\begin{aligned}
A_{\tau+1}^{m}= & A_{\tau}^{m}+\mu_{m}-y_{0}(1)+\frac{1}{2}\left(e_{\text {divm }}+B_{\tau}^{m}\right)^{\prime} \Sigma\left(e_{\text {divm }}+B_{\tau}^{m}\right) \\
& -\left(e_{\text {divm }}+B_{\tau}^{m}\right)^{\prime} \Sigma^{\frac{1}{2}}\left(\Lambda_{0}-\Sigma^{\frac{1}{2}} e_{\pi}\right), \\
B_{\tau+1}^{m \prime}= & \left(e_{\text {divm }}+e_{\pi}+B_{\tau}^{m}\right)^{\prime} \Psi-e_{y n}^{\prime}-\left(e_{\text {divm }}+e_{\pi}+B_{\tau}^{m}\right)^{\prime} \Sigma^{\frac{1}{2}} \Lambda_{1},
\end{aligned}
$$

initialized at $A_{0}^{m}=0$ and $B_{0}^{m}=0$. 
Proof. We conjecture the affine structure and solve for the coefficients $A_{\tau+1}^{m}$ and $B_{\tau+1}^{m}$ in the process of verifying this conjecture using the Euler equation:

$$
\begin{aligned}
P_{t, \tau+1}^{d}= & \mathbb{E}_{t}\left[M_{t+1} P_{t+1, \tau}^{d} \frac{D_{t+1}^{m}}{D_{t}^{m}}\right]=E_{t}\left[\exp \left\{m_{t+1}^{\$}+\pi_{t+1}+\Delta d_{t+1}^{m}+p_{t+1}^{d}(\tau)\right\}\right] \\
= & \mathbb{E}_{t}\left[\exp \left\{-y_{t, 1}^{\$}-\frac{1}{2} \Lambda_{t}^{\prime} \Lambda_{t}-\Lambda_{t}^{\prime} \varepsilon_{t+1}+\pi_{0}+e_{\pi}^{\prime} z_{t+1}+\mu^{m}+e_{d i v m}^{\prime} z_{t+1}+A_{\tau}^{m}+B_{\tau}^{m \prime} z_{t+1}\right\}\right] \\
= & \exp \left\{-y_{0}^{\$}(1)-e_{y n}^{\prime} z_{t}-\frac{1}{2} \Lambda_{t}^{\prime} \Lambda_{t}+\pi_{0}+e_{\pi}^{\prime} \Psi z_{t}+\mu_{m}+e_{d i v m}^{\prime} \Psi z_{t}+A_{\tau}^{m}+B_{\tau}^{m /} \Psi z_{t}\right\} \\
& \times \mathbb{E}_{t}\left[\exp \left\{-\Lambda_{t}^{\prime} \varepsilon_{t+1}+\left(e_{d i v m}+e_{\pi}+B_{\tau}^{m}\right)^{\prime} \Sigma^{\frac{1}{2}} \varepsilon_{t+1}\right] .\right.
\end{aligned}
$$

We use the log-normality of $\varepsilon_{t+1}$ and substitute for the affine expression for $\Lambda_{t}$ to get:

$$
\begin{aligned}
P_{t, \tau+1}^{d}= & \exp \left\{-y_{0}^{\$}(1)+\pi_{0}+\mu_{m}+A_{\tau}^{m}+\left[\left(e_{\text {divm }}+e_{\pi}+B_{\tau}^{m}\right)^{\prime} \Psi-e_{y n}^{\prime}\right] z_{t}\right. \\
& +\frac{1}{2}\left(e_{\text {divm }}+e_{\pi}+B_{\tau}^{m}\right)^{\prime} \Sigma\left(e_{\text {divm }}+e_{\pi}+B_{\tau}^{m}\right) \\
& \left.-\left(e_{\text {divm }}+e_{\pi}+B_{\tau}^{m}\right)^{\prime} \Sigma^{\frac{1}{2}}\left(\Lambda_{0}+\Lambda_{1} z_{t}\right)\right\}
\end{aligned}
$$

Taking logs and collecting terms, we obtain a log-linear expression for $p_{t}^{d}(\tau+1)$ :

$$
p_{t, \tau+1}^{d}=A_{\tau+1}^{m}+B_{\tau+1}^{m \prime} z_{t}
$$

where:

$$
\begin{aligned}
A_{\tau+1}^{m}= & A_{\tau}^{m}+\mu_{m}-y_{0}^{\$}(1)+\pi_{0}+\frac{1}{2}\left(e_{\text {divm }}+e_{\pi}+B_{\tau}^{m}\right)^{\prime} \Sigma\left(e_{\text {divm }}+e_{\pi}+B_{\tau}^{m}\right) \\
& -\left(e_{\text {divm }}+e_{\pi}+B_{\tau}^{m}\right)^{\prime} \Sigma^{\frac{1}{2}} \Lambda_{0}, \\
B_{\tau+1}^{m \prime}= & \left(e_{\text {divm }}+e_{\pi}+B_{\tau}^{m}\right)^{\prime} \Psi-e_{y n}^{\prime}-\left(e_{\text {divm }}+e_{\pi}+B_{\tau}^{m}\right)^{\prime} \Sigma^{\frac{1}{2}} \Lambda_{1} .
\end{aligned}
$$

We recover the recursions in (23) and (24) after using equation (15).

Like we did for the stock market as a whole, we define the strip risk premium as:

$$
\begin{aligned}
\mathbb{E}_{t}\left[r_{t+1, \tau}^{d, \$}\right]-y_{t, 1}^{\$}+\frac{1}{2} \mathbb{V}_{t}\left[r_{t+1, \tau}^{d, \$}\right] & =-\mathbb{C}_{t}\left[m_{t+1}^{\$}, r_{t+1, \tau}^{d, \$}\right] \\
& =\left(e_{\text {divm }}+e_{\pi}+B_{\tau}^{m}\right)^{\prime} \Sigma^{\frac{1}{2}} \Lambda_{t}
\end{aligned}
$$

The risky strips for REITs, infrastructure, small stocks, growth stocks, and natural resources are defined analogously. 


\section{A.4.2 Expected Holding Period Return over k-horizons on Dividend Strips}

The expected return on a dividend strip that pays the realized nominal dividend $k$ quarters hence and that is held to maturity is:

$$
\begin{aligned}
\mathbb{E}_{t}\left[R_{t \rightarrow t+k}\right] & =\frac{\mathbb{E}_{t}\left[\frac{D_{t+k}^{\$}}{D_{t}^{\$}}\right]}{P_{t, k}^{d}}-1 \\
& =\exp \left(-A_{k}^{m}-B_{k}^{m \prime} z_{t}+\mathbb{E}_{t}\left[\sum_{s=1}^{k} \Delta d_{t+s}+\pi_{t+s}\right]+\frac{1}{2} \mathbb{V}_{t}\left[\sum_{s=1}^{k} \Delta d_{t+s}+\pi_{t+s}\right]\right)-1 \\
& =\exp \left(-A_{k}^{m}-B_{k}^{m \prime} z_{t}+k\left(\mu_{m}+\pi_{0}\right)+\left(e_{\text {divm }}+e_{\pi}\right)^{\prime}\left[\sum_{s=1}^{k} \Psi^{s}\right] z_{t}+\frac{k}{2}\left(e_{\text {divm }}+e_{\pi}\right)^{\prime} \Sigma\left(e_{\text {divm }}+e_{\pi}\right)\right)-1
\end{aligned}
$$

These are the building blocks for computing the expected return on a PE investment.

\section{A.4.3 Dividend Futures: Price and Return}

The price of a dividend futures contract which delivers one quarter worth of nominal dividends at quarter $t+\tau$, divided by the current dividend, is equal to:

$$
\frac{F_{t, \tau}^{d}}{D_{t}^{\$}}=P_{t, \tau}^{d} \exp \left(\tau y_{t, \tau}^{\$}\right)
$$

where $P_{t, \tau}^{d}$ is the spot price-dividend ratio. Using the affine expressions for the strip price-dividend ratio and the nominal bond price, it can be written as:

$$
\frac{F_{t, \tau}^{d}}{D_{t}^{\$}}=\exp \left(A_{\tau}^{m}-A_{\tau}^{\$}+\left(B_{\tau}^{m}-B_{\tau}^{\$}\right)^{\prime} z_{t}\right),
$$

The one-period holding period return on the dividend future of maturity $\tau$ is:

$$
R_{t+1, \tau}^{f u t, d}=\frac{F_{t+1, \tau-1}^{d}}{F_{t, \tau}^{d}}-1=\frac{F_{t+1, \tau-1}^{d} / D_{t+1}^{\$}}{F_{t, \tau}^{d} / D_{t}^{\$}} \frac{D_{t+1}^{\$}}{D_{t}^{\$}}-1
$$

It can be written as:

$$
\begin{aligned}
\log \left(1+R_{t+1, \tau}^{f u t, d}\right)= & A_{\tau-1}^{m}-A_{\tau-1}^{\$}-A_{\tau}^{m}+A_{\tau}^{\$}+\mu_{m}+\pi_{0} \\
& +\left(B_{\tau-1}^{m}-B_{\tau-1}^{\$}+e_{\text {divm }}+e_{\pi}\right)^{\prime} z_{t+1}-\left(B_{\tau}^{m}-B_{\tau}^{\$}\right)^{\prime} z_{t}
\end{aligned}
$$

The expected log return, which is already a risk premium on account of the fact that the dividend future already takes out the return on an equal-maturity nominal Treasury bond, equals:

$$
\begin{aligned}
\mathbb{E}_{t}\left[\log \left(1+R_{t+1, \tau}^{f u t, d}\right)\right]= & A_{\tau-1}^{m}-A_{\tau-1}^{\$}-A_{\tau}^{m}+A_{\tau}^{\$}+\mu_{m}+\pi_{0} \\
& +\left[\left(B_{\tau-1}^{m}-B_{\tau-1}^{\$}+e_{\text {divm }}+e_{\pi}\right)^{\prime} \Psi-\left(B_{\tau}^{m}-B_{\tau}^{\$}\right)^{\prime}\right] z_{t}
\end{aligned}
$$


Given that the state variable $z_{t}$ is mean-zero, the first row denotes the unconditional dividend futures risk premium.

\section{A.5 Capital Gain Strips}

A capital gain strip is a strip that pays the realized ex-dividend stock price $P_{t+k}^{m}$ at time $t+k$. For convenience, we scale this payout by the current stock price $P_{t}^{m}$. In other words, the claim pays off the realized cumulative capital gain between periods $t$ and $t+k, \frac{P_{t+k}^{m}}{P_{t}^{m}}$.

By value additivity of the dividend strips, the time-t price of this claim is today's stock price minus the prices of the dividend strips of horizons $1, \cdots, k$ :

$$
\frac{P_{t}^{m}-\left(P_{t, 1}^{d}+\cdots+P_{t, k}^{d}\right) D_{t}^{m}}{P_{t}^{m}}=1-\frac{P_{t, 1}^{d}+\cdots+P_{t, k}}{P_{t}^{m} / D_{t}^{m}}=1-\frac{\sum_{\tau=1}^{k} \exp \left\{A_{\tau}^{m}+\left(B_{\tau}^{m}\right)^{\prime} z_{t}\right\}}{\exp \left\{\overline{p d^{m}}+e_{p d m}^{\prime} z_{t}\right\}}
$$

The expected return on the capital gains strip is given by

$$
\begin{aligned}
& \frac{\mathbb{E}_{t}\left[P_{t+k}^{m}\right]}{P_{t}^{m}-\left(P_{t, 1}^{d}+\cdots+P_{t, k}^{d}\right) D_{t}^{m}}=\frac{\mathbb{E}_{t}\left[\frac{P_{t+k}^{m}}{P_{t}^{m}}\right]}{1-\frac{\sum_{\tau=1}^{k} \exp \left\{A_{\tau}^{m}+\left(B_{\tau}^{m}\right)^{\prime} z_{t}\right\}}{\exp \left\{\overline{p d^{m}}+e_{p d m}^{\prime} z_{t}\right\}}}=\frac{\mathbb{E}_{t}\left[\frac{P_{t+k}^{m} / D_{t+k}^{m}}{P_{t}^{m} / D_{t}^{m}} \frac{D_{t+k}^{m}}{D_{t}^{m}}\right]}{1-\frac{\sum_{\tau=1}^{k} \exp \left\{A_{\tau}^{m}+\left(B_{\tau}^{m}\right)^{\prime} z_{t}\right\}}{\exp \left\{\overline{p d^{m}}+e_{p d m}^{\prime} z_{t}\right\}}} \\
& =\frac{\mathbb{E}_{t}\left[\exp \left\{e_{p d m}^{\prime}\left(z_{t+k}-z_{t}\right)+\Delta d_{t+k}^{\$}+\cdots+\Delta d_{t+1}^{\$}\right\}\right]}{1-\frac{\sum_{\tau=1}^{k} \exp \left\{A_{\tau}^{m}+\left(B_{\tau}^{m}\right)^{\prime} z_{t}\right\}}{\exp \left\{\overline{p d^{m}}+e_{p d m}^{\prime} z_{t}\right\}}} \\
& =\frac{\mathbb{E}_{t}\left[\exp \left\{e_{p d m}^{\prime}\left(z_{t+k}-z_{t}\right)+k\left(\mu_{m}+\pi_{0}\right)+\sum_{\tau=1}^{k}\left(e_{\text {divm }}+e_{\pi}\right)^{\prime} z_{t+\tau}\right\}\right]}{1-\frac{\sum_{\tau=1}^{k} \exp \left\{A_{\tau}^{m}+\left(B_{\tau}^{m}\right)^{\prime} z_{t}\right\}}{\exp \left\{\overline{d^{m}}+e_{p d m}^{\prime} z_{t}\right\}}} \\
& =\frac{\exp \left\{k\left(\mu_{m}+\pi_{0}\right)+\left[e_{p d m}^{\prime}\left(\Psi^{k}-I\right)+\left(e_{d i v m}+e_{\pi}\right)^{\prime} \sum_{\tau=1}^{k}(\Psi)^{\tau}\right] z_{t}+\frac{1}{2} \mathcal{V}\right\}}{1-\frac{\sum_{\tau=1}^{k} \exp \left\{A_{\tau}^{m}+\left(B_{\tau}^{m}\right)^{\prime} z_{t}\right\}}{\exp \left\{\overline{p d^{m}}+e_{p d m}^{\prime} z_{t}\right\}}}
\end{aligned}
$$

where

$$
\mathcal{V}=e_{p d m}^{\prime}\left[\sum_{\tau=1}^{k} \Psi^{\tau-1} \Sigma\left(\Psi^{\tau-1}\right)^{\prime}\right] e_{p d m}+\left(e_{\text {divm }}+e_{\pi}\right)^{\prime}\left[\sum_{\tau=1}^{k} \sum_{n=1}^{\tau} \Psi^{n-1} \Sigma \Psi^{n-1}\right]\left(e_{\text {divm }}+e_{\pi}\right)
$$

\section{A.6 Covariance PE with stock and bond returns}

The covariance of PE fund returns with stock returns and with bond returns is given by the covariance of the PE fund's replication portfolio return with stock and bond returns. The return on the replicating portfolio is the weighted average of the return on the strips that make up the portfolio. The weights are described in equation (2), where $w^{i}$ is a $1 \times H K$ vector with generic element $w_{t, h, k}^{i}=q_{t, h}^{i}(k) P_{t, h}(k)$. The weights sum to one. We focus on the one-period, conditional stock beta $\beta_{t, m}^{i}$ and bond beta $\beta_{t, b}^{i}$ of PE fund 
$i$. For the bond beta, we focus on the beta with the nominal five-year bond $(\tau=20)$.

$$
\begin{aligned}
\beta_{t, m}^{i} & =\frac{\mathbb{C}_{t}\left(r_{t+1}^{i}, r_{t+1}^{m}\right)}{\mathbb{V}_{t}\left(r_{t+1}^{m}\right)}=\frac{\mathbb{C}_{t}\left(\sum_{h, k}^{H K} w_{t, h, k}^{i} r_{t+1, h, k}, r_{t+1}^{m}\right)}{\mathbb{V}_{t}\left(r_{t+1}^{m}\right)}=\frac{\sum_{h, k}^{H K} w_{t, h, k}^{i} \mathbb{C}_{t}\left(r_{t+1, h}(k), r_{t+1}^{m}\right)}{\mathbb{V}_{t}\left(r_{t+1}^{m}\right)} \\
& =\frac{\sum_{h, k}^{H K} w_{t, h, k}^{i}\left(e_{\text {strip }, k, h}\right)^{\prime} \Sigma\left(e_{\text {divm }}+e_{\pi}+\kappa_{1}^{m} e_{p d}\right)}{\left(e_{\text {divm }}+e_{\pi}+\kappa_{1}^{m} e_{p d}\right)^{\prime} \Sigma\left(e_{\text {divm }}+e_{\pi}+\kappa_{1}^{m} e_{p d}\right)} \\
\beta_{t, b}^{i} & =\frac{\sum_{h, k}^{H K} w_{t, h}^{i}(k)\left(e_{\text {strip }, k, h}\right)^{\prime} \Sigma\left(B_{20}^{\$}\right)}{\left(B_{20}^{\$}\right)^{\prime} \Sigma\left(B_{20}^{\$}\right)}
\end{aligned}
$$

For example, the three factor model for Real Estate PE funds implies that:

$$
\begin{aligned}
& e_{\text {strip }, 1, h}=B_{h}^{\$} \\
& e_{\text {strip }, 2, h}=e_{\text {divm }}+e_{\pi}+B_{h}^{m} \\
& e_{\text {strip }, 3, h}=e_{\text {divreit }}+e_{\pi}+B_{h}^{\text {reit }}
\end{aligned}
$$

As another example, the three-factor model for VC funds implies:

$$
\begin{aligned}
& e_{\text {strip }, 1, h}=B_{h}^{\$} \\
& e_{\text {strip }, 2, h}=e_{\text {divsmall }}+e_{\pi}+B_{h}^{\text {small }} \\
& e_{\text {strip }, 3, h}=e_{\text {divgrowth }}+e_{\pi}+B_{h}^{\text {growth }}
\end{aligned}
$$

Similar expressions are obtained for the other fund categories and for models with fewer or more risk factors. 


\section{B Point Estimates Baseline Model}

\section{B.1 VAR Estimation}

In the first stage we estimate the VAR companion matrix by OLS, equation by equation. We start from an initial VAR where all elements of $\Psi$ are non-zero. We zero out the elements whose t-statistic is less than 1.96. We then re-estimate $\Psi$ and zero out the elements whose t-statistic is less than 1.96. We continue this procedure until the $\Psi$ matrix no longer changes and all remaining elements have t-statistic greater than 1.96. The resulting VAR companion matrix estimate, $\widehat{\Psi}$, is listed below.

\begin{tabular}{|c|c|c|c|c|c|c|c|c|c|c|c|c|c|c|c|c|c|}
\hline 0.90 & 0.00 & 0.00 & 0.00 & 0.00 & 0.00 & 0.00 & 0.00 & 0.00 & 0.00 & 0.00 & 0.00 & 0.00 & 0.00 & 0.00 & 0.00 & 0.00 & 0.00 \\
\hline 0.00 & 0.21 & 0.00 & 0.00 & 0.02 & 0.00 & 0.01 & 0.00 & -0.02 & 0.00 & 0.00 & 0.00 & 0.00 & 0.00 & 0.00 & 0.00 & 0.00 & 0.00 \\
\hline 0.07 & 0.00 & 0.95 & 0.00 & 0.00 & 0.00 & 0.00 & 0.00 & 0.00 & 0.00 & 0.00 & 0.00 & 0.00 & 0.00 & 0.00 & 0.00 & 0.00 & 0.00 \\
\hline 0.00 & 0.00 & 0.00 & 0.83 & 0.00 & 0.00 & 0.00 & 0.00 & 0.00 & 0.00 & 0.00 & 0.00 & 0.00 & 0.00 & 0.00 & 0.00 & 0.00 & 0.00 \\
\hline-4.77 & 0.00 & 0.00 & 0.00 & 0.96 & 0.00 & -0.07 & 0.00 & 0.00 & 0.65 & 0.00 & 0.00 & 0.00 & 0.00 & 0.00 & 0.00 & 0.00 & 0.00 \\
\hline 0.00 & 0.00 & 0.00 & 0.00 & 0.00 & 0.37 & 0.02 & 0.00 & 0.00 & 0.00 & 0.00 & 0.00 & 0.00 & 0.00 & 0.00 & 0.00 & 0.00 & 0.00 \\
\hline 0.00 & 0.00 & -3.66 & 0.00 & 0.00 & 0.00 & 0.89 & 0.00 & 0.00 & 0.00 & 0.00 & 0.00 & 0.00 & 0.00 & 0.00 & 0.00 & 0.00 & 0.00 \\
\hline 0.00 & 0.00 & 1.97 & 0.00 & 0.07 & 0.00 & 0.09 & 0.00 & -0.07 & 0.00 & 0.00 & 0.00 & 0.00 & 0.00 & 0.00 & 0.00 & 0.00 & 0.00 \\
\hline 0.00 & 0.00 & 0.00 & 0.00 & 0.08 & 0.00 & 0.00 & 0.00 & 0.92 & 0.00 & 0.00 & 0.00 & 0.00 & 0.00 & 0.00 & 0.00 & 0.00 & 0.00 \\
\hline 0.00 & 0.00 & 0.00 & 0.00 & -0.05 & 0.00 & 0.00 & 0.00 & 0.05 & 0.00 & 0.00 & 0.00 & 0.00 & 0.00 & 0.00 & 0.00 & 0.00 & 0.00 \\
\hline-9.33 & 0.00 & 0.00 & 0.00 & 0.00 & 0.00 & 0.00 & 0.00 & 0.00 & 0.00 & 0.87 & 0.00 & 0.00 & 0.00 & 0.00 & 0.00 & 0.00 & 0.00 \\
\hline 0.00 & 0.00 & 0.00 & -6.72 & 0.00 & 0.00 & 0.00 & 0.00 & 0.00 & 0.00 & 0.00 & 0.00 & 0.00 & 0.00 & 0.00 & 0.00 & 0.00 & 0.00 \\
\hline-3.00 & 0.00 & 0.00 & 0.00 & 0.00 & 0.00 & 0.00 & 0.00 & 0.00 & 0.54 & 0.00 & 0.00 & 0.93 & 0.00 & 0.00 & 0.00 & 0.00 & 0.00 \\
\hline 0.00 & 0.00 & 0.00 & 0.00 & 0.00 & 0.00 & 0.00 & -0.21 & 0.00 & 0.00 & 0.00 & 0.00 & 0.00 & 0.00 & 0.00 & 0.00 & 0.00 & 0.00 \\
\hline 0.00 & 0.00 & 0.00 & 0.00 & 0.31 & 0.00 & 0.00 & 0.00 & -0.15 & 0.00 & 0.00 & 0.00 & -0.26 & 0.00 & 0.83 & -0.36 & 0.00 & 0.00 \\
\hline 0.00 & 0.00 & 0.00 & 0.00 & 0.00 & 0.00 & 0.00 & 0.00 & 0.00 & 0.00 & 0.00 & 0.00 & 0.00 & 0.00 & 0.04 & 0.49 & 0.00 & 0.00 \\
\hline 0.00 & 2.73 & -10.68 & 0.00 & 0.58 & 0.00 & 0.00 & -0.72 & 0.00 & 0.00 & 0.00 & 0.00 & -0.36 & 0.00 & 0.00 & 0.00 & 0.67 & -0.31 \\
\hline 0.00 & 0.00 & 6.90 & 0.00 & -0.49 & 0.00 & -0.09 & 0.56 & 0.00 & 0.00 & 0.05 & 0.00 & 0.22 & 0.00 & 0.00 & 0.00 & 0.29 & 0.43 \\
\hline
\end{tabular}


The Cholesky decomposition of the residual variance-covariance matrix, $\Sigma^{\frac{1}{2}}$, multiplied by 100 for readability is given by:

\begin{tabular}{|c|c|c|c|c|c|c|c|c|c|c|c|c|c|c|c|c|c|}
\hline 0.25 & 0.00 & 0.00 & 0.00 & 0.00 & 0.00 & 0.00 & 0.00 & 0.00 & 0.00 & 0.00 & 0.00 & 0.00 & 0.00 & 0.00 & 0.00 & 0.00 & 0.00 \\
\hline 0.04 & 0.67 & 0.00 & 0.00 & 0.00 & 0.00 & 0.00 & 0.00 & 0.00 & 0.00 & 0.00 & 0.00 & 0.00 & 0.00 & 0.00 & 0.00 & 0.00 & 0.00 \\
\hline 0.03 & 0.06 & 0.17 & 0.00 & 0.00 & 0.00 & 0.00 & 0.00 & 0.00 & 0.00 & 0.00 & 0.00 & 0.00 & 0.00 & 0.00 & 0.00 & 0.00 & 0.00 \\
\hline-0.01 & -0.01 & -0.08 & 0.09 & 0.00 & 0.00 & 0.00 & 0.00 & 0.00 & 0.00 & 0.00 & 0.00 & 0.00 & 0.00 & 0.00 & 0.00 & 0.00 & 0.00 \\
\hline-1.42 & 1.11 & -1.22 & -0.61 & 8.08 & 0.00 & 0.00 & 0.00 & 0.00 & 0.00 & 0.00 & 0.00 & 0.00 & 0.00 & 0.00 & 0.00 & 0.00 & 0.00 \\
\hline-0.03 & -0.07 & 0.11 & -0.14 & -0.17 & 2.13 & 0.00 & 0.00 & 0.00 & 0.00 & 0.00 & 0.00 & 0.00 & 0.00 & 0.00 & 0.00 & 0.00 & 0.00 \\
\hline-0.82 & 0.91 & -1.17 & -0.59 & 5.42 & 0.80 & 7.46 & 0.00 & 0.00 & 0.00 & 0.00 & 0.00 & 0.00 & 0.00 & 0.00 & 0.00 & 0.00 & 0.00 \\
\hline 0.29 & -0.06 & 0.04 & -0.15 & 0.03 & 0.62 & -1.51 & 3.21 & 0.00 & 0.00 & 0.00 & 0.00 & 0.00 & 0.00 & 0.00 & 0.00 & 0.00 & 0.00 \\
\hline-0.58 & 0.70 & -0.93 & -0.76 & 6.39 & 0.97 & 0.34 & 0.51 & 4.45 & 0.00 & 0.00 & 0.00 & 0.00 & 0.00 & 0.00 & 0.00 & 0.00 & 0.00 \\
\hline-0.08 & 0.09 & 0.07 & -0.10 & -0.42 & 0.52 & -0.08 & -0.07 & -0.59 & 1.89 & 0.00 & 0.00 & 0.00 & 0.00 & 0.00 & 0.00 & 0.00 & 0.00 \\
\hline-2.31 & 1.64 & -1.69 & -0.10 & 10.10 & -0.06 & 0.77 & 0.89 & 0.10 & -0.07 & 8.57 & 0.00 & 0.00 & 0.00 & 0.00 & 0.00 & 0.00 & 0.00 \\
\hline 0.17 & -0.02 & 0.73 & 0.04 & -0.70 & 3.09 & 0.24 & 0.37 & -0.89 & 0.51 & -4.72 & 4.95 & 0.00 & 0.00 & 0.00 & 0.00 & 0.00 & 0.00 \\
\hline-1.62 & 1.40 & -1.29 & -0.97 & 8.18 & -1.25 & -1.48 & -0.66 & -1.09 & 0.74 & 0.57 & -0.17 & 4.55 & 0.00 & 0.00 & 0.00 & 0.00 & 0.00 \\
\hline 0.03 & -0.18 & -0.12 & -0.04 & -0.28 & 3.03 & -0.01 & 0.15 & 0.75 & -0.38 & -0.32 & -0.09 & -2.85 & 2.68 & 0.00 & 0.00 & 0.00 & 0.00 \\
\hline-0.14 & 0.38 & -0.26 & -0.94 & 3.48 & 0.65 & 0.35 & 1.23 & 4.49 & 0.17 & 0.24 & 0.38 & 0.36 & -0.17 & 6.69 & 0.00 & 0.00 & 0.00 \\
\hline 0.00 & 0.09 & -0.13 & -0.10 & -0.03 & -0.27 & 0.54 & -0.65 & -0.66 & 0.85 & -0.22 & 0.00 & -0.24 & 0.41 & -1.67 & 3.51 & 0.00 & 0.00 \\
\hline-1.36 & -0.00 & -2.79 & 0.31 & 8.34 & -0.49 & 2.22 & 1.02 & 1.26 & -3.25 & 0.78 & 1.24 & -2.37 & 0.04 & -1.25 & 1.12 & 8.64 & 0.00 \\
\hline 0.17 & 0.83 & 0.58 & -0.76 & -1.09 & 2.45 & -0.70 & -0.66 & -0.74 & 3.33 & -0.18 & -0.36 & 1.64 & -0.38 & 1.13 & -1.07 & -6.20 & 4.48 \\
\hline
\end{tabular}

The diagonal elements report the standard deviation of the VAR innovations, each one orthogonalized to the shocks that precede it in the VAR, expressed in percent per quarter.

\section{B.2 Market Price of Risk Estimates}

The market prices of risk are pinned down by the moments discussed in the main text. Here we report and discuss the point estimates. Note that the prices of risk are associated with the orthogonal VAR innovations $\varepsilon \sim \mathcal{N}(0, I)$. Therefore, their magnitudes can be interpreted as (quarterly) Sharpe ratios. The constant in the market price of risk estimate $\widehat{\Lambda_{0}}$ is:

\begin{tabular}{|l|l|l|l|l|l|l|l|l|l|l|l|l|l|l|l|l|l|}
\hline-0.23 & 0.53 & -0.44 & -0.06 & -0.18 & 0.68 & 0.00 & 0.35 & 0.00 & 0.34 & 0.00 & -0.12 & 0.00 & 0.03 & 0.00 & 0.66 & 0.00 & 0.18 \\
\hline
\end{tabular}

The matrix that governs the time variation in the market price of risk is estimated to be $\widehat{\Lambda_{1}}=$ :

\begin{tabular}{|c|c|c|c|c|c|c|c|c|c|c|c|c|c|c|c|c|c|}
\hline 61.3 & 0.0 & 0.0 & 0.0 & 0.0 & 0.0 & 0.0 & 0.0 & 0.0 & 0.0 & 0.0 & 0.0 & 0.0 & 0.0 & 0.0 & 0.0 & 0.0 & 0.0 \\
\hline 0.0 & 11.0 & 0.0 & 0.0 & 0.0 & 0.0 & 0.0 & 0.0 & 0.0 & 0.0 & 0.0 & 0.0 & 0.0 & 0.0 & 0.0 & 0.0 & 0.0 & 0.0 \\
\hline 0.0 & 0.0 & -54.1 & -250.3 & 0.0 & 0.0 & 0.0 & 0.0 & 0.0 & 0.0 & 0.0 & 0.0 & 0.0 & 0.0 & 0.0 & 0.0 & 0.0 & 0.0 \\
\hline 53.5 & -7.2 & 0.0 & 0.3 & 0.0 & 0.0 & 0.0 & 0.0 & 0.0 & 0.0 & 0.0 & 0.0 & 0.0 & 0.0 & 0.0 & 0.0 & 0.0 & 0.0 \\
\hline-6.0 & 4.0 & 5.9 & 9.2 & -0.2 & 4.6 & 0.0 & 0.0 & 0.0 & 0.0 & 0.0 & 0.0 & 0.0 & 0.0 & 0.0 & 0.0 & 0.0 & 0.0 \\
\hline-104.1 & -17.5 & -89.1 & -161.6 & -1.0 & -0.0 & -1.9 & 0.0 & 0.0 & 7.7 & 0.0 & 0.0 & 0.0 & 0.0 & 0.0 & 0.0 & 0.0 & 0.0 \\
\hline 0.0 & 0.0 & 0.0 & 0.0 & 0.0 & 0.0 & 0.0 & 0.0 & 0.0 & 0.0 & 0.0 & 0.0 & 0.0 & 0.0 & 0.0 & 0.0 & 0.0 & 0.0 \\
\hline 101.0 & -3.6 & -70.6 & -31.5 & 2.3 & -7.7 & -0.4 & 0.0 & -1.8 & -3.4 & 0.0 & 0.0 & 0.0 & 0.0 & 0.0 & 0.0 & 0.0 & 0.0 \\
\hline 0.0 & 0.0 & 0.0 & 0.0 & 0.0 & 0.0 & 0.0 & 0.0 & 0.0 & 0.0 & 0.0 & 0.0 & 0.0 & 0.0 & 0.0 & 0.0 & 0.0 & 0.0 \\
\hline 159.7 & -6.0 & -6.1 & -7.2 & 1.6 & -10.8 & 1.2 & 0.0 & -1.5 & -5.3 & 0.0 & 0.0 & 0.0 & 0.0 & 0.0 & 0.0 & 0.0 & 0.0 \\
\hline 0.0 & 0.0 & 0.0 & 0.0 & 0.0 & 0.0 & 0.0 & 0.0 & 0.0 & 0.0 & 0.0 & 0.0 & 0.0 & 0.0 & 0.0 & 0.0 & 0.0 & 0.0 \\
\hline-110.8 & 1.0 & 31.2 & -93.5 & 0.3 & -5.9 & 1.2 & 0.0 & 0.6 & -3.7 & -2.7 & 0.0 & 0.0 & 0.0 & 0.0 & 0.0 & 0.0 & 0.0 \\
\hline 0.0 & 0.0 & 0.0 & 0.0 & 0.0 & 0.0 & 0.0 & 0.0 & 0.0 & 0.0 & 0.0 & 0.0 & 0.0 & 0.0 & 0.0 & 0.0 & 0.0 & 0.0 \\
\hline 47.0 & -7.4 & -31.9 & -67.8 & 1.6 & -16.7 & 1.1 & -7.8 & -0.1 & 10.7 & -0.3 & 0.0 & -2.4 & 0.0 & 0.0 & 0.0 & 0.0 & 0.0 \\
\hline 0.0 & 0.0 & 0.0 & 0.0 & 0.0 & 0.0 & 0.0 & 0.0 & 0.0 & 0.0 & 0.0 & 0.0 & 0.0 & 0.0 & 0.0 & 0.0 & 0.0 & 0.0 \\
\hline 2.0 & -3.2 & -18.0 & 3.1 & 7.7 & 1.7 & -0.2 & 0.6 & -3.3 & 0.6 & 0.4 & 0.0 & -6.8 & 0.0 & -3.9 & 2.8 & 0.0 & 0.0 \\
\hline 0.0 & 0.0 & 0.0 & 0.0 & 0.0 & 0.0 & 0.0 & 0.0 & 0.0 & 0.0 & 0.0 & 0.0 & 0.0 & 0.0 & 0.0 & 0.0 & 0.0 & 0.0 \\
\hline 111.3 & 57.1 & -103.1 & -50.7 & 2.5 & -7.4 & -1.2 & -3.9 & 0.1 & -1.5 & 1.5 & 0.0 & -3.3 & 0.0 & 0.0 & -0.0 & -1.1 & 2.5 \\
\hline
\end{tabular}


The first four elements of $\Lambda_{0}$ and the first four rows of $\Lambda_{1}$ govern the dynamics of bond yields and bond returns. The price of inflation risk is allowed to move with the inflation rate. The estimation shows that the price of inflation risk is negative on average $\left(\widehat{\Lambda_{0}}(1)=-0.23\right)$, indicating that high inflation states are bad states of the world. The market price of inflation risk becomes larger (less negative) when inflation is higher than average $\left(\widehat{\Lambda_{1}}(1,1)=61.26\right)$. The price of real GDP growth risk is positive $\left(\widehat{\Lambda_{0}}(2)=0.53\right)$, indicating that high growth states are good states of the world. The price of growth risk increases when GDP growth is above average $\left(\widehat{\Lambda_{1}}(2,2)=11.00\right)$. The price of level risk (the shock to short rates that is orthogonal to inflation and real GDP growth) is estimated to be negative $\left(\widehat{\Lambda_{0}}(3)=-0.44\right)$, consistent with e.g., the Cox, Ingersoll, and Ross (1985) model. The price of level risk is allowed to change with both the level of interest rates, as in those simple term structure models, and also with the slope factor to capture the fact that bond excess returns are predictable by the slope of the yield curve (Campbell and Shiller, 1991). When interest rate levels are unusually high and the term structure steepens, the price of level risk becomes more negative $\left(\widehat{\Lambda_{1}}(3,3)=-\right.$ 54.14and $\left.\widehat{\Lambda_{1}}(3,4)=-250.30\right)$, and expected future bond returns increase. The positive association between the slope and future bond returns is consistent with the bond return predictability evidence (Cochrane and Piazzesi, 2006). The price of (orthogonal) slope risk is estimated to be slightly negative on average $\left(\widehat{\Lambda_{0}}(4)=-\right.$ 0.06). Since the spread between the five-year bond yield and the short rate is the fourth element of the state vector, and the short rate is the third element of the state vector, the five year bond yield can be written as:

$$
y_{t, 20}^{\$}=y_{0,20}^{\$}+\left(e_{y n}+e_{y s p r}\right)^{\prime} z_{t}=-\frac{A_{20}^{\$}}{20}-\frac{B_{20}^{\$ \prime}}{20} z_{t}
$$

A necessary and sufficient condition to match the five-year bond yield dynamics is to allow for the first four elements of the fourth row of $\Lambda_{1}$ to be non-zero.

The last eight elements of $\Lambda_{0}$ and last eight rows of $\Lambda_{1}$ govern stock pricing. We assume that the market prices of risk associated with the price-dividend ratios are zero, since those variables only play a role as predictors. The only exception is the price-dividend ratio on the stock market. The evidence from dividend strip spot and futures prices and the evidence on strip future returns helps us identify the market prices of risk associated with the pd ratio (fifth element of $\Lambda_{t}$ ).

The risk prices in the 6th, 8th, 10th, 12th, 14th, 16th, and 18th rows of $\Lambda_{t}$ are chosen to match the observed mean and dynamics of the equity risk premium in model, as shown in Appendix A, and data, as implied by the VAR. We only free up those elements of the 6th, 8th, 10th, 12th, 14th, 16th, and 18th rows of $\Lambda_{1}$ that are strictly necessary to allow the equity risk premia in the model to move with the same state variables as they do in the VAR. These rows of of $\Lambda_{t}$ are also influenced by our insistence on matching the entire time series of the price-dividend ratio on the stock market, real estate, infrastructure, small, growth, natural resource, and value stocks. 


\section{Shock-exposure and Shock-price Elasticities}

Borovička and Hansen (2014) provide a dynamic value decomposition, the asset pricing counterparts to impulse response functions, which let a researcher study how a shock to an asset's cash-flow today affects future cash-flow dynamics as well as the prices of risk that pertain to these future cash-flows. What results is a set of shock-exposure elasticities that measure the quantities of risk resulting from an initial impulse at various investment horizons, and a set of shock-price elasticities that measure how much the investor needs to be compensated currently for each unit of future risk exposure at those various investment horizons. We now apply their analysis to our VAR setting.

\section{C.1 Derivation}

Recall that the underlying state vector dynamics are described by:

$$
z_{t+1}=\Psi z_{t}+\Sigma^{\frac{1}{2}} \varepsilon_{t+1}
$$

The log cash-flow growth rates on stocks, REITs, and infrastructure stocks are described implicitly by the VAR since it contains both log returns and log price-dividend ratios for each of these assets. The log real dividend growth rate on an asset $i \in\{m$, reit, infra $\}$ is given by:

$$
\log \left(D_{t+1}^{i}\right)-\log \left(D_{t}^{i}\right)=\Delta d_{t+1}^{i}=A_{0}^{i}+A_{1}^{i} z_{t}+A_{2}^{i} \varepsilon_{t+1}
$$

where $A_{0}^{i}=\mu_{m}, A_{1}=e_{d i v i}^{\prime} \Psi$, and $A_{2}^{i}=e_{d i v i}^{\prime} \sum^{\frac{1}{2}}$.

Denote the cash-flow process $Y_{t}=D_{t}$. Its increments in logs can we written as:

$$
y_{t+1}-y_{t}=\Gamma_{0}+\Gamma_{1} z_{t}+z_{t}^{\prime} \Gamma_{3} z_{t}+\Psi_{0} \varepsilon_{t+1}+z_{t}^{\prime} \Psi_{1} \varepsilon_{t+1}
$$

with coefficients $\Gamma_{0}=A_{0}^{i}, \Gamma_{1}=A_{1}^{i}, \Gamma_{3}=0, \Psi_{0}=A_{2}^{i}$, and $\Psi_{1}=0$.

The one-period log real SDF, which is the log change in the real pricing kernel $S_{t}$, is a quadratic function of the state:

$$
\log \left(S_{t+1}\right)-\log \left(S_{t}\right)=m_{t+1}=B_{0}+B_{1} z_{t}+B_{2} \varepsilon_{t+1}+z_{t}^{\prime} B_{3} z_{t}+z_{t}^{\prime} B_{4} \varepsilon_{t+1}
$$

where $B_{0}=-y_{0}^{\$}(1)+\pi_{0}-\frac{1}{2} \Lambda_{0}^{\prime} \Lambda_{0}, B_{1}=-e_{y n}^{\prime}+e_{\pi}^{\prime} \Psi-\Lambda_{0}^{\prime} \Lambda_{1}, B_{2}=-\Lambda_{0}^{\prime}+e_{\pi}^{\prime} \sum^{\frac{1}{2}}, B_{3}=-\frac{1}{2} \Lambda_{1}^{\prime} \Lambda_{1}$, and $B_{4}=-\Lambda_{1}^{\prime}$.

We are interested in the product $Y_{t}=S_{t} D_{t}$. Its increments in logs can be written as in equation (26), with coefficients $\Gamma_{0}=A_{0}^{i}+B_{0}, \Gamma_{1}=A_{1}^{i}+B_{1}, \Gamma_{3}=B_{3}, \Psi_{0}=A_{2}^{i}+B_{2}$, and $\Psi_{1}=B_{4}$.

Starting from a state $z_{0}=z$ at time 0 , consider a shock at time 1 to a linear combination of state variables, $\alpha_{h}^{\prime} \varepsilon_{1}$. The shock elasticity $\epsilon(z, t)$ quantifies the date- $t$ impact:

$$
\epsilon(z, t)=\alpha_{h}^{\prime}\left(I-2 \tilde{\Psi}_{2, t}\right)^{-1}\left(\tilde{\Psi}_{0, t}^{\prime}+\tilde{\Psi}_{1, t}^{\prime} z\right)
$$

where the $\tilde{\Psi}$ matrices solve the recursions

$$
\tilde{\Psi}_{0, j+1}=\hat{\Gamma}_{1, j} \Sigma^{1 / 2}+\Psi_{0}
$$




$$
\begin{aligned}
& \tilde{\Psi}_{1, j+1}=2 \Psi^{\prime} \hat{\Gamma}_{3, j} \Sigma^{1 / 2}+\Psi_{1} \\
& \tilde{\Psi}_{2, j+1}=\left(\Sigma^{1 / 2}\right)^{\prime} \hat{\Gamma}_{3, j} \Sigma^{1 / 2}
\end{aligned}
$$

The $\hat{\Gamma}$ and $\tilde{\Gamma}$ coefficients follow the recursions:

$$
\begin{aligned}
& \tilde{\Gamma}_{0, j+1}=\hat{\Gamma}_{0, j}+\Gamma_{0} \\
& \tilde{\Gamma}_{1, j+1}=\hat{\Gamma}_{1, j} \Psi+\Gamma_{1} \\
& \tilde{\Gamma}_{3, j+1}=\Psi^{\prime} \hat{\Gamma}_{3, j} \Psi+\Gamma_{3} \\
& \hat{\Gamma}_{0, j+1}=\tilde{\Gamma}_{0, j+1}-\frac{1}{2} \log \left(\left|I-2 \tilde{\Psi}_{2, j+1}\right|\right)+\frac{1}{2} \tilde{\Psi}_{0, j+1}\left(I-2 \tilde{\Psi}_{2, j+1}\right)^{-1} \tilde{\Psi}_{0, j+1}^{\prime} \\
& \hat{\Gamma}_{1, j+1}=\tilde{\Gamma}_{1, j+1}+\tilde{\Psi}_{0, j+1}\left(I-2 \tilde{\Psi}_{2, j+1}\right)^{-1} \tilde{\Psi}_{1, j+1}^{\prime} \\
& \hat{\Gamma}_{3, j+1}=\tilde{\Gamma}_{3, j+1}+\frac{1}{2} \tilde{\Psi}_{1, j+1}\left(I-2 \tilde{\Psi}_{2, j+1}\right)^{-1} \tilde{\Psi}_{1, j+1}^{\prime}
\end{aligned}
$$

starting from $\hat{\Gamma}_{0,0}=0, \hat{\Gamma}_{1,0}=0_{1 \times N}, \hat{\Gamma}_{2,0}=0_{N \times N}$, and where $I$ is the $N \times N$ identity matrix.

Let $\epsilon_{g}(z, t)$ be the shock-exposure elasticity (cash-flows $Y=D$ ) and $\epsilon_{s g}(z, t)$ the shock-value elasticity, then the shock-price elasticity $\epsilon_{p}(z, t)$ is given by

$$
\epsilon_{p}(z, t)=\epsilon_{g}(z, t)-\epsilon_{s g}(z, t)
$$

In an exponentially affine framework like ours, the shock price elasticity can also directly be derived by setting $Y_{t}=S_{t}^{-1}$ or $y_{t+1}-y_{t}=-m_{t+1}$, with coefficients in equation (26) equal to $\Gamma_{0}=-B_{0}, \Gamma_{1}=-B_{1}$, $\Gamma_{3}=-B_{3}, \Psi_{0}=-B_{2}$, and $\Psi_{1}=-B_{4}$.

The shock-price elasticity quantifies implied market compensation for horizon-specific risk exposures. In our case, these risk compensations are extracted from a rich menu of observed asset prices matched by a reduced form model, rather than by constructing a structural asset pricing model. The horizon-dependent risk prices are the multi-period impulse responses for the cumulative stochastic discount factor process.

\section{C.2 Results}

Figure C.1 plots the shock-exposure elasticities of the six dividend growth processes -on the market (blue), small stocks (cyan), growth (magenta), value (yellow), REITs (red), infrastructure (green), and natural resource stocks (black)- to a one-standard deviation shock to inflation (top left), real per capital GDP growth (top second), the short rate (top third), the slope factor (top fourth), the price-dividend ratio on the market (top fifth), the dividend growth rate on the market (top right), the dividend growth rate on small stocks (bottom left), the dividend growth rate on growth stocks, on value stocks, on REITs, on infrastructure, and the dividend growth rate on natural resource stocks (bottom right). The shock exposure elasticities are essentially impulse-responses to the original (i.e., non-orthogonalized) VAR innovations. They describe properties of the VAR, not of the asset pricing model. Since our private equity cash-flows are linear combinations of these dividends, the PE cash flow exposures to the VAR shocks will be linear combinations of the plotted shock exposure elasticities of these three dividend growth rates. 


\section{FIGURE C.1: Shock Exposure Elasticities}

The figure plots the shock-exposure elasticities of dividend growth on the market, dividend growth of REITs, dividend growth of infrastructure shocks, dividend growth of small stocks, dividend growth of growth stocks, and dividend growth of natural resource stocks to a one-standard deviation shock to inflation (top left), real GDP growth (top second), the short rate (top third), the slope factor, the price-dividend ratio on the market, dividend growth rate on the market (top right), dividend growth rate on small stocks (bottom left), dividend growth on growth stocks (bottom second), dividend growth on value stocks, on REITs, on infrastructure stocks, and dividend growth of natural resource stocks (bottom right). The shock exposures are to the non-orthogonalized VAR innovations $\sum^{\frac{1}{2}} \varepsilon$.
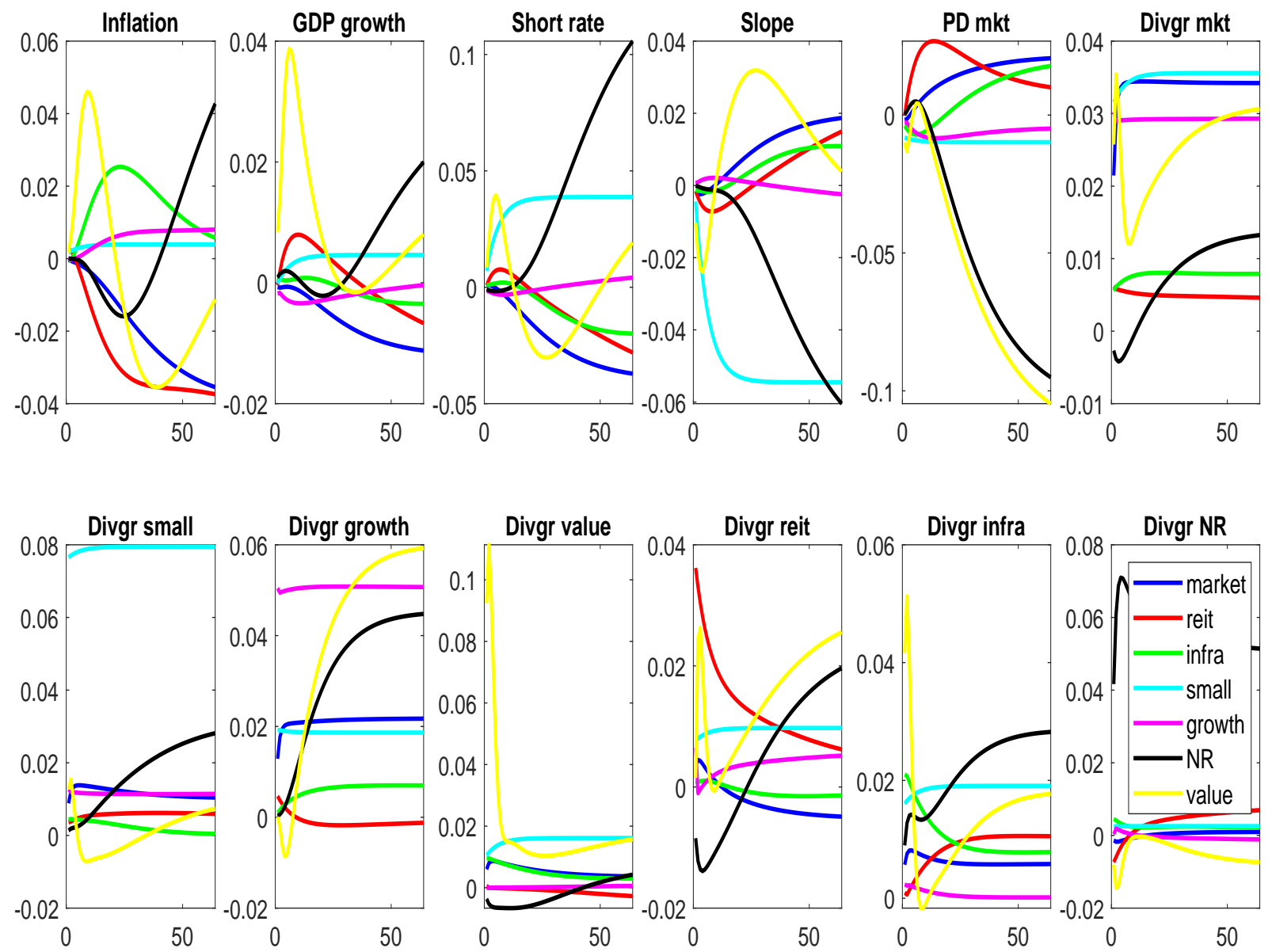

There is interesting heterogeneity in the cash flow exposures of the seven risky assets to the VAR shocks. For example, the top left panel shows that infrastructure and to a lesser extent small stock cash flows increase in the wake of a positive inflation shock, while the dividend growth responses for the aggregate stock market and especially for REITs, growth stocks, and natural resource stocks are negative. This points to the inflation hedging potential of infrastructure assets and the inflation risk exposure of REITs, growth stocks, natural resource stocks, and the market as a whole. The second panel shows that REIT and small stock dividend growth responds positively to a GDP growth shock, while cash flow growth on the market and on growth stocks (ironically) respond negatively. It is well known that the market portfolio as a whole is fairly growth-oriented. NR stocks have strong exposure to GDP growth especially at longer horizons. All cash flows except NR respond negatively to an increase in interest rates in the long-run. The response of REIT and small stock cash flows is positive in the short run. REIT cash flows are rents which can be adjusted upwards when rates increase, which typically occurs in a strong economy (see the GDP panel). 
Value stocks also have very strong short-run GDP exposure. Small and growth stocks have a lot more interest rate level risk exposure than the other asset classes, while NR cash flows are a great interest rate hedge. The market dividend growth shows a substantial positive response to a steepening yield curve. Slope exposure is even larger for growth stocks. When the slope steepens, which tends to happen during recessions, NR cash flows fall. The bottom panels show that the dividend growth shock to the market is nearly permanent, while the other five cash flow shocks are mean-reverting. A positive innovation in REIT cash flows is associated with a decline in cash flows on growth firms. This makes sense given the value-like behavior of REITs (Van Nieuwerburgh, 2019). A positive shock to infrastructure cash flows has strong and often long-lasting positive effects on the other five cash flow series (bottom middle panel). Positive growth stock cash flow innovations have strongly persistent positive effects for NR cash flows. NR cash flows have few spillovers on the other stock segments.

\section{FIGURE C.2: Shock Price Elasticities}

The figure plots the shock-price elasticities to a one-standard deviation shock to the inflation factor (top left), real GDP growth (top second), short rate (top third), the slope factor, the price-dividend ratio on the market, the dividend growth rate on the market (top right), the dividend growth rate on small stocks (bottom left), the dividend growth rate on growth stocks, on value stocks on REITs, on infrastructure stocks, and on natural resources stocks (bottom right). The shocks whose risk prices are plotted are the (non-orthogonalized) VAR innovations $\Sigma^{\frac{1}{2}} \varepsilon$.
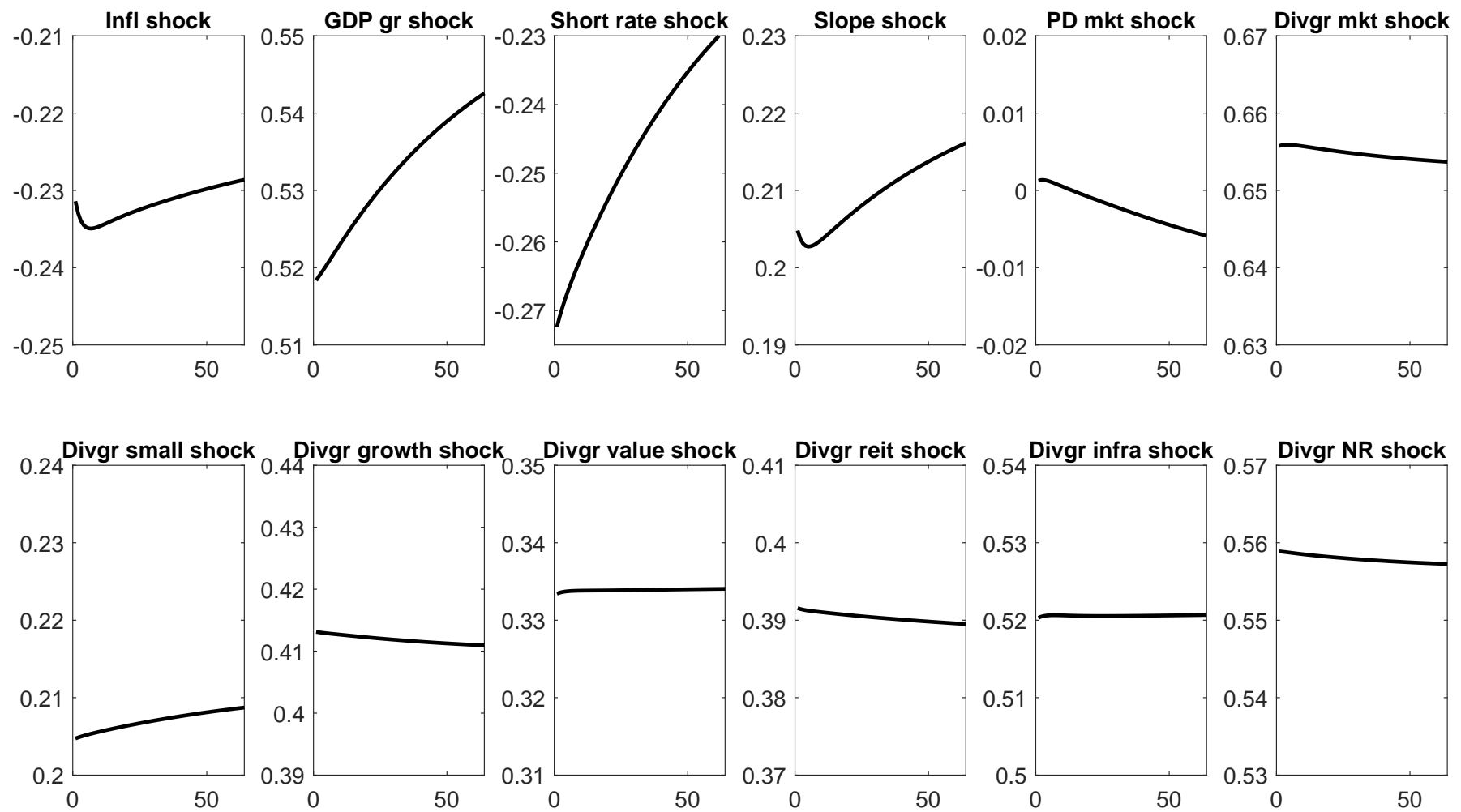

Figure C.2 plots the shock-price elasticities to a one-standard deviation shock to each of the same (nonorthogonalized) VAR innovations. Shock price elasticities are properties of the SDF process, and therefore depend on the estimated market price of risk parameters. They quantify the compensation investors demand for horizon-dependent risk exposures. The price of inflation risk is negative, consistent with increases 
in inflation being bad states of the world. GDP growth risk is naturally priced positively, and more so at longer horizons. Level risk is negatively priced, consistent with standard results in the term structure literature that consider high interest rate periods bad states of the world. The price of level risk becomes less negative at longer horizons. The price of slope risk is positive, consistent with the findings in Koijen, Lustig, and Van Nieuwerburgh (2017). All cash-flow shocks in the bottom six panels naturally have positive risk prices since increases in cash-flow growth are good shocks to the representative investor. The highest risk price is associated with shocks to the aggregate stock market, followed by infrastructure shocks, then growth shocks. Compensation for exposure to the various dividend shocks varies little with the horizon. 


\section{Additional Results}

\section{FIGURE D.1: Cash-Flows by Vintage, Alternate Categories}
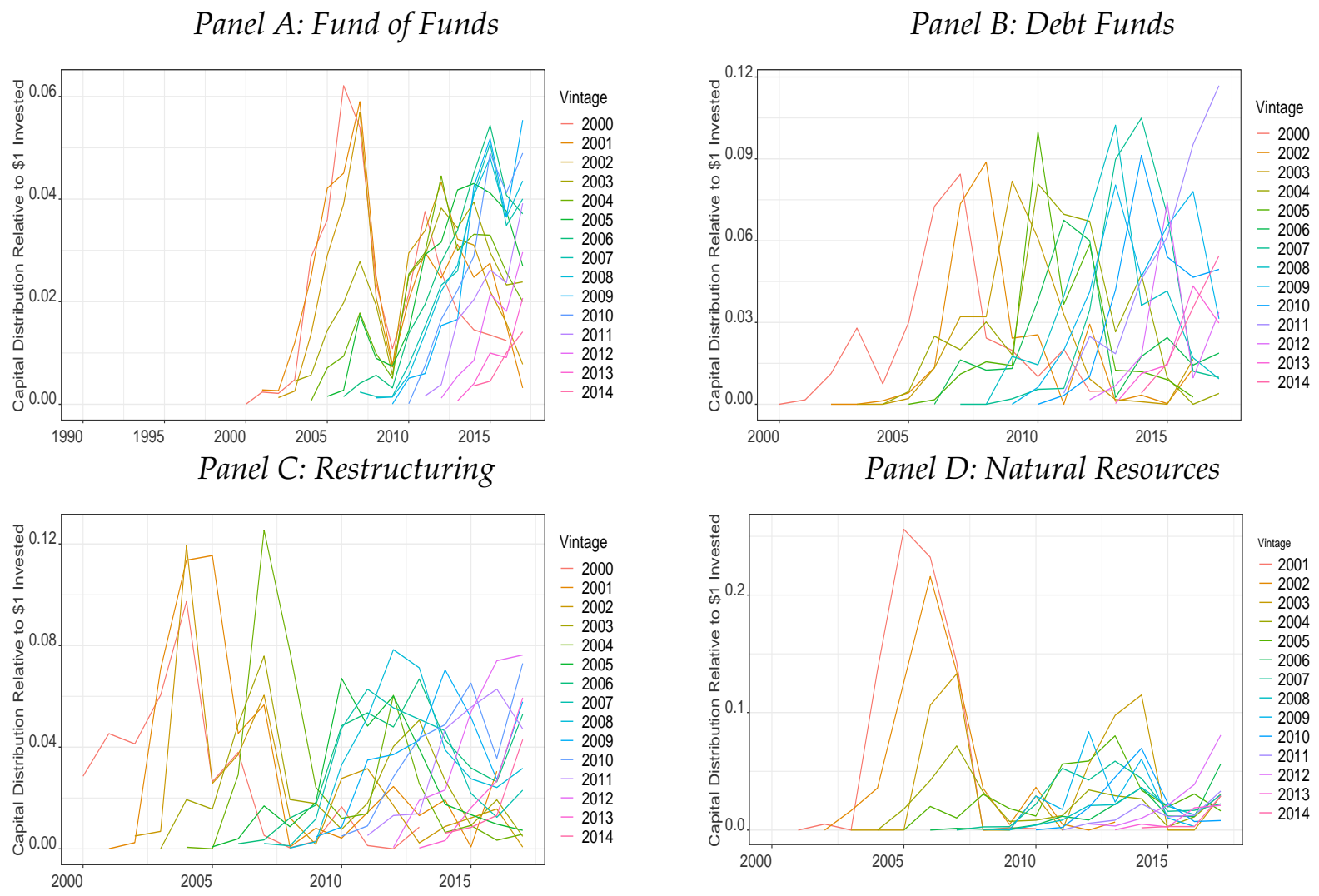


\section{FIGURE D.2: Factor Exposure for other Categories by Fund Horizon}

\section{Panel A: Restructuring}
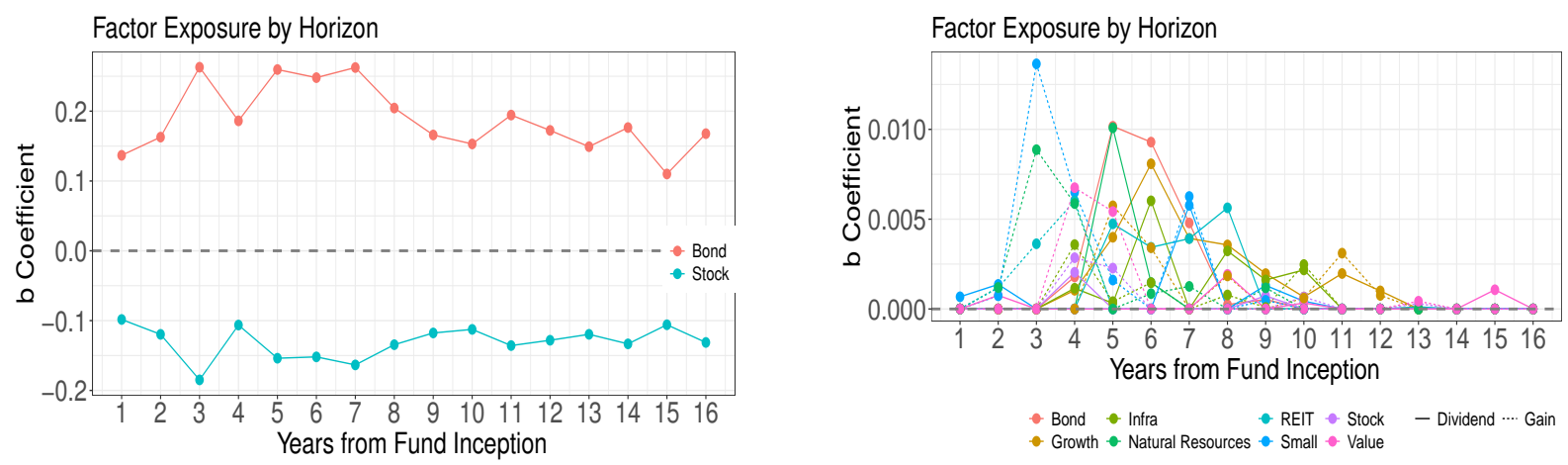

\section{Panel B: Debt Fund}
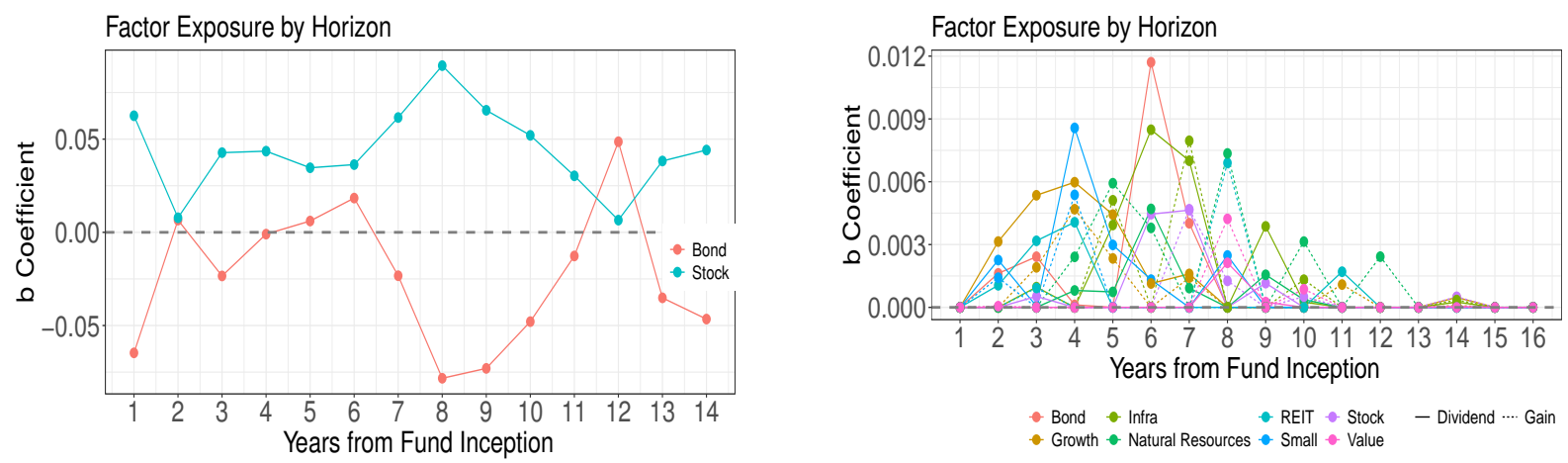

Panel C: Fund of Funds
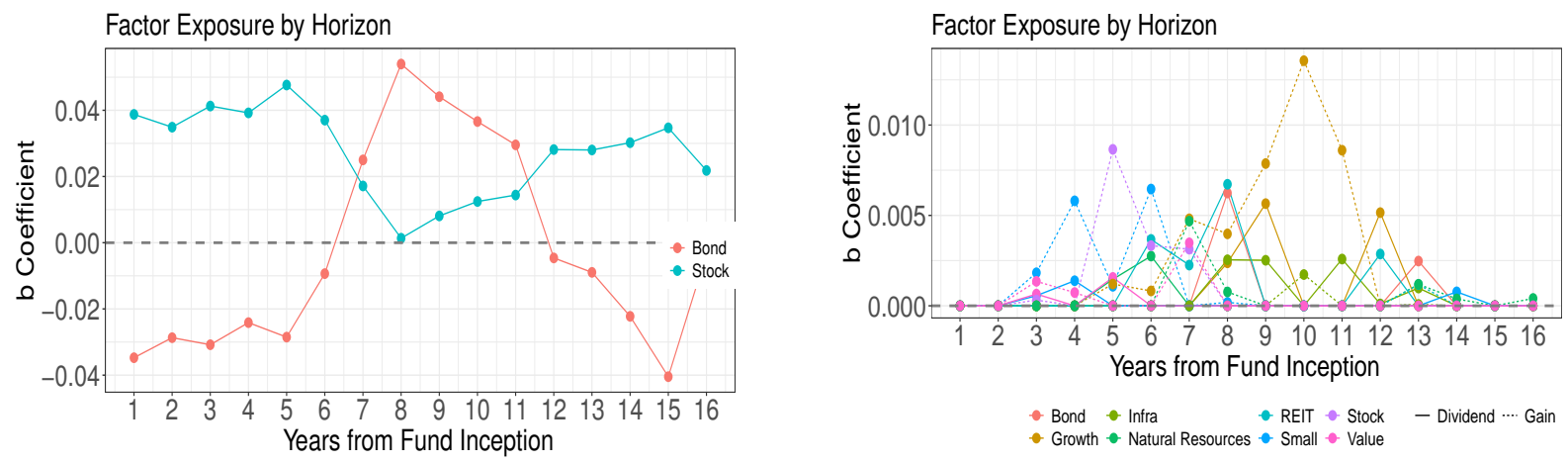

Panel D: Natural Resources
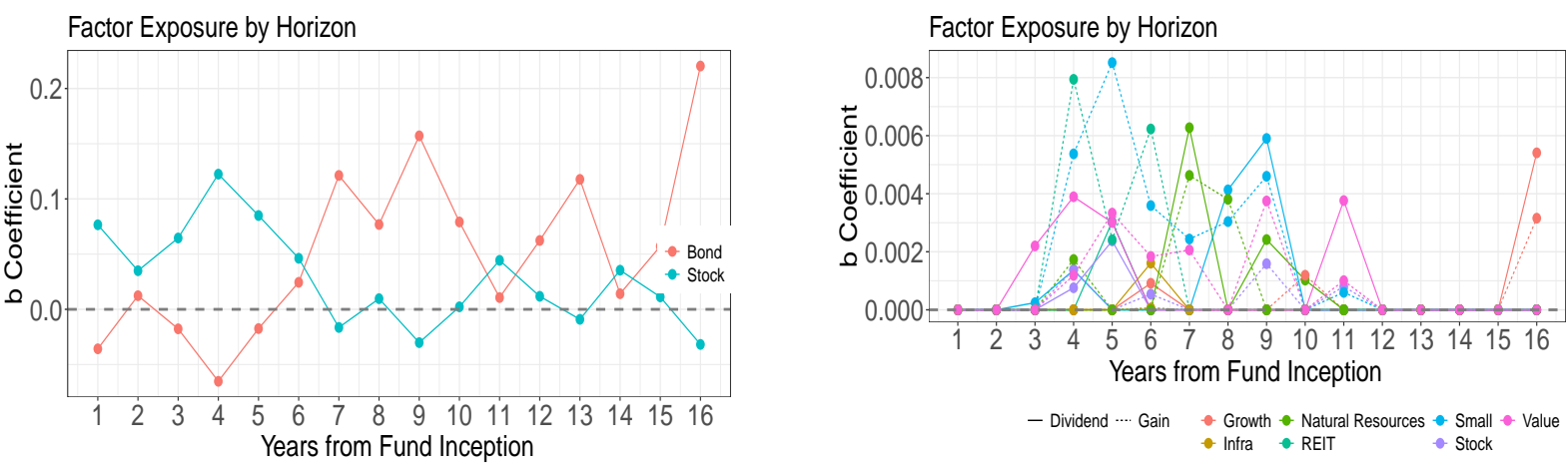


\section{FIGURE D.3: Factor Exposure by P/D Quartile}

\section{2-Factor}

\section{Elastic Net}

\section{Panel A: Buyout}
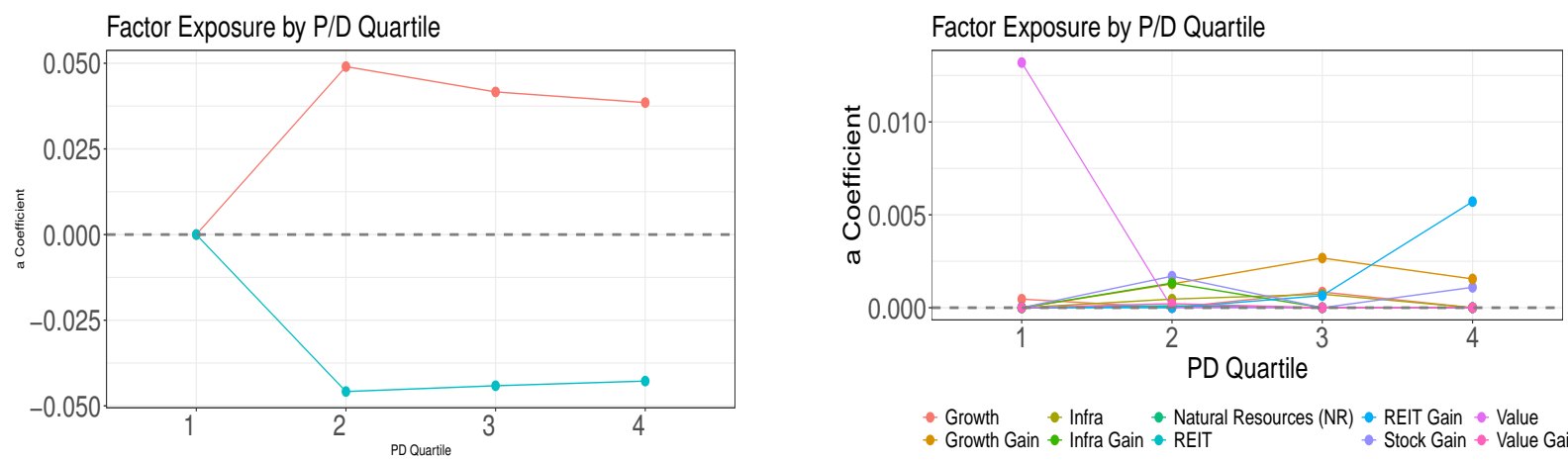

Panel B: Venture Capital
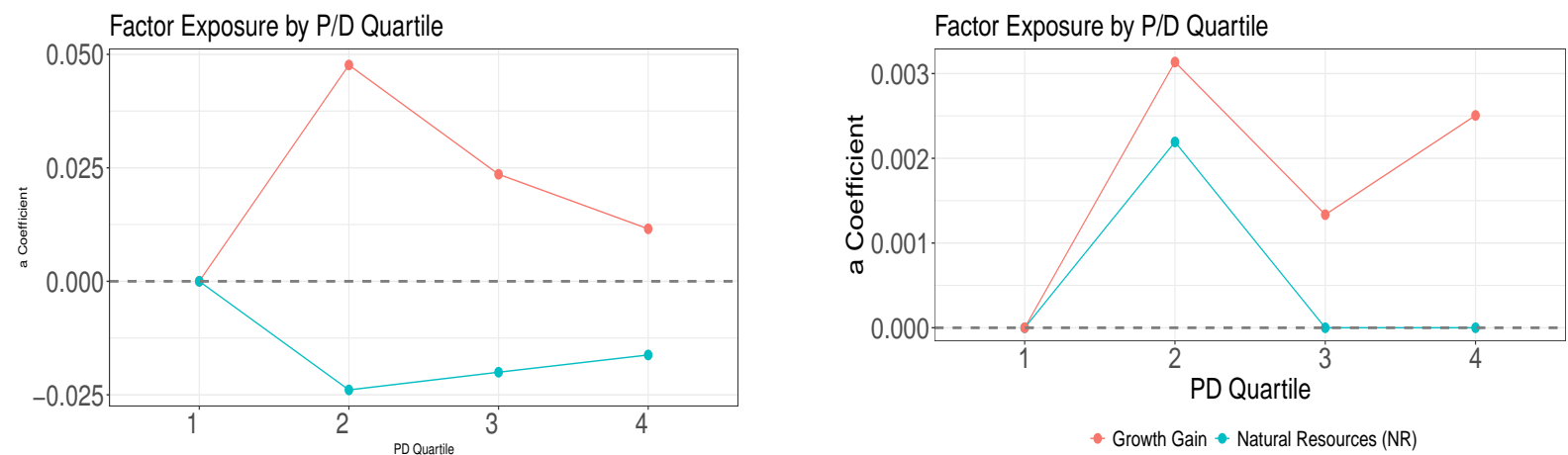

Panel C: Real Estate
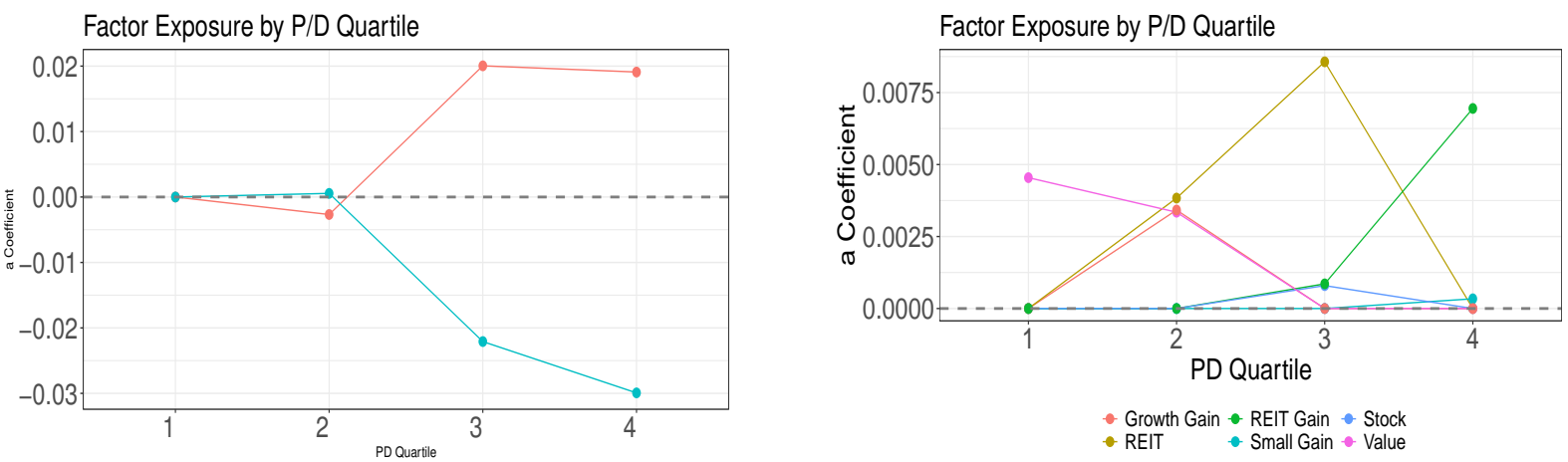

\section{Panel D: Infrastructure}
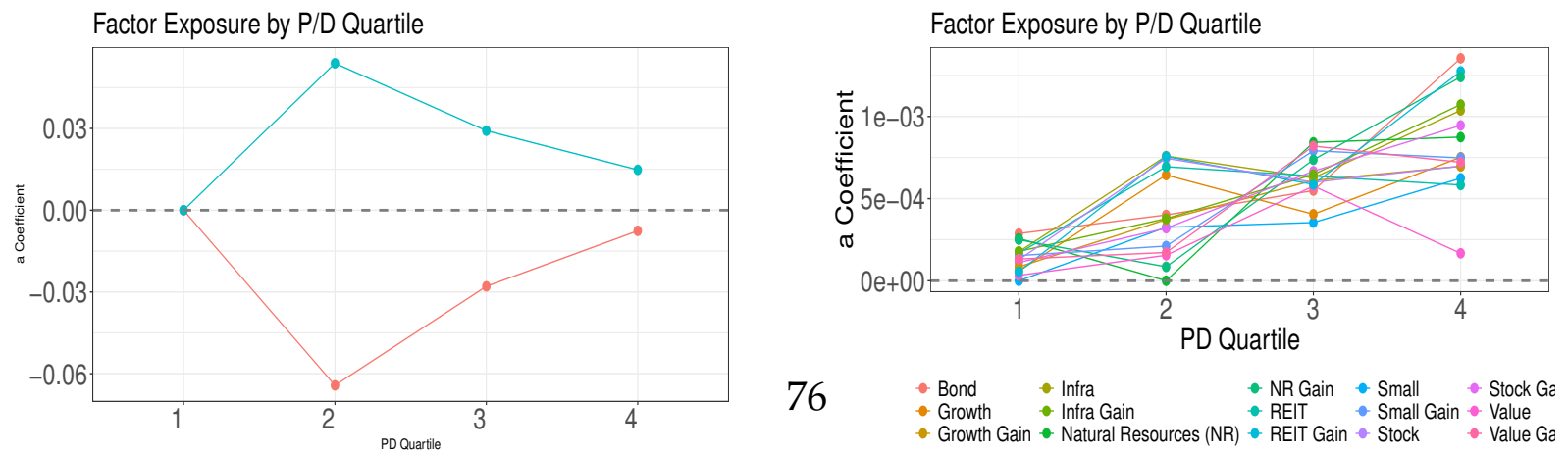


\section{FIGURE D.4: Factor Exposure by P/D Quartile}

\section{2-Factor}

\section{Elastic Net}

\section{Panel A: Restructuring}
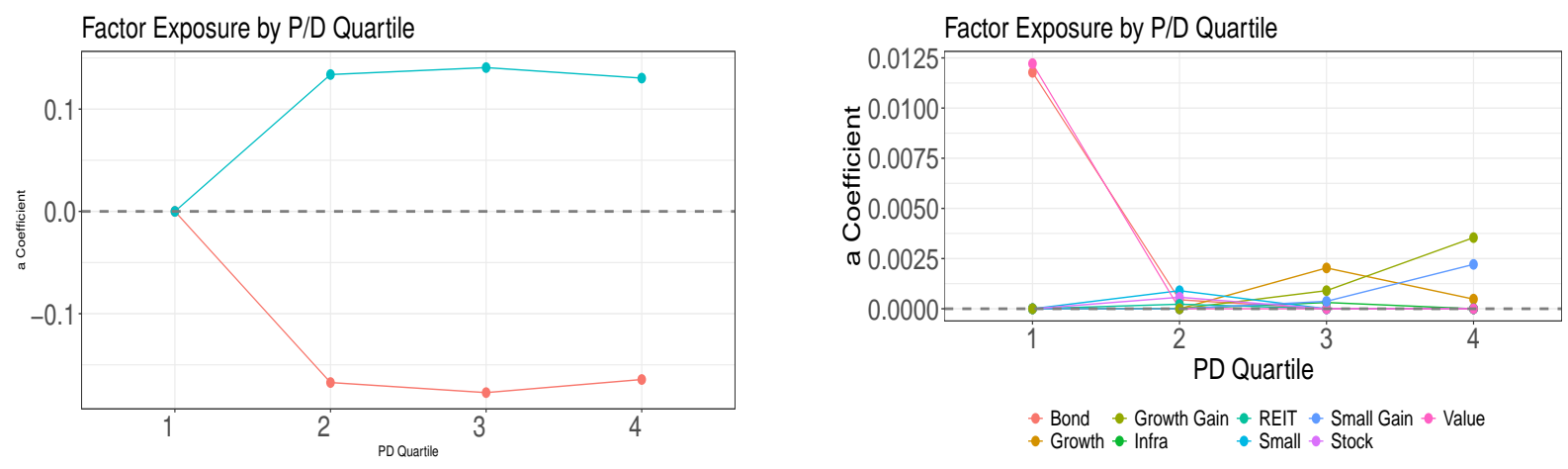

Panel B: Fund of Funds
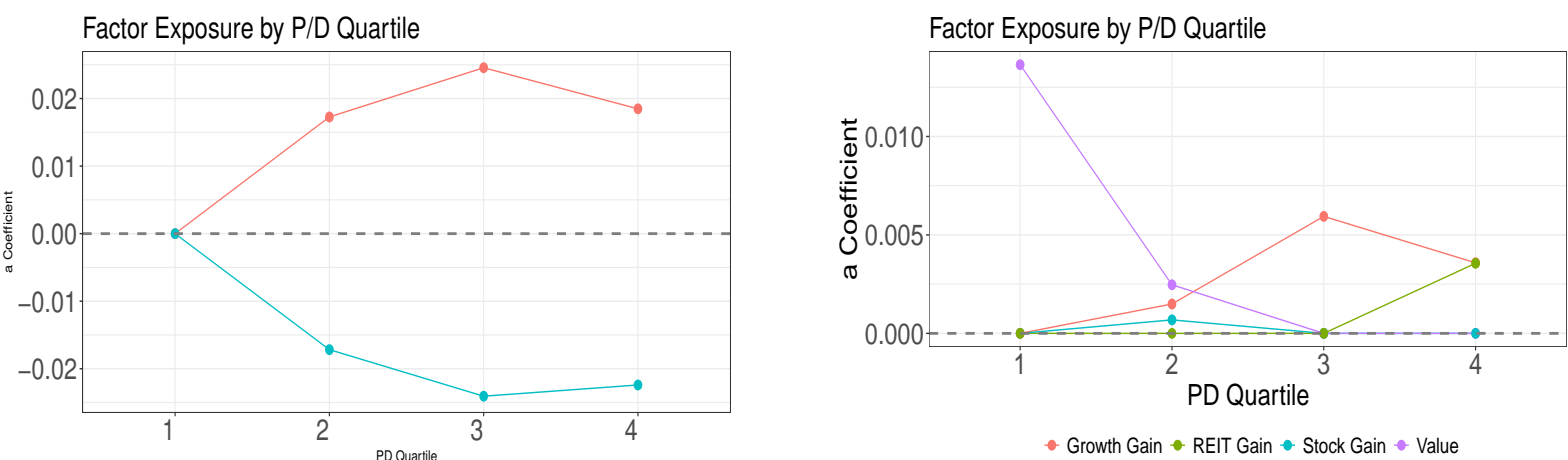

Panel C: Debt Fund
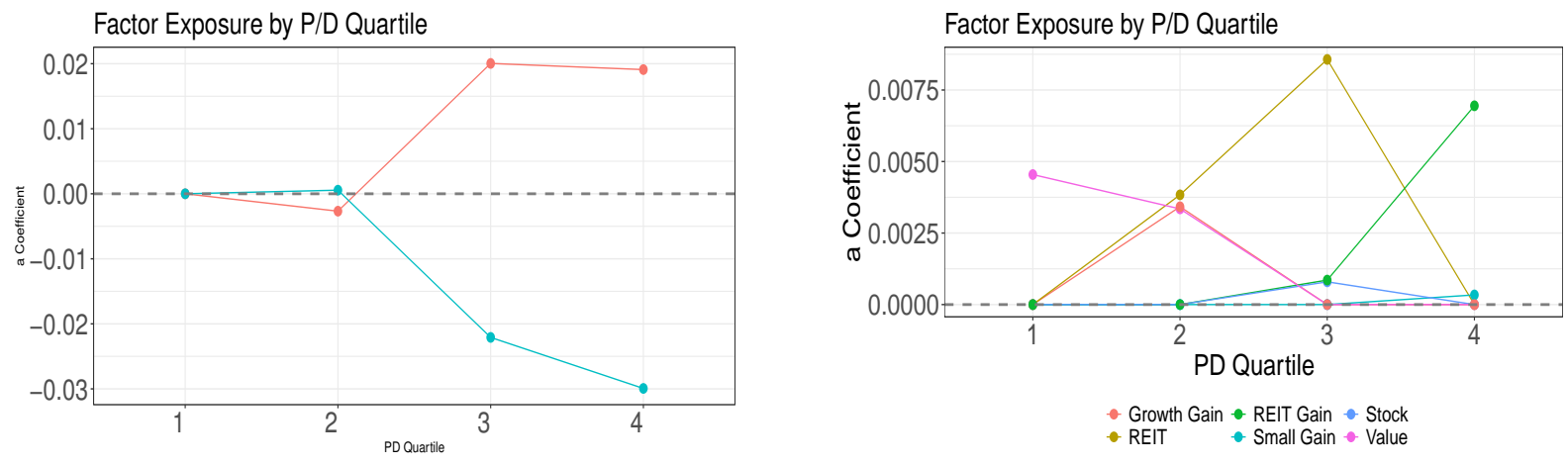

Panel D: Natural Resources
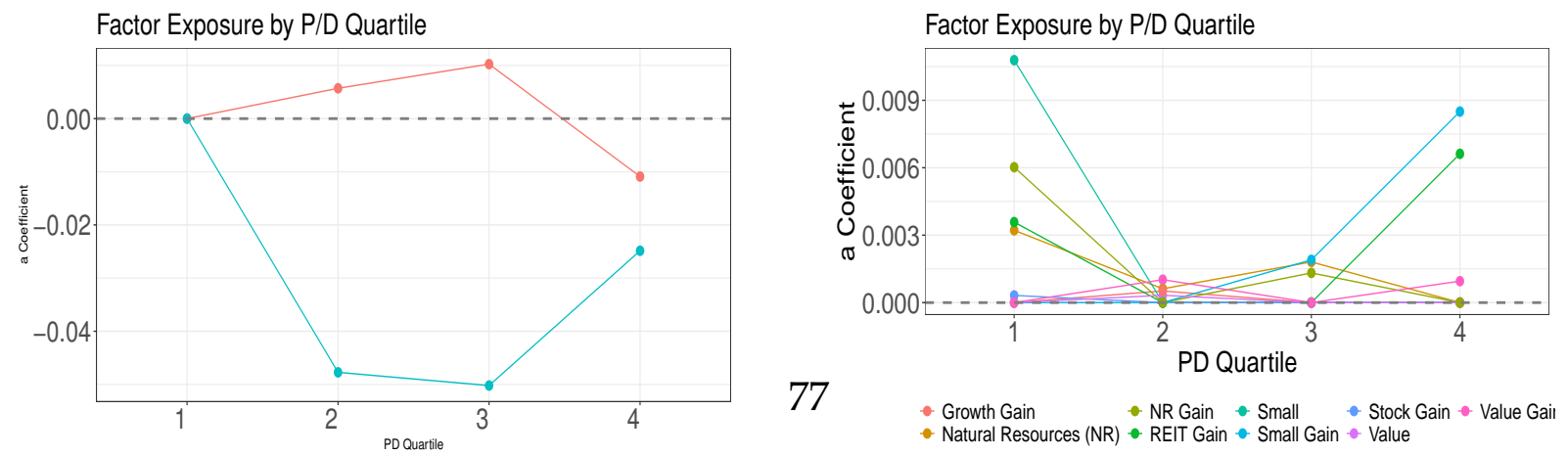
FIGURE D.5: Expected Returns by Vintage for Additional Categories

\section{Panel A: Restructuring}
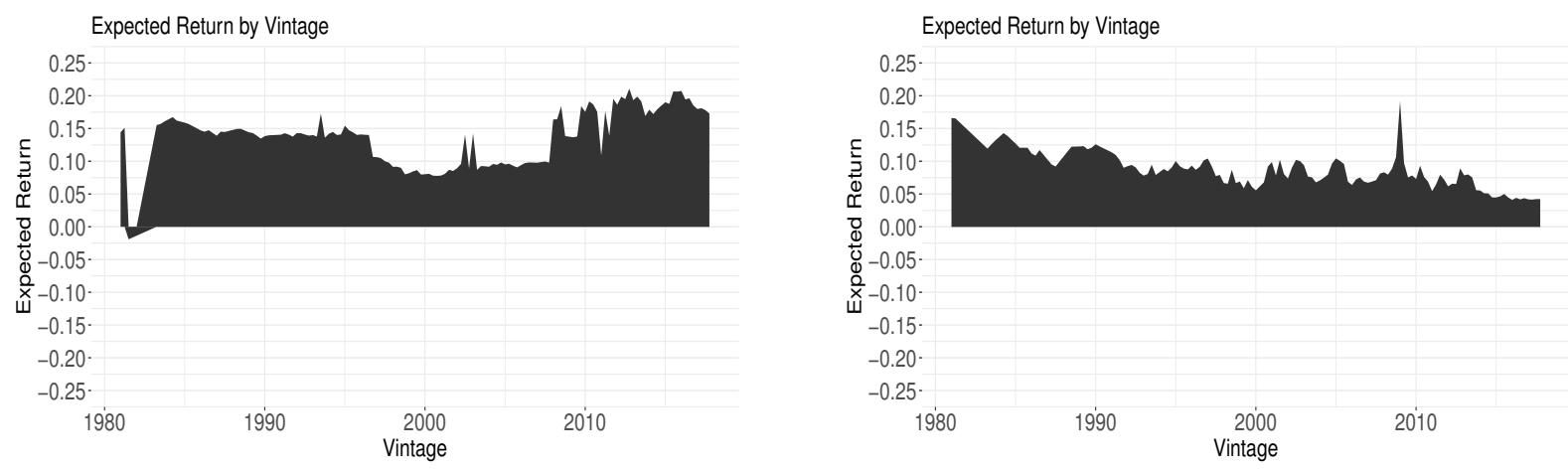

Panel B: Fund of Funds
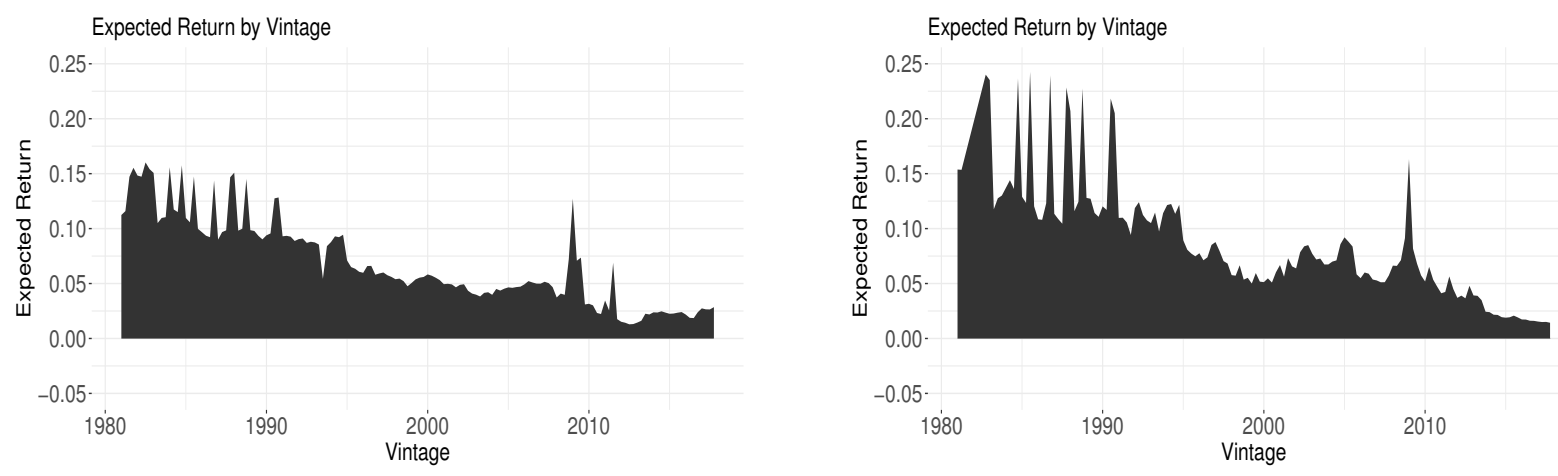

Panel C: Debt Fund
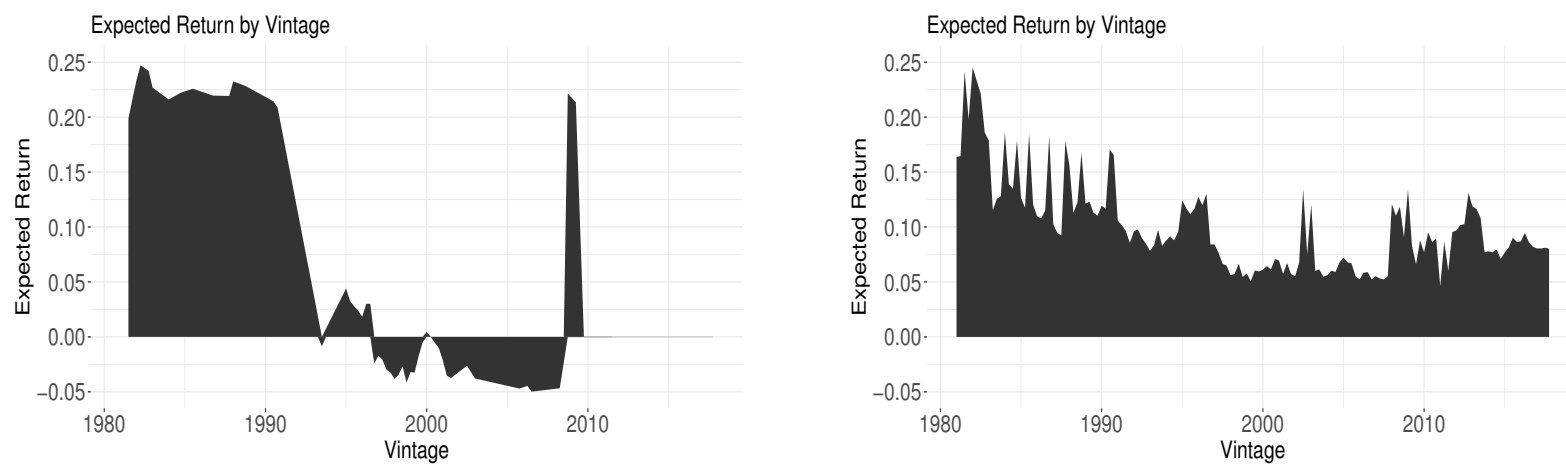

Panel D: Natural Resources
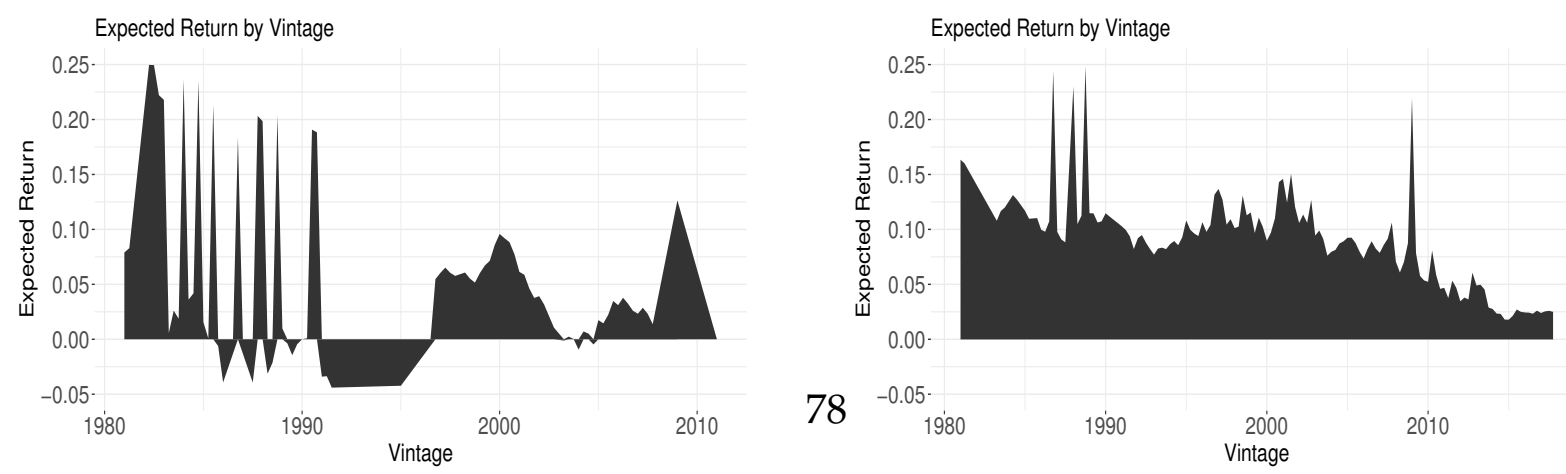


\section{FIGURE D.6: Profit Comparison for Alternate Categories}

\section{2-Factor}

Panel A: Restructuring

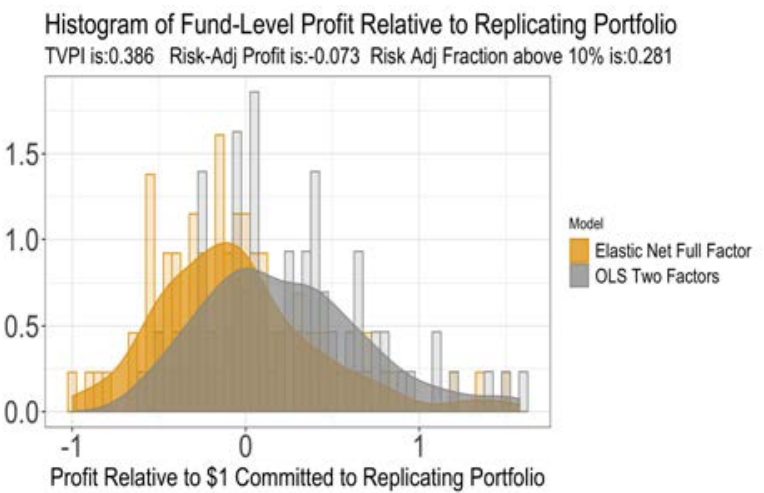

Panel C: Debt Fund

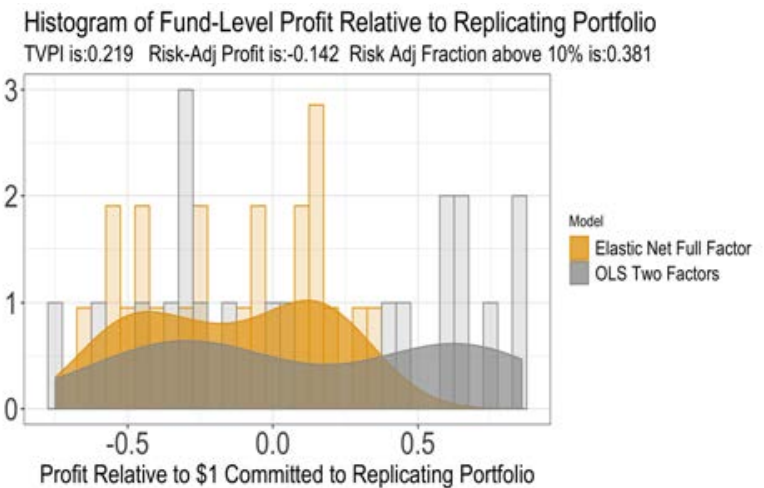

\section{Elastic Net}

Panel B: Fund of Funds

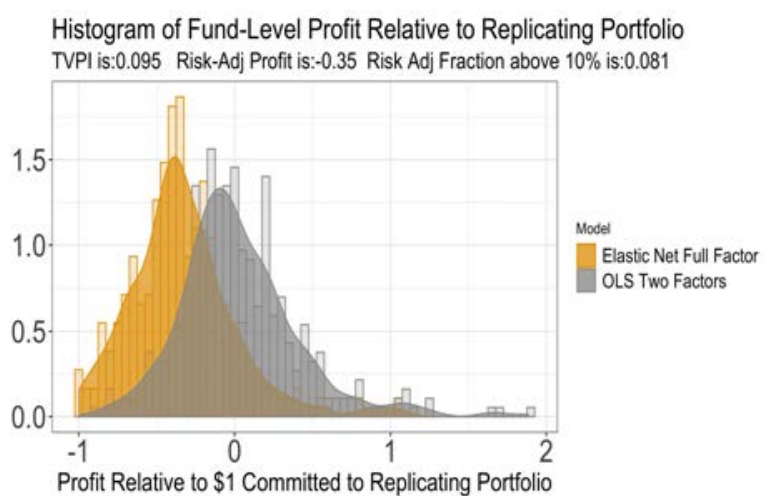

Panel D: Natural Resources

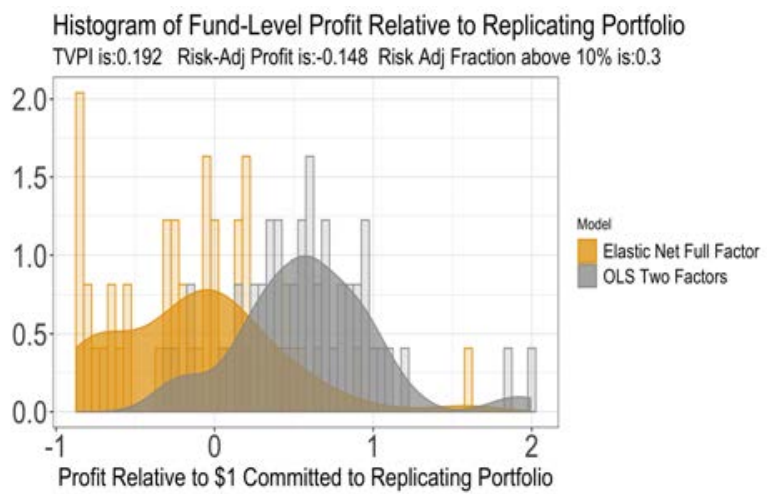




\section{FIGURE D.7: Profits Over Time for Additional Categories}

\section{2-Factor}

\section{Elastic Net}

\section{Panel A: Restructuring}
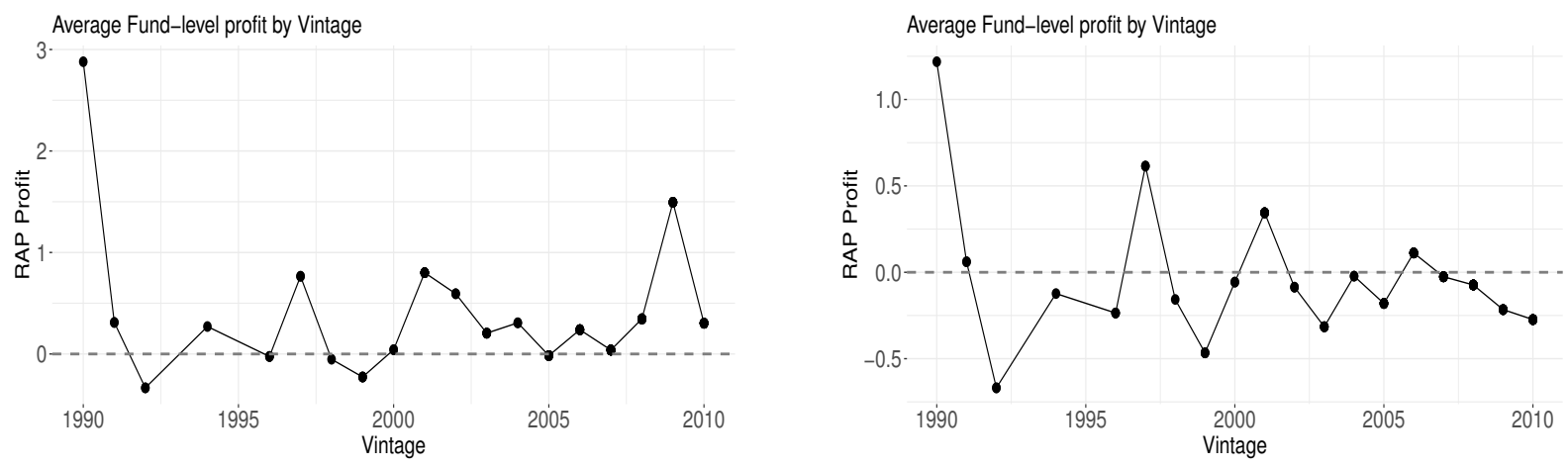

Panel B: Fund of Funds
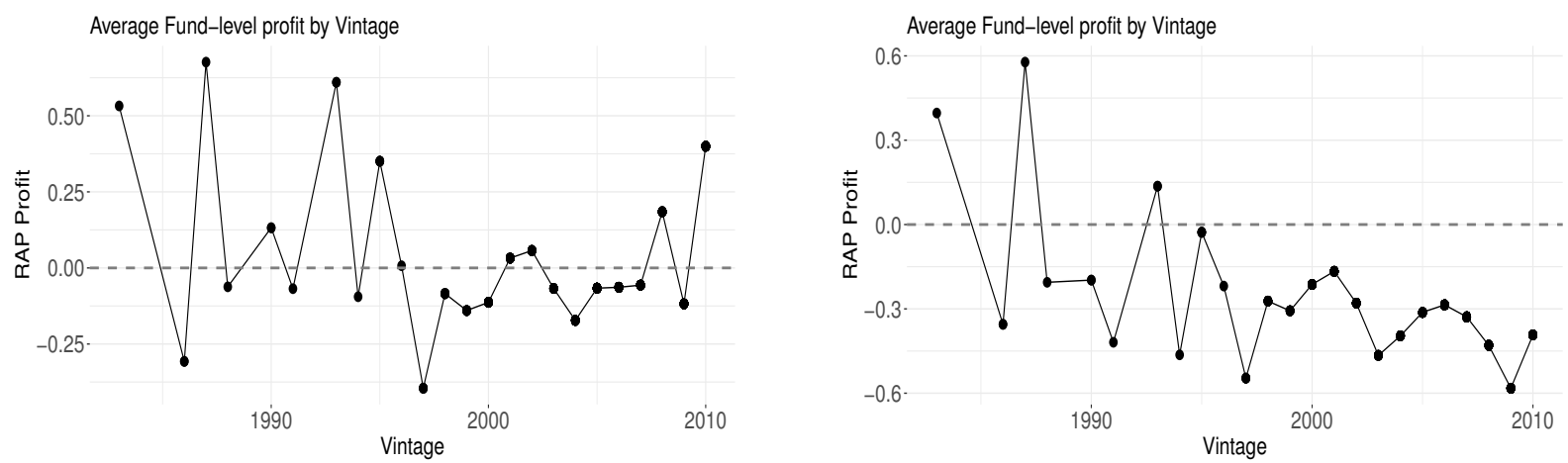

Panel C: Debt Fund
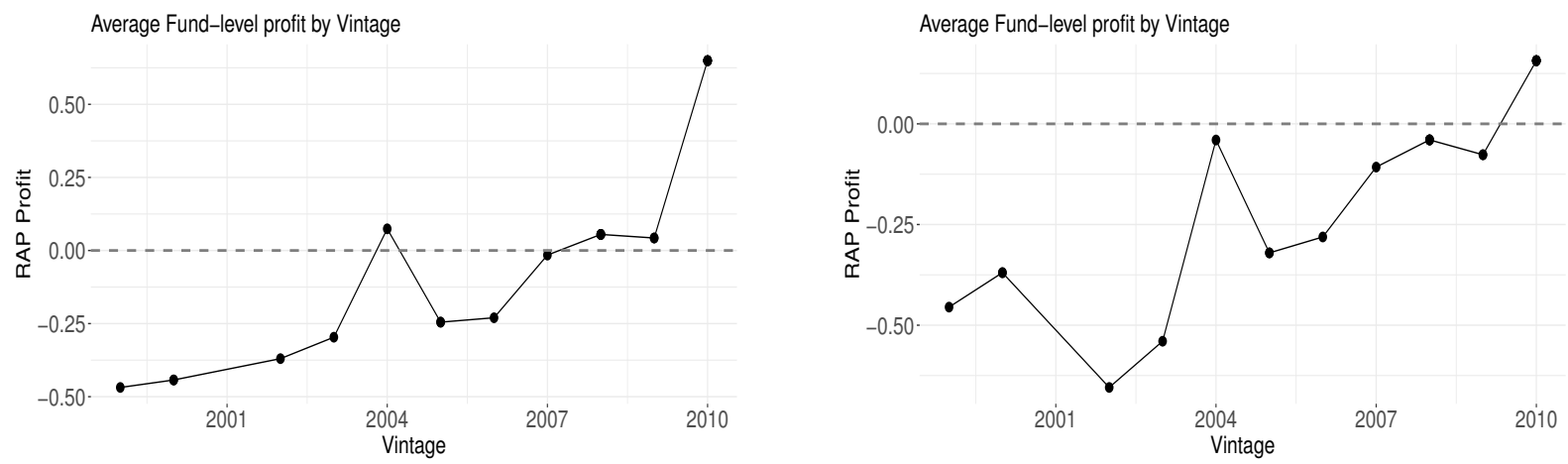

Panel D: Natural Resources
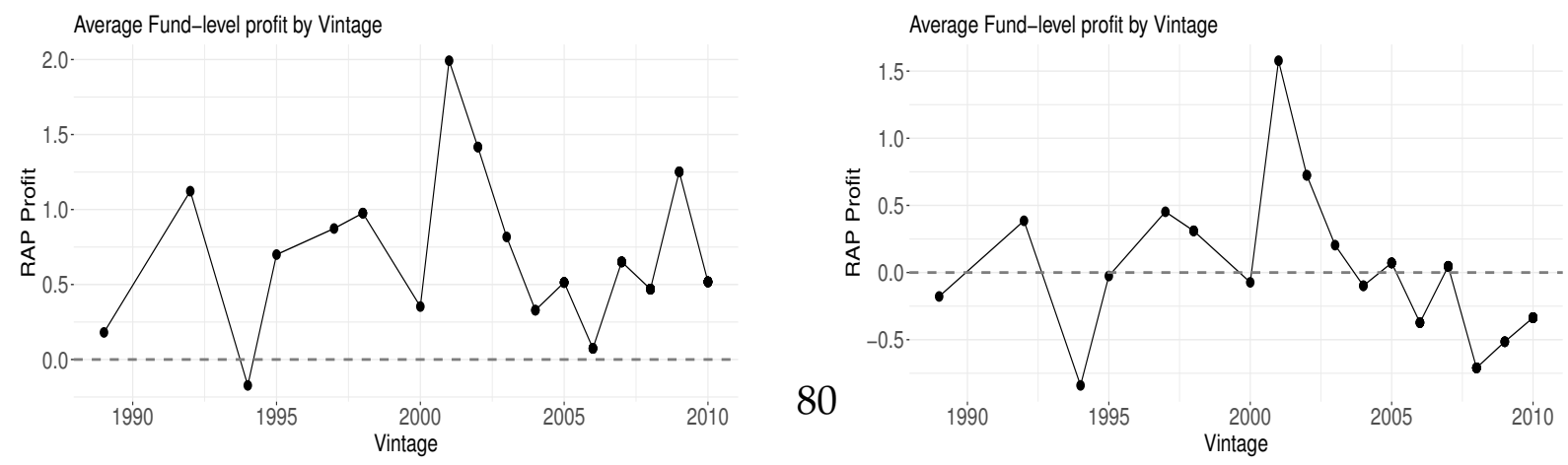


\section{FIGURE D.8: Elastic Net Model Comparison for Additional Categories}

\section{Panel A: Restructuring}
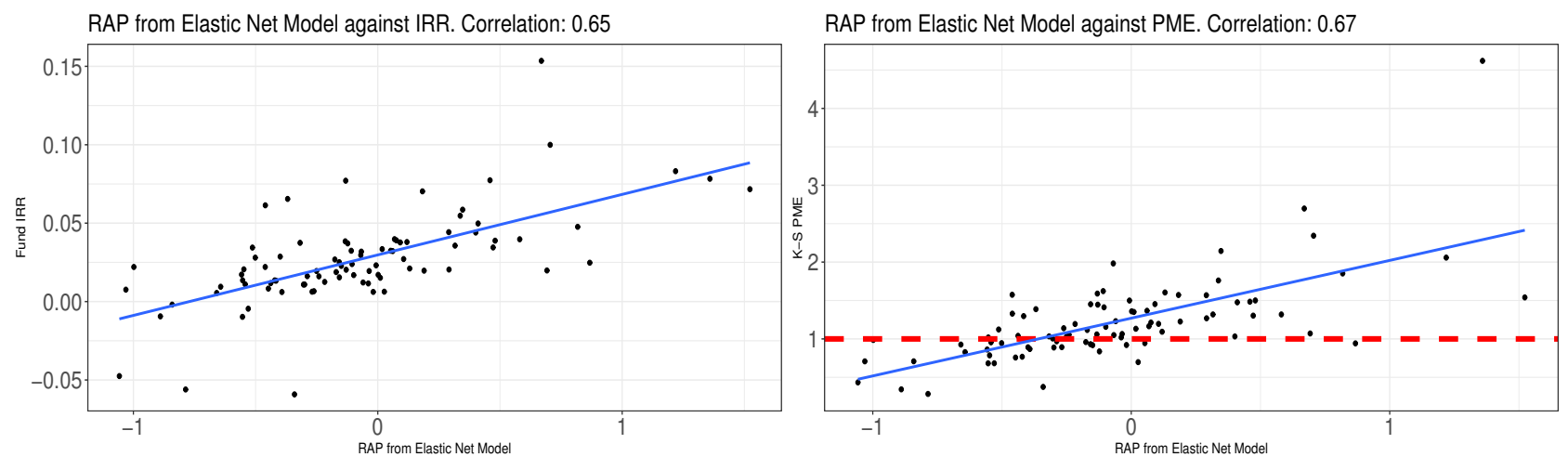

\section{Panel B: Fund of Funds}
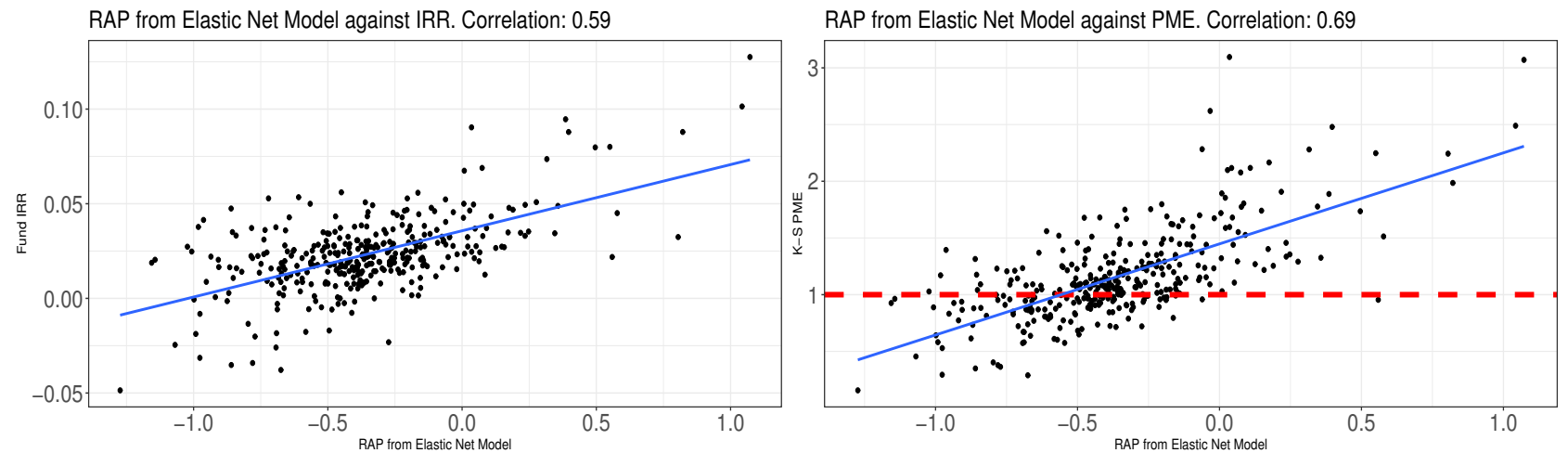

Panel C: Debt Fund
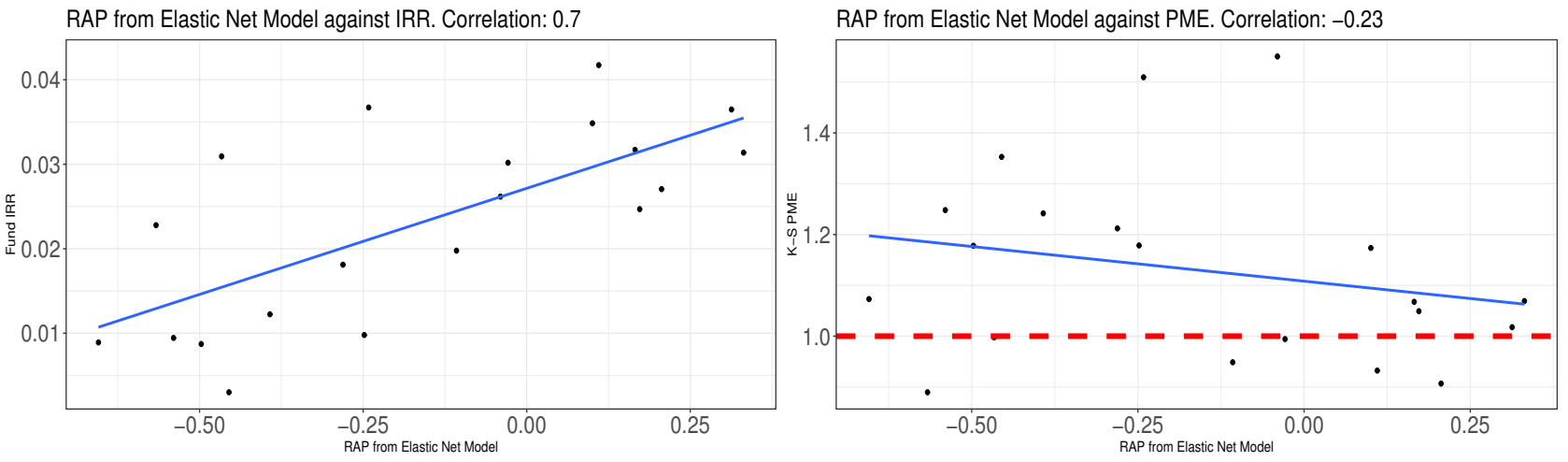

Panel D: Natural Resources
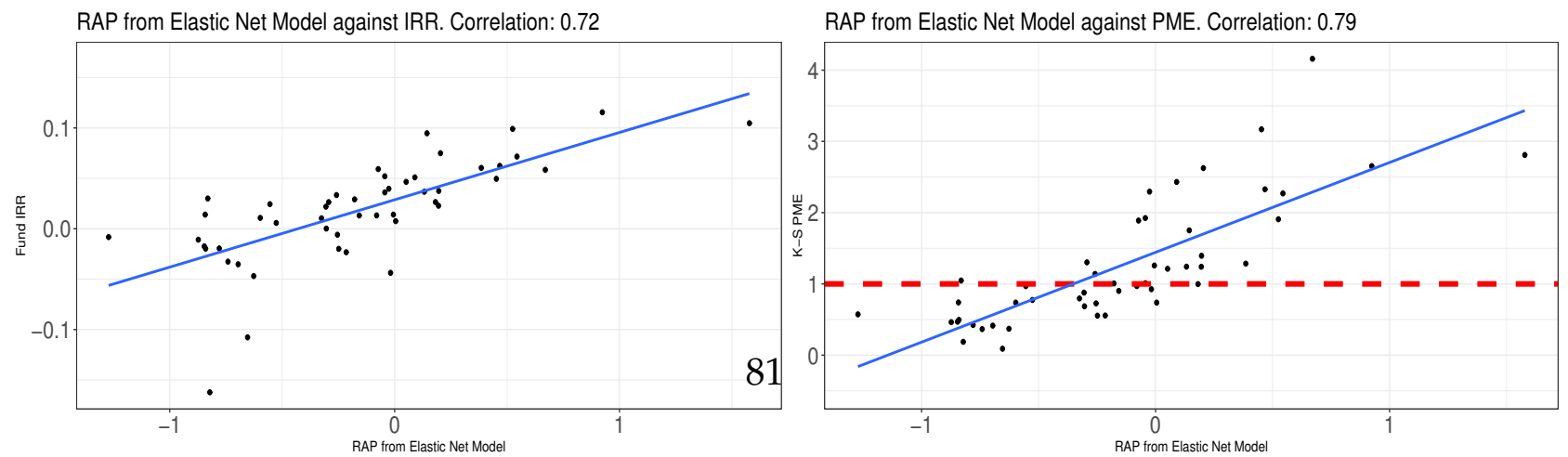


\section{E Validation on Public Equities}

To benchmark out methodology against existing approaches, we attempt a direct comparison between our strip approach to valuation and the return factor approach of Fama and French (1992). We sort stocks based on their Fama and French (1992) factor exposure, and find that portfolios with high factor exposure in the preceding period, also have high factor exposure as measured using our strip approach.

We first sort stocks into portfolios based on a rolling 60-month regressing using the Fama and French (1992) factors. We select CRSP stocks which pay out dividends on at least $60 \%$ of periods to ensure a more comparable sample against Buyout deals. ${ }^{15}$ In each quarter, we sort all stocks into portfolios on the basis of their factor exposure. We generate five portfolios sorted along HML, five portfolios sorted along SMB, and five portfolios sorted along exposure to the excess market return (Mkt) in each quarter of our sample.

Next, we look forward for the subsequent 15 years of data, matching our sample selection in Private Equity. We normalize the price of each portfolio to $\$ 1$ in the initial period, following our approach in PE, and measure the equal-weighted portfolio price quarterly for the subsequent 15 years.

In Figure E.1 we plot the results of our factor methodology approach, as in equation 7 , on the subsequent 15 years of portfolio prices. In picking factors, we allow for a bond strip exposure that varies across fund life; and two cross-sectional factor exposures matched to the portfolios. For the HML-sorted portfolio, we pick a value dividend and value growth gains strip and allow these to vary across the HML portfolios. We plot the outcome of the value gains strip across portfolios, which should correspond most closely to the realized price of the value portfolio. Similarly, for the SMB analysis, we allow for small stock dividend and gains factors which vary across the SMB portfolios; and for the Mkt plot we allow for stock dividend and stock gains strips across Excess Return factor-sorted portfolios.

Across each of the factor exposures we analyze, we find a strong and monotonic relationship between our factor-specific gains strips and Fama and French (1992) factor exposure. This exposure is not driven by any mechanical relationship. The Fama and French (1992) factor exposure is estimated on the 5-year period before we begin our analysis; while the gains strip exposure is estimated on the 15 year period after this Fama and French (1992) exposure is estimated. Further, the Fama and French (1992) approach estimates factor exposure on the basis of stock returns regressed against factor returns.

\footnotetext{
${ }^{15}$ Our results are not affected by this assumption.
} 
Our approach measures exposure on the basis of stock prices regressed against realized payoffs of growth gains strips. This exercise suggests that approach lines up with conventional measures of factor exposure when we have available data, but has the additional advantage of generalizability to cases in which prices are not observed. We estimate $R^{2}$, at the individual stock level, of around 0.25 , but around $0.84-0.88$ at the portfolio level.

FIGURE E.1: Application of Strip Methodology on Public Equities

Panel A: HML-Sorted Portfolios

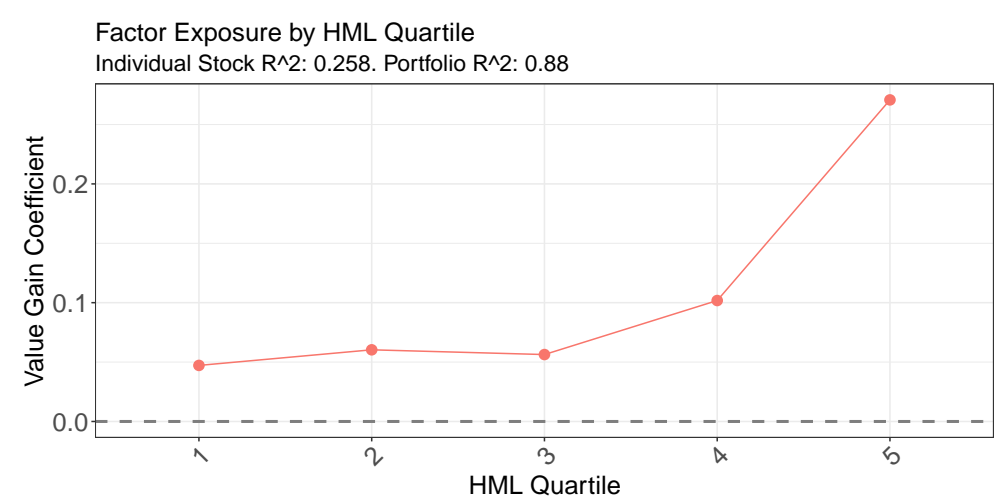

Panel B: SMB-Sorted Portfolios

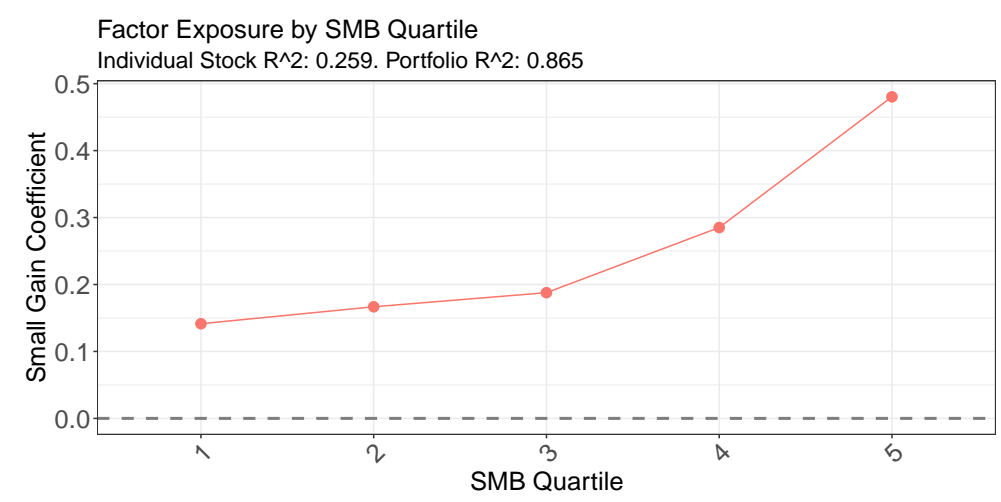

Panel C: Excess Market Return-Sorted Portfolios

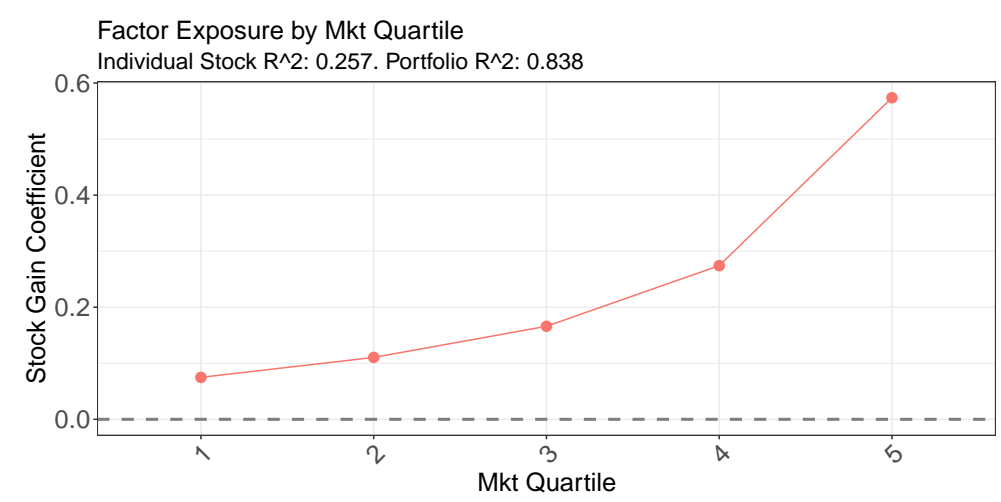




\section{F Burgiss}

FIGURE F.1: Expected Returns for Fund Categories in Burgiss

Panel A: Buyout

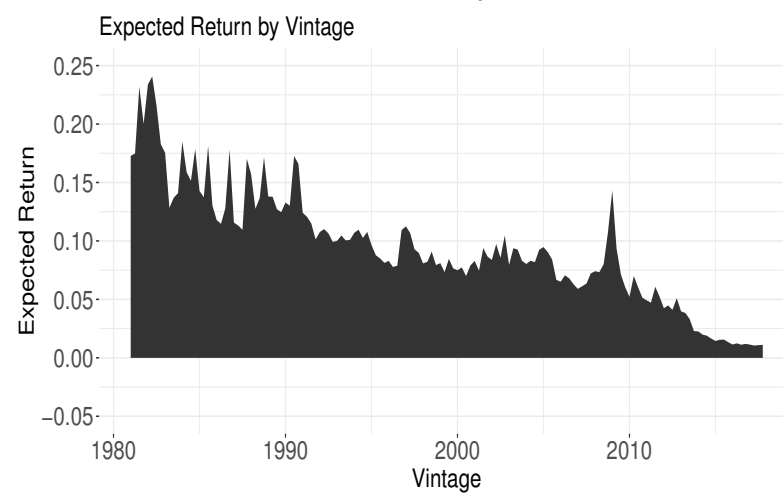

Panel C: Real Estate

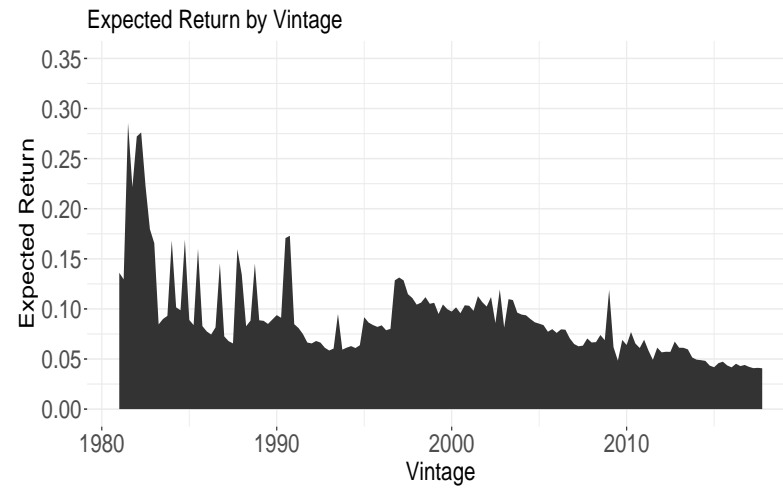

Panel B: Venture Capital Expected Return by Vintage

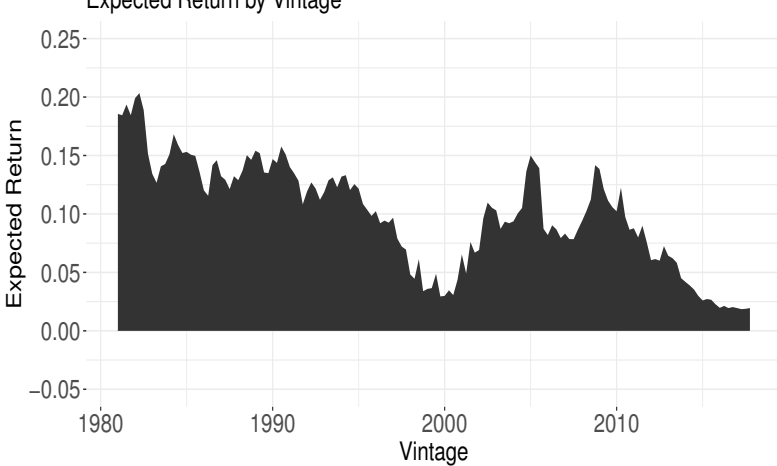

Panel D: Infrastructure

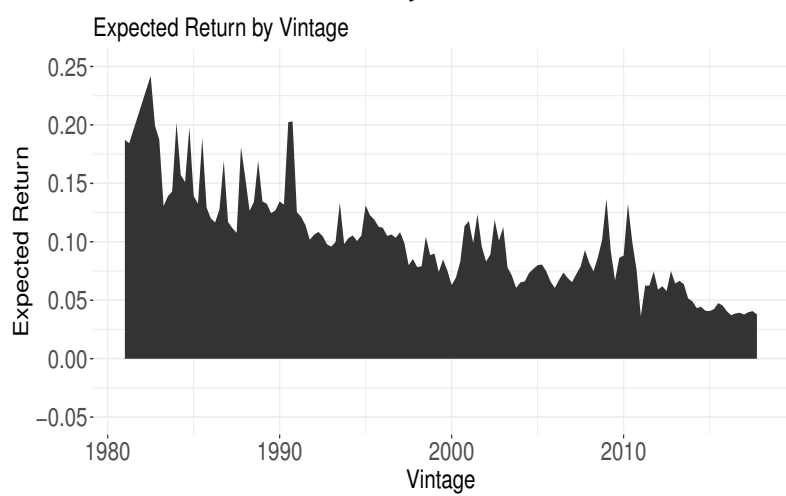


FIGURE F.3: Fund-Level Profits in Burgiss

Profit Histogram

Profits over Time

Panel A: Buyout
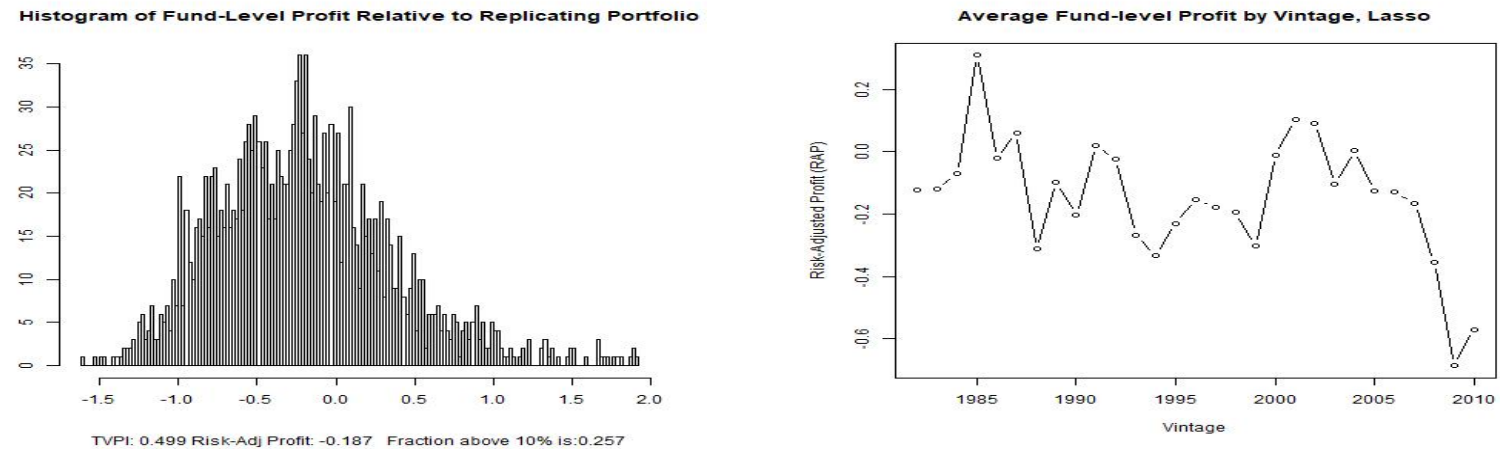

Panel B: Venture Capital
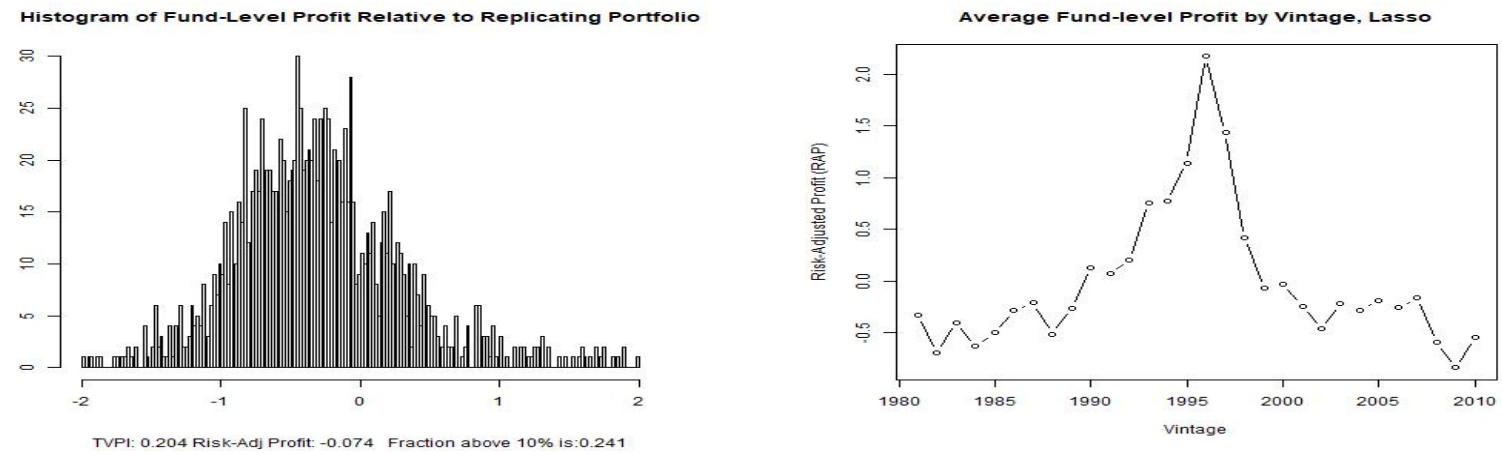

Panel C: Real Estate
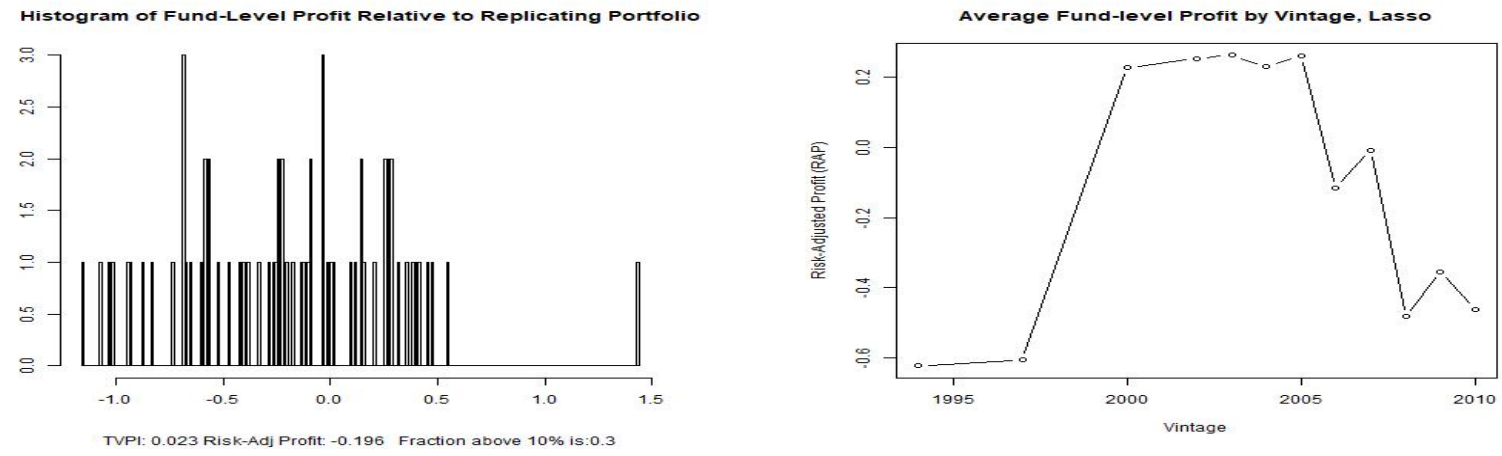

Panel D: Infrastructure
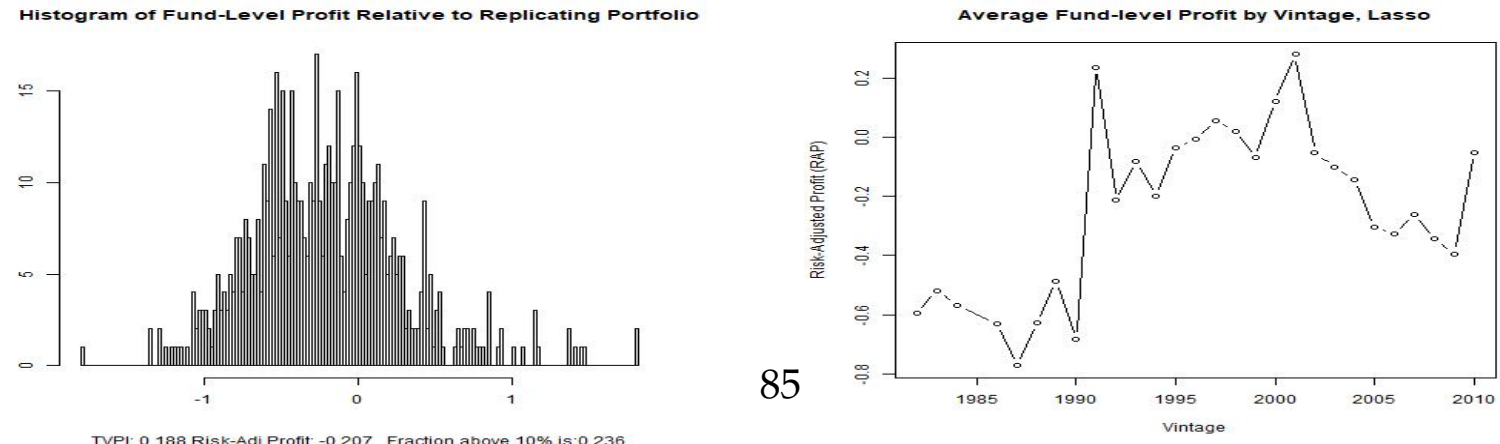